Remaking Gender and the Family 


\title{
Women and Gender in China Studies
}

\author{
Series Editor \\ Grace S. Fong (McGill University) \\ Editorial Board \\ Louise Edwards (University of New South Wales) \\ Nicola Spakowski (Albert-Ludwigs-Universität Freiburg) \\ Robin D. S. Yates (McGill University) \\ Harriet T. Zurndorfer (Leiden University)
}

VOLUME 9

The titles published in this series are listed at brill.com/wgcs 


\section{Remaking Gender and the Family}

Perspectives on Contemporary Chinese-language

Film Remakes

By

Sarah Woodland

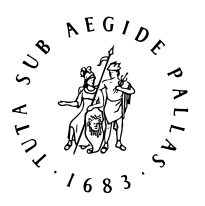

B R I L L

LEIDEN | BOSTON 
This is an open access title distributed under the terms of the CC BY-NC 4.0 license, which permits any non-commercial use, distribution, and reproduction in any medium, provided the original author(s) and source are credited. Further information and the complete license text can be found at https://creativecommons.org/licenses/by-nc/4.o/

The terms of the Cc license apply only to the original material. The use of material from other sources (indicated by a reference) such as diagrams, illustrations, photos and text samples may require further permission from the respective copyright holder.

The Library of Congress Cataloging-in-Publication Data is available online at https://catalog.loc.gov LC record available at https://lccn.loc.gov/2018012372

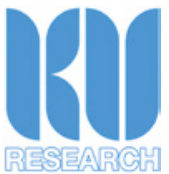

An electronic version of this book is freely available, thanks to the support of libraries working with Knowledge Unlatched. More information about the initiative can be found at www.knowledgeunlatched.org.

Typeface for the Latin, Greek, and Cyrillic scripts: "Brill”. See and download: brill.com/brill-typeface.

ISSN 1877-5772

ISBN 978-90-04-36329-8 (hardback)

ISBN 978-90-04-36330-4 (e-book)

Copyright 2018 by Sarah Woodland. Published by Koninklijke Brill NV, Leiden, The Netherlands. Koninklijke Brill NV incorporates the imprints Brill, Brill Hes \& De Graaf, Brill Nijhoff, Brill Rodopi, Brill Sense and Hotei Publishing.

Koninklijke Brill NV reserves the right to protect this publication against unauthorized use.

This book is printed on acid-free paper and produced in a sustainable manner. 


\section{Contents}

\section{Acknowledgements IX}

1 Introduction 1

Defining a Remake 2

Originality, Similarity and Cross-Culturality 5

The Cross-Cultural Remake 6

Franco-American Exchanges 6

Remaking Images of Japan 7

Remakes in Chinese-language Cinema 8

Gendering Remakes 13

Gender in Franco-American Remakes 13

Chinese Remakes and Gender 15

Aims and Structure of This Book 19

2 Remaking the Modern Family 22

The Construction of Gender in What Women Want 24

Good, Ol' Fashioned Masculinity: Men in What Women Want (2000) 24

The New Chinese Man: Remaking Masculinity in What Women

Want (2011) 26

Performing Gender in What Women Want 27

What Do Women Want? Femininity in What Women Want 29

What Do Chinese Women Want? 30

Sexuality in What Women Want 32

Freud and What Women Want 32

Jung and What Women Want 35

The Paratextual Construction of Gender in What Women

Want 36

The Family in What Women Want 37

The 'Traditional' Chinese Family 38

The 'Modern' Chinese Family 39

Commerciality and the Modern Family 43

Reflections 46 
3 Gender, Genre and the Auteur 47

The Coen Brothers' Blood Simple 48

The Coen Brothers-American Auteurs 48

Genre and Gender in Blood Simple $\quad 5^{2}$

The Failures of Masculinity $5^{2}$

Approaching the Femme Fatale 55

Blood Simple Remade-A Woman, A Gun and a Noodle Shop 57

Zhang Yimou-China's Most Acclaimed Director $5^{8}$

Making Audiences Laugh: Humour in China 60

Symbols of Beijing/Peking Opera 64

Gender in A Woman, A Gun and a Noodle Shop: A Lesson in

'Zhangification' 67

Zhang Yimou and Gender 67

Masculinity 'Zhang-ified' 68

Femininity 'Zhang-ified' 72

Reflections 75

4 Ghosts of Chinas Past and Present 78

Locating A Chinese Ghost Story (1987) in Hong Kong Cinema 79

Remaking A Chinese Ghost Story (2011) 82

Manifestations of Gender and Sexuality in A Chinese Ghost Story 84

The Legacy of Leslie Cheung 84

Remaking Gender through Ning Caichen, the Fragile

Scholar 86

Yan, the Daoist Warrior in Love 88

The Monstrous-Feminine and Dangerous Female Sexuality 90

Looking and Being Looked at - the Gaze within A Chinese Ghost

Story 92

The Gaze Remade 95

Forgetting History 97

Reflections: The 'State' of Hong Kong and Chinese Cinemas

5 History Repeating in Spring in a Small Town 103

Cultural Politics in Spring in a Small Town (1948) 104

Social versus Critical Realism 104

From Outlaw to Auteur-Fei's Post-1980s Transformation 106

Reading Gender in Spring in a Small Town 107

The Changing Politics of Cultural Policy: Springtime in a Small Town (2002) 109

The Fifth Generation Directors 110 
Re-reading the Remake-Gender and Politics in Springtime in a Small Town 115

Springtime in a Small Town-The Changing Nature of Gender, the Family and Allegory 117 The Metaphor of the Family Home 119 Springtime in a Small Town and Political Revolution 124 Reflections 127

\section{Remaking “China” 129}

Remakes and Perspectives on Being Chinese 129

Remakes and Transnational Chinese-language Cinema 135 The Future of Remake Studies 136

Glossary 141

References 143

Index 154 
Sarah Woodland - 978-90-04-36330-4 Downloaded from Brill. come4/26/2023 12:13:58AM via free access 


\section{Acknowledgements}

My biggest thanks go to my parents Ian and Vicki, and my younger brother Paul, who have always supported, loved and encouraged me. Thank you to Dr. Rosie Roberts, Dr. Joe Hardwick and Dr. Lara Vanderstaay, who have been so patient and helpful personally and academically. I have been so lucky to have such dedicated mentors to help me on my academic journey.

To my friends, thank you for all of your support. For many years you have patiently listened to my seemingly never-ending stories about my research, and let me bounce my ideas off of you when I needed to get the clarity that comes from talking things through. You kept me going when I was feeling defeated, and I could not have done this without you.

Thank you to my colleagues and fellow Ph.D. students at the University of Queensland School of Languages and Cultures for your encouragement and support. I am grateful for every day I have spent with such motivated and inspirational people, and your energy and enthusiasm for your work and research, and for mine, has made me feel valued and appreciated.

Thank you to the team at Brill, Qin Higley and Victoria Menson, and the editors of this series, for your support and insightful feedback that greatly assisted me in revising this work for publication. 
Sarah Woodland - 978-90-04-36330-4 Downloaded from Brill. come4/26/2023 12:13:58AM via free access 


\section{Introduction}

For as long as there has been cinema, there has been the remake; and for as long as there has been the remake, there has been a sense of critical unease about the value of making a film which has 'already been made'. And yet, wave upon wave of remakes continue to wash over audiences worldwide. Arguably the most prolific global creator of these remakes, Hollywood, has audiences geared up for another round of re-imaginings, with 2016-2020 looking to feature, among others, new versions of Mary Poppins (1964), Jumanji (1995), The Magnificent Seven (1960), Ghost in the Shell (1995) and Death Note (2006) (All Upcoming Movie Remakes/ Reboots (2017-2022), 2017). No era, or genre, is immune from the remaking phenomenon.

While the value of the remake is no longer debated in academic circles at least, with the remaking practices of Hollywood having been scrutinised in monographs and academic articles, there is one dimension of remaking which remains comparatively under-researched — the cross-cultural remake. Despite all of the complexities and nuances that might inhabit this form of remaking, the cross-cultural remake has so far been primarily investigated through the lens of Hollywood film. Early work on the subject by scholars including Durham (1998), Mazdon (2000) and Verevis (2006), focused on how American remakes of French films might reflect, in hindsight, quite static notions of cultural difference, articulating the dynamics of the cultural-political relationships between national cinemas, particularly Hollywood and 'Other' cinemas, within a set time-period and socio-cultural context of production, such as the 1980 . From this body of research emerged a complex set of factors involved in transferring a source film into its remake form.

However, studies into Asian cinematic remakes are still a relatively new endeavor in remake studies. From Death Note (2006 and 2017) to other pairings such as Ringu (1998) and The Ring (2002), The Grudge (2003 and 2004) and Ghost in the Shell (1995 and 2017), it is clear that cross-cultural remaking is alive and well today. Despite this, there are very few full-length monographs that address the remake in Asian cinema-a situation which does not reflect the true power of the industries and audiences in these regions. This is particularly true in the case of China, which has seen a period of astounding growth in film production and viewership both domestically and abroad. Remake studies in the Chinese-language cinematic sphere have so far demonstrated 
the same tendency as early French studies, focusing on the relationship between Hollywood and 'Other' cinema-in this case, Hollywood remakes of Hong Kong and Chinese-language films (Chan, 2009; Li, 2011). As such, they have only considered in depth issues and themes of remaking in this direction, lending themselves to a focus on Hollywood's tendency towards cultural (mis) appropriation. This focus does not engage with a Chinese-language cinema industry that now remakes films from other countries, as well as its own films.

This book attempts to move beyond a focus on questions of cultural politics, to look at the phenomenon of remaking in Chinese-language cinema from a myriad of perspectives. It aims to take full advantage of the unique opportunity provided by remakes to compare and contrast two versions of the same narrative, and expand this to incorporate the latest developments in research in a number of disciplines. It draws upon a combination of textual, psychoanalytic and semiotic analysis techniques inspired by earlier studies (Durham, 1998; Mazdon, 2000; Verevis 2006) and builds on recent research that has engaged with Chinese-language film remakes (Chan, 2009; Li, 2011; Wang, 2013). Through the following chapters, this book will bring together eight films created across different time periods, genres and cultural contexts which have not been analysed together in remake studies before. In doing so, the aim is to investigate the changes that occur between source films and remakes, framed through gender representation and depictions of the family. What changes might have occurred, and what is the significance of these changes?

The films which will be analysed (in their pairs) are What Women Want (2000 and 2011) (我知女人心), Blood Simple (1984) and A Woman, A Gun and A Noodle Shop (2009) (三枪拍案惊奇), A Chinese Ghost Story (1987 and 2011) (倩女幽魂), and Spring in a Small Town (1948) and Springtime in a Small Town (2002) (小城之春). Through conducting comparative analyses between and across pairs of films and their remakes, interrogating how textual elements such as narrative, camera angles, costumes and settings work to construct gender and the family, this work looks closely at questions of sexuality, marriage, love, gender roles, and familial structures, using gender and the family as a form of narrative barometer that effectively measures difference and change. The study is thus located at the juncture of remake studies, Chinese-language cinema studies, cultural studies and gender studies.

\section{Defining a Remake}

While the introduction to this book has so far used the term 'remake' liberally, in order to understand the function of remakes, there must first be a clear 
definition of what a 'remake' is. This is particularly important, as, according to Constantine Verevis, the term 'remake' has been "conceived more through actual usage and common understanding than through rigorous definition" (Verevis, 2006, p. 11). As a result, a large amount of research in the field has been directed towards developing taxonomies of remakes, determining what classifies a film as a remake, and what makes a remake unique among other cinematic works or forms of media. As the aim of this book, however, is not to re-define the term 'remake', the definition applied in this work will draw upon the definition of remakes already established in the literature.

According to Verevis (2006), the most overt indicator that a film is a remake is a textual reference to the legally sanctioned use of another person's work, usually indicated in the form of a screen credit. To audiences, critics and academics, this open acknowledgement of the repetition and reproduction of semantic and syntactic elements from a source film is the most clear-cut identifier of a remake. This overt recognition of a source film also sets the remake apart from the 'adaptation' and its associated arguments, which are often more concerned with issues that arise from "the movement of texts between different semiotic registers" (most often literature to film) (Eberwein, 1998 as cited by Verevis, 2006, p. 82), as well as from other types of films such as 'spin-offs', 'sequels', or 'made-over' films, which all imply more significant changes to source material.

While there is still significant discussion regarding the boundaries of what constitutes a remake, the majority of remake studies acknowledge that for a film to be considered a remake, there must be a significant reliance on repetition and re-production, usually in narrative themes and characterizations, but also in other filmic features such as editing, shots, location, costumes and style (Durham, 1998; Eberwein, 1998; Horton \& McDougal, 1998; Loock \& Verevis, 2012; Mazdon, 2000; Verevis, 2006). Further investigations into where the boundaries of remakes lie have seen the development of taxonomies of remakes by authors such as Druxman (1975), Greenberg (1998), Eberwein (1998) and Leitch (1998), which were subsequently adapted by authors such as Verevis (2006), all of whom categorise films according to how much they openly disclose and seek to maintain their relationship with a source film, and the degree to which these films repeat or transform elements of the source text. According to Verevis, "films are situated on a continuum based on how they seek to maintain semantic and syntactic relationships present in the original as much as possible through a process of 'repetitional transferral' (close remake), transformed or disguised remakes in the middle (transforming semantic more than syntactic elements), to the non-remake which adopts a tactic of 'differential dispersal'" (2006, p. 85). In the process 
of establishing this relationship, 'any given remake can seek to define itself either in relation to the film it remakes or to the material on which the films are based' (Verevis, 2006, p. 12). As will be seen in the films chosen for this study, differing approaches to these issues have implications for the reading of remakes.

An equally important factor in establishing the legitimacy of a remake is in how it engages with extra-textual structures (Verevis, 2006). In addition to the textual copyright acknowledgement, the remake may also employ various extra-textual markers, such as drawing upon the original film's reception and promotion, as evidence of its reproduction from an earlier source. These extra-textual markers are important, as they "stabilize the film's point of origin when otherwise similarities between could just be put down to cinematic conventions" (Verevis, 2006, p. 86). Extra-textual markers include interviews in which director and cast establish a relationship between the source film and the remake, promotional materials which link the two films, exhibition practices such as re-release/re-prints and the simultaneous release of originals and remakes (indicative of a symbiotic rather than competitive relationship between the two versions), and critical reviews (Verevis, 2006).

Rather than interrogating taxonomies of remakes in great detail, or questioning existing definitions within the literature, this study focuses on acknowledged remakes and the cultural, political, social and cinematic elements that distinguish these remakes from their source texts. The films chosen for this study are therefore not controversial in their position as remakes. They all openly acknowledge and heavily rely upon their source films. As a result, in this monograph, the description of remakes as described by these previous scholars, considering remakes to be acknowledged reproductions of a source film, will be adopted. However, even after copyright is sought for a film to be classified as a remake of another, there is an enormous range of difference which occurs between original and remake. The boundaries of what is considered an appropriate amount of change can be quite fluid, depending on how the above-mentioned elements are combined, and this book will look at some of the reasons for, and the significance of, these changes.

Additionally, the films chosen for analysis in this book allow for the investigation of two dimensions of cross-cultural remakes, dividing this type of film into two further subcategories of "inter-cultural" and "intra-cultural" remakes, in order to try to encompass the variety of cultural, temporal and generic contexts and different target audiences that they respond to. In doing so, it endeavours to investigate the complexities of remaking processes in a Chinese-language cinematic context, with a view to exploring the ways in which remakes might reflect different perspectives on Chinese society more broadly, through their ability to compel the viewer to reflect not only on the 
past, by virtue of the relationship with a source text, but also on the present, through the way in which the remake reshapes this text to address its audience.

\section{Originality, Similarity and Cross-Culturality}

So, despite being compelled to demonstrate such strong narrative similarities to another text, why do remakes often speak to questions of difference? Recent scholarly works relating to Hollywood remakes have attempted to answer this question, with edited monographs and readers ${ }^{1}$ investigating the depth and breadth of the remake phenomenon, discussing the boundaries of what constitutes a remake, what motivates filmmakers to create remakes, and how these films relate to wider trends of the reproduction and repetition of texts.

These studies adopt some key methodologies which warrant mention, as they form the basis of scholarly understanding of remakes to date. The first of these methodologies is intertextual analysis, which involves the reading of a remake in light of "the co-existence of two or more texts" (Horton \& McDougal, 1998, p. 3). While remakes can be understood to be independent works, Horton and McDougal argue that their reading by audiences is often influenced by comparisons with the original film, and that this effect can be heightened by self-conscious references which may also be deliberately inserted to exaggerate communication between the texts (Horton \& McDougal, 1998, pp. 3-6). This book will consider the intertextual relationships between source texts and their remakes, with each pair of films demonstrating a slightly different perspective on this issue.

Bound up with the idea of intertextuality is the notion of originality, a concept which is complicated by the remake. As a film which actively draws upon the work of others through its citation, allusion to, and perhaps even plagiarism of, texts that came before it, the remake is often subject to criticism for a lack of originality (Horton \& McDougal, 1998, p. 163). Questions regarding the originality of a remake also implicate the auteur, who figures strongly in remake studies, with a number of perspectives given on why directors might choose to remake a film. For films that fit the intracultural typology proposed in this book, Stuart McDougal discusses how Alfred Hitchcock's remaking of his own films connected with the director's desire to perfect his craft (1998).

1 See Play it Again, Sam: Retakes on Remakes (Horton \& McDougal, 1998); Dead Ringers: The Remake in Theory and Practice (Forrest \& Koos, 2002); Film Remakes as Ritual and Disguise: From Carmen to Ripley (Zanger, 2006); Second takes: Critical Approaches to the Film Sequel (Jess-Cooke \& Verevis, 2010), and Film Remakes, Adaptations and Fan Productions (Looke \& Verevis, 2012). 
Harvey R. Greenberg (1998) relates Steven Spielberg's remake Always (1989), a remake of Victor Fleming's A Guy Named Joe (1943), to psychoanalytic theory, positing an Oedipal relationship between original and remake that reflects Spielberg's conflicting need to both honour and supersede the original director's work, in the same way a son might compete with a father. This study, however, concerns itself with another angle, considering how the backgrounds and styles of certain directors may have influenced the changes that have occurred to the source film, and what this means for understanding remakes in a Chinese-language cinematic context.

Importantly, Horton and McDougal, amongst others, identified another factor in understanding the remake, that is, the significance of cultural and historical context. Using the film pair Cape Fear (1962 and 1991) as an example, Horton and McDougal highlight that watching the remake "is not just to watch widely differing acting and directorial styles but to experience the historical and cultural changes that have occurred within the twenty-nine years separating these films" (Horton \& McDougal, 1998, p. 6). This temporal factor is also an important factor in the reading of Chapter Five's film pairing, Spring in a Small Town (1948) and Springtime in a Small Town (2002). The reading of a remake is thus also contingent on the changing conditions of spectatorship, and as Robert Eberwein notes, different audiences bring their own knowledge of the original film as well as their understanding of their own context to reading a remake (Eberwein, 1998, p. 16). This connection with audience expectations and understanding plays a role in all of the remakes, to varying degrees, across the following chapters.

What these scholarly works show is that reading a remake actually involves understanding the complex interplay between many factors. As Horton and McDougal state, "significant strands of narrative, cinema, culture, psychology, and textuality come together" in the remake (Horton \& McDougal, 1998, p. 6). While being a product of a source text, remakes must also balance concerns of commercial viability and success, the personal styles of directors and stars, and a dynamic social context. Thus, the "investigation of remakes, takes us into several distinct areas: the personal (psychological), the sociocultural (political-cultural-anthropological), and the artistic (cinematic narrative:stylesubstance-presentation)" (Horton \& McDougal, 1998, p. 6).

\section{The Cross-Cultural Remake}

Franco-American Exchanges

These remake studies also established the value of the cross-cultural remake as a reflection of the complexity of translating narratives across time, space and culture. Very early discussions of the cross-cultural remake often positioned 
this kind of film as a vehicle for cultural imperialism, and change between a source film and its remake as evidence of how Hollywood had remade and re-distributed (in most cases, French) films in its own patriarchal, hegemonic image. Carolyn Durham states that critics made a number of assertions about remakes, labelling them an ultimately futile attempt to replicate an inimitable, superior product of French national cinema and culture; a stateless, cultureless void, or a blatant application of American dominant culture which sought to eliminate the cultural Other (Durham, 1998, p. 11).

However, these researchers in Franco-American remake studies including Lucy Mazdon (2000), Durham $(1998,2002)$ and Verevis (2006) worked to discredit this myth, with each of their books in part discussing how remakes are a longstanding part of cinematic tradition, and not just examples of cultural imperialism at work. These scholars also aimed to break down the pervasive attitude that privileged the French cinema/source text as 'high' art, and labelled the American film/remake as a degraded, mass cultural product. Their research opened up possibilities for using remakes as a fruitful means of investigating the cultural specificity of film. However, many of these studies were also written in response to the political and cultural issues of their times, and were thus dominated by concerns surrounding the perceived Americanisation of French culture epitomized by the Euro-Disney saga ${ }^{2}$ (Durham, 1998). As such, these works did not fully disengage from the argument surrounding cultural imperialism, and therefore are at times slightly defensive in their attempts to re-balance the power dynamics between French cinema and Hollywood.

\section{Remaking Images of Japan}

From an Asian cinematic perspective, research on remakes so far has primarily focused on the Japanese cinematic industry and its relationship with other cinemas. Seiko King's thesis "Remade in Asia: Transformation across Asian Markets and Popular Culture" (2012) discusses how rights to products such as films, TV shows and manga/anime are traded around Japan, South Korea and Taiwan in a dynamic process of cultural exchange (King, 2012). Focusing on remakes of television dramas Akai Giwaku and Winter Sonata and manga Hana yori Dango and Janguru Taitei, King argues that these cross-border exchanges bring to bear questions of economic, industry and legal rights, as well as notions of cultural identity as stories from one region are transformed for different audiences. The benefits for the Japanese media industry of such

2 According to Durham (1998), the Euro-Disney saga refers to the negative response of the French people to perceived peddling of American culture via a newly opened Disneyland in France in the 1990s. 
remake exchanges are manifold, with economic gains from the sale of products within East Asia, a growth market for cultural products, providing important capital for economic growth and development in Japan. Furthermore, the dissemination and popularity of Japanese cultural products such as manga have had a much wider effect of improving the perception of Japanese culture globally as well as in the East Asia region, and arguably political relationships between Korea and Japan in particular (an example of "soft power" at work).

While manga is the most recent popular global product out of Japan, an earlier wave of genre films paved the way for Japanese cinema to enter the global cultural sphere, through its impact on Hollywood in the 199os. In this period, Hollywood film experienced what Kevin Heffernan refers to as the "J-horror remake cycle" (Heffernan, 2014, p. 62), a period in which an inordinate amount of Hollywood remakes of Japanese films were made. Heffernan's work addresses production trends behind such remakes, explaining that in the context of a growing desire to broader horror's generic horizons as well as tap into emerging Asian markets, savvy Hollywood film production agents bought rights to several East Asian films, which were remade as mid-budget Hollywood films that "displayed tremendous suppleness and ingenuity in their deployment of motifs drawn from both the original movies and contemporaneous horror films" (p. 62). In changing the focus towards a Chinese-language cinematic context, methodologies and arguments in the field of remake studies will need to be re-evaluated in terms of how they address (or do not address) the specific factors involved in creating Chinese-language remakes.

\section{Remakes in Chinese-language Cinema}

Following on from these previous works, a small body of research on Chineselanguage cinema and Hollywood film remakes has now emerged. In a similar vein to earlier research, these studies seek to establish remakes as an important tool for illuminating cross-cultural issues. However, they also begin to adapt prior scholarship to suit the specific historical, cultural and social context of the Chinese-language cinematic landscape.

Where these scholars most overtly diverge from prior theory is their employment of transnational theory. While early works on remakes in a FrancoAmerican context tended to place comparatively more emphasis on the distinctions between films and their separate and distinct modes of production, the transnational nature of contemporary Chinese-language cinema has taken scholarship on Chinese remakes in a different direction. These transnationally-oriented studies are instead underpinned by theory that assumes an increasingly globalized film market, in which the traditional barriers between 
film industries, which also served as a means of clearly attributing nationality and culture to a film, have broken down. On the reception side, audiences are now able to access films from across the world, and filmmakers make films targeted to a range of different viewers, or a 'global' audience. Transnationalism has been used to test the boundaries of what constitutes 'Chinese' cinema, and thus this theory is closely tied to representations of culture, as a means of exploring what it means to be Chinese. Studies investigating the evershifting boundaries of Chinese cinema have addressed themes including, but not limited to, representations of gender, diasporic cinema, politics, economics and industry structures (see for example, Berry, C. \& Farquhar, M. 2006; Kam, Marchetti \& Feng, 2009; Lu, 1998).

Chinese-language remake studies have similarly drawn upon transnational theory in their attempts to emphasise the subjective, fragmented and international nature of 'Chinese cinema'. Rather than positioning remakes as a form of inferior 'rip-off' of other films, Patricia Aufderheide considers Hong Kong's reenvisionings of Hollywood films and genres to be representative of a "flourishing, unabashedly imitative cinema inescapably commenting on surrounding social and political tensions in the choices of its adaptations" (Aufderheide, 1998, p. 192). Aufderheide argues that Hong Kong cinema's obsession with borrowing from Hollywood is a dual-purposed endeavour that uses any means to make a film commercially successful while at the same time using parody, mimicry and allusion to mock Hollywood's internationally dominant film culture. By "imitating Hollywood styles and narratives, the treatment, style, and selection of films become more important than the originality of raw material, thus Hong Kong remakes represent a creative and enterprising form of commercial and cultural appropriation of the source text" (Aufderheide, 1998, p. 193).

Kenneth Chan's book Remade in Hollywood takes a much broader look at how ideas and politics relating to 'China' are remade in the films of mainland Chinese-born, Chinese-American and Chinese diasporic film-makers and stars in Hollywood, particularly after the 1997 Hong Kong handover. Chan undertakes analyses of a broad range of films, including remakes such as Infernal Affairs (2002) and The Departed (2006), as well as stand-alone films such as Crouching Tiger, Hidden Dragon (2000) and House of Flying Daggers (2004). Through his "mapping of the topical problematic, through the tracing of the significant and predominant themes, ideas, trends, questions and concerns" (K. Chan, 2009, p. 9), Chan seeks to investigate how "transnational and multinational collaborative production affects cultural, political and aesthetic expression in movies involving the Chinese in Hollywood" (K. Chan, 2009, p. 4). 
Drawing upon the theory of transculturation, Chan describes the ChineseHollywood cinematic relationship as one characterized by asymmetrical power relations, whereby the Chinese are often branded Other by the dominant Hollywood cinema industry, even as ethnic Chinese directors self-exoticise to engage with non-Chinese viewers (K. Chan, 2009, p. 11). This uneven relationship produces films which are characterized by tension, ambiguity and slippages, reflective of the difficulties of locating 'Chineseness' and the Chinese identity in this type of industry and power structure (K. Chan, 2009, p. 77). Chan's approach positions Hollywood not just as a collaborative partner, but ultimately as a dominant party that is uncomfortable with, or unable to fully appreciate, a non-Western presence within its cinema. Chan argues that within the dominant film culture of Hollywood, the production of 'China' is often displaced, dislocated, or attempting to subvert the Hollywood hegemony. This theoretical approach does not so much focus on observable differences between texts as it does on perceived power imbalances in the much broader state of affairs between America and China.

Jinhua Li (2011, p. iv), following Chan, also argues that Chinese-language cinema in the last twenty years has been "characterized by transnational production and distribution strategies", and that exchanges between Hollywood and Chinese cinema involve the "transformation of prior narratives to accommodate new political, ideological, gender and cultural agendas" (J. Li, 2011, pp. iv-v). Using Hollywood remakes of Chinese-language films, Li seeks to explore whether the changes which occur in five pairs of cross-cultural remakes are the result of purely "linguistic transformation", a necessary endeavour when translating a film into another language, or whether these changes go beyond this basic function into the realm of appropriating culture and politics (J. Li, 2011, p. v). Li builds upon and extends the work of Chan, also partially addressing issues of differences between the development of the Hong Kong, mainland Chinese and Taiwanese cinema industries, by including in her study the original Hong Kong film Infernal Affairs (2002) and the original Taiwanese film Eat Drink Man Woman (1994). While films from these three areas are all categorized as Chinese-language cinema, their industries have followed distinctly different developmental patterns (K. Chan, 2009; J. Li, 2011). Through the inclusion of these two films, Li's study highlights how Hong Kong films in the 1980 s and 1990 s reflected concerns of integration and identity, while the cinema of Taiwan in the 1990s similarly expressed confusion over the region's political and cultural future (J. Li, 2011, p. 6).

But the primary focus of Li's work, with its emphasis on Hollywood remakes of Chinese-language films, is like Chan's, weighted towards Hollywood 
cinematic re-interpretations of Chinese films. As such, while her work carefully outlines the transnational flows and interactions between these two cinemas, it also addresses the Sino-American cinematic relationship in cultural/ political terms. Li concludes from her analyses that Hollywood remakes appropriate Chinese culture and impose Western notions of individualism, capitalism and patriarchy to reassert Hollywood's dominance as the primary player in a global context where it is losing its monopoly on cultural production. When combined, these works by Chan and Li appear to approach the cultural politics framework from slightly different angles, but still come to a similar conclusion about, and against, Hollywood's tendency to (mis)appropriate other cultures.

However, Li's discussion also presents an interesting twist on this cultural politics argument through the analysis of the Disney "remake" of the story of Mulan. In this final chapter, Li argues that the Chinese-language film deploys a comparatively multicultural, post-feminist, transnational, almost benevolent approach to cinema, in contrast with its Hollywood source film. Li states that "a new rhetoric of Chinese post-feminism characterizes transnational Chinese cinemas, and Eurocentric cultural politics become symptomatic of Hollywood commercial cinema's remaking of these Chinese language films" (J. Li, 2011, p. $\mathrm{x}$ ). Thus, a new divide emerges between Hollywood and Chinese cinemas which actually inverts the power relationship between these two industries, privileging the Chinese film over the Hollywood source text. Simultaneously, there is a de-emphasis of the potential for Chinese-language films to also be engaged in the promotion of stereotypical or hegemonic values and political agendas to their own audience/s.

Li's final chapter thus provides an insight into what has been a serious turning point in the theory of cultural politics in cinema more broadly, where Hollywood has begun to lose its clout in the global cultural political scene, and the theoretical approaches to film analysis are evolving as a result. Leading scholars in Chinese cinema are now discussing the Sino-Hollywood relationship as a "battlefield", in which China seeks to flex its growing economic muscle to promote soft power globally. As the Chinese film industry grows, forging new alliances with international production houses and strengthening the influence of its own companies at home and abroad, the Chinese-language remake's attempts to cross cultural, political, social and economic divides form a vital part of this environment of "courtship and competition" (Zhu, Y, 2015).

Following on from this argument, Yiman Wang's book Remaking Chinese Cinemas (2013) shifts further away from the earlier discussions in the field that fixated on cultural imperialism. Like Aufderheide (1998), Wang refuses to simply accept that Hollywood remakes represent "another instance of hegemony 
that vampirises and destroys peripheral film industries" (Y. Wang, 2013, p. 1), arguing that this does not reflect the "historical complexity of remaking practices" in the context of East Asian cinema (Y. Wang, 2013, p. 1). Wang discusses the relationship between Hollywood and East Asian cinema through consideration of film remaking practices between Hollywood, Shanghai, and Hong Kong throughout the twentieth and twenty-first centuries. The focus is on considerations of national cinema and collective subjectivity through the lens of cross-Pacific film remaking. The book includes a wide span of films, including Hollywood remakes of The Departed (2006), The Eye (2008), The Ring (2002) and The Karate Kid (2010), as well as collaborative works such as Kung Fu Panda (2008), and The Mummy: Tomb of the Dragon Emperor (2008), and remakes of silent films.

Drawing on theories of colonialism, nationalism, postwar socialism, postcolonialism, post-socialism, and globalization, Wang focuses on the "understudied strain of peripheral and subaltern remaking: namely, Shanghai and Hong Kong remakes of certain Hollywood genre films, and Hong Kong remakes of Shanghai and Hollywood films" (Y. Wang, 2013, p. 1). Wang argues that in the case of Shanghai and Hong Kong cinema, the compulsion of repetition associated with film remaking has historically been "driven by the desire for reinvention and reconfiguration" (Y. Wang, 2013, p. 3). Wang argues that the practice of remaking films from one culture to another "involves a complex repertoire of negotiation strategies between domestication and foreignisation ... thus we must place the recent Hollywood remaking of East Asian popular cinema in the context of twentieth century cross-Pacific remaking" (Y. Wang, 2013, p. 17). In discussing this, she highlights the simultaneous hope and anxiety which is associated with the practice of film remaking - that is, the still extant concerns of cultural imperialism, versus the commercial, economic and possibly cultural gains which can be brought about through greater collaboration between the two cinematic superpowers that are China and America.

It is to Wang's work that this current monograph is perhaps most methodologically indebted, in the shared acknowledgement of the significance of comparative analysis in the study of filmic remakes and the recognition of the complexities of cross-cultural remaking practices. However, where the focus of this current monograph diverges from Wang's approach in Remaking Chinese Cinemas is in the latter's concern for redefining the theoretical parameters of national cinema and colonialism, and how these parameters relate to subaltern remake practices. This is a very different endeavor to this work, which considers a broader range of films, not all of which warrant the application of colonial/subaltern methods of analysis. This book instead directs its attention to building upon the significant methodological and thematic approaches 
developed by all of the earlier mentioned researchers to look at remakes not from the perspective of Hollywood representing China in the form of colonized or exotic Other but instead to shed light on how contemporary, and often mainstream, Chinese-language remakes depict "Chinese" and "Other" cultures for primarily domestic Chinese audiences.

\section{Gendering Remakes}

While there are many approaches to the analysis of changes that may occur between a source film and remake, recent research has honed in on one particular facet which provides a very effective lens through which differences can be observed and discussed. It appears that in cross-cultural remakes, some of the most overt changes the source film undergoes relate to representations of gender and the family. What might the reasons be for these changes? Is it as simple as being the result of a change in target audience from source film to remake? Or are the changes a reflection of influences considered to be institutional, such as differences between film industry structures and regulatory laws (such as censorship), and those which are economic, such as commercial agreements? Or are we looking at issues of style, generic conventions, or the influence of the auteur, filtering through into gender representations? What might be the role of culture in representing gender and the family in films which have been remade in different genres, locations or periods of history? This book will consider the remake with a focus on gender and the family to consider the multiple reasons which might explain why such changes have occurred. In discussing the question of gender, the following section outlines how explanations for changes to gender representations in remakes have become increasingly sophisticated, from early Franco-American research to the current situation in Chinese-language remake studies.

\section{Gender in Franco-American Remakes}

Consistent with the situation in remake studies more broadly, the majority of research on gender in remakes also relates to French original films and their Hollywood remakes. Carolyn Durham's book Double Takes (Durham, 1998) investigates the relationship between culture and gender in French films and their American remakes. Through consideration of the social, political and cultural factors which shape Franco-American cinematic exchanges, Durham attempts to understand the cross-cultural differences in gender representation which can be observed within this specific remake phenomenon. Through "careful comparison of a series of paired originals and remakes, significant 
differences between the two versions of the 'same' film emerge" (Durham, 1998, p. 16). Durham argues that these differences, particularly in relation to gender representation, are the result of different cultural perspectives on gender and perceived concerns of national culture in America and France.

Durham's work provides a detailed example of the current methodologies and themes within this field. By using several pairs of films, she is able to identify patterns and distinguish "differences and similarities that may be specifically cultural in nature from those attributable to other factors" (Durham, 1998, p. 16). She advocates the use of a variety of methodological approaches involving textual, intertextual, feminist film studies and crosscultural comparative analysis techniques. By using a postmodern comparative approach, Durham worked to avoid privileging one text over another (source text over remake) and as such avoids reducing her arguments to those which can appear in critics' reviews of films - which film is 'better' or 'worse' aesthetically - and whether the remake is 'faithful' to the original text (the 'fidelity vs. free' argument derived from translation studies) (Durham, 1998).

Durham's central argument in Double Takes links together issues of national identity, culture and gender. Selecting films which were concerned with the "relationships between men and women, narratives of romance and parenting, and the gendered nature of human behavior", Durham found that comparing the French and American pairs "revealed areas of cultural difference with great clarity" (Durham, 1998, p. 17). Interestingly, Durham argues that these gender constructs are not just the product of different social/cultural views on gender roles and relations, but also reflect broader internal and external conflicts within and between America and France. Durham highlights the struggles for identity and culture which have occurred in these countries due to issues such as immigration, feminist movements, and the perceived threat of cultural imperialism, as being influential factors shaping themes, gender roles, relations and characterizations in the chosen films.

Throughout her work, Durham problematizes essentialist notions of national identity, culture and national cinema through discussion and intertextual analysis of a number of films including About de Souffle (1960), Cousin, Cousine (1975), and Trois Hommes et un couffin (1985) and their remakes. Rather than making very broad generalizations as to what constitutes 'Frenchness' or 'Americanness', which misrepresent these concepts as being static, fully representative and objective, Durham states that researchers need to focus on how "concrete practices" such as film express dynamic and relational discourses of national culture and identity (Durham, 1998, p. 14). In Durham's opinion, the 'Frenchness' of a film is only identified through its comparison with its American counterpart, as national identity and culture are constructed 
through contrast with those cultural and national groups which are considered Other (Durham, 1998, p. 31).

Lucy Mazdon's work Encore Hollywood, while heavily focused on the roles industry financing and politics play in the production, distribution and interpretation of remakes, also addresses the topic of gender and family-related discourses, in particular focusing on Three Men and a Baby (1987), My Father the Hero (1994) and their French source movies. Like Durham, Mazdon also finds that "cultural representation and reappraisal of masculinity in particular emerged from the shifts in society brought about by feminism and changing gender roles in the family and workplace" (Mazdon, 2000, p. 61). Thus, the

"particular representations of paternity and masculinity described in the films reveal the rootedness of certain themes in specific 'national' cultures and their simultaneous ability to transcend these national boundaries. Although they may treat them differently, remake and source film share almost identical themes and concerns" (Mazdon, 2000, p. 65). This is a very important observation for the study of gender in remakes, as it clearly articulates that not only can there can be difference in actual narrative content and themes between a source film and its remake, there may also be instances where differing executions in representing gender and the family actually reflect similarities in topics or themes across cultures. Both sides of this coin, similarity within difference, and difference concealed within similarity, will be explored in this book.

\section{Chinese Remakes and Gender}

The research on Franco-American remakes present a convincing case that culture, as well as historical, political and social contexts, are important factors in shaping changes that occur from French source films to their American remakes. With an increasing amount of sophistication, these works consider first how culture, then how culture and differences between cinema industries, might impact upon changes between source film and remake, and they nevertheless argue very convincingly that different cultural perspectives on gender strongly influence these differences. Narrative, semiotics, camera angles, costumes, and other cinematic factors are combined with cultural, social and political context to produce a greater understanding of what the changes between source films and remakes might be attributed to.

But the important question is, do these findings and methodologies relate to what is occurring within Chinese-language cinema? While many of the themes identified in Franco-American remakes such as love, marriage and parenting are also relevant in Chinese-American exchanges, the differences in social, political and historical situations warrant discussion of specific points relating to gender in the Chinese-language film remake. For inspiration on themes 
and methodological approaches, we will return to the works of Chan and $\mathrm{Li}$, discussed earlier in this chapter.

Chan's (2009) discussion of gender representation is first framed in terms of how Hollywood films have a long tradition of reinforcing white patriarchal culture by desexualizing and feminizing Asian males, and subjecting Asian women to the erotic gaze (K. Chan, 2009). Chan argues that this approach is still apparent in the films of Jackie Chan, Chow Yun-fat, Jet Li, Michelle Yeoh, Zhang Ziyi and Lucy Liu, and he identifies many of Hollywood's Chinese stereotypes, including the sexualisation of the "Dragon Lady"/warrior woman stereotype in the James Bond franchise, Charlie's Angels (2000) and Kill Bill (2002). Chan also explores how the relationship between Hollywood and Chinese cinemas has evolved, whereby ambiguity within films such as Crouching Tiger, Hidden Dragon (2000), and House of Flying Daggers (2004), might subvert this Hollywood order. Chan thus exposes the anxieties and contradictory readings which emerge from the complexity of representing gender in contemporary Chinese-language film.

Chan also examines the director's role in attempting to shape these genderrelated aspects of a film, through the use of interview excerpts, particularly from Ang Lee. This approach provides insight into the director's own stated perspective, and his understanding of his own filmic tradition. When included in a feminist film-based analysis, interviews can supplement the reading of a film, and thus materials such as interview transcripts, if available, are useful additions to filmic analysis. Of course, Chan does not argue that what a director intends and what ends up on the screen are necessarily the same thing; while the director's opinions, desires and motivations can be taken into consideration, they in no way constitute a definitive reading of a filmic text, which is inherently open to many interpretations by the viewing public (Wang, 2013). Nevertheless, Chan's work makes an important contribution through its recognition of the role the director in shaping Chinese-language cinematic gender representations.

Jinhua Li argues that her chosen contemporary Chinese films "are characterized by post-feminist, post-socialist re-imaginings of China in a global economy", and employ "a new gender rhetoric which uses female sexuality as a platform to advocate the co-dependence and inter-connectedness between the masculine and the feminine, the center and the peripheral, and West and East" (J. Li, 2011, p. 22). Hollywood remakes of Chinese language films meanwhile are dominated by "Eurocentric cultural politics" (J. Li, 2011, p. x). The five pairs of films included in Li's study are Letter from an Unknown Woman (1948 and 2005); Infernal Affairs (2002) and The Departed (2006); The Eye (2004 and 
2008); Eat, Drink, Man Woman (1998) and Tortilla Soup (2001); Mulan (1998) and Hua Mulan (2009).

Li's comparative analysis of two versions of Letter from an Unknown Woman finds that the representation of gender in the Hollywood original (1948), is dominated by classical Hollywood notions of the heterosexual couple. The structure of the narrative, and cinematic devices such as camera angles, subsequently follow this approach by sexualising the main female protagonist and denying her subjectivity and agency (J. Li, 2011, p. 37). In the case of the remade film, the male lead's control is undermined by re-structuring the narrative to give the female lead more agency through female narration, and the deemphasis of feminine sexuality.

Whether or not Xu Jinglei's Chinese-language remake is considered one of China's post-feminist films is nevertheless open for debate. Scholars such as Vanderstaay (2010) and $\mathrm{Li}$ (2011) consider the remake to be one of China's first post-feminist films, where post-feminism is defined as "a re-instatement of female power by way of celebrating what has been previously labeled as regressive by traditional feminism" (J. Li, 2011, p. 167). The remake was the vision of a highly successful female director, recognized for her commercial success and her multitude of artistic talents comprising of screenwriting, directing, acting, and singing, the film stands as an example of women's power in 21st century China, and in this way, "her (Xu's) remake epitomizes the new visibility of women in the postfeminist era in the image of a strong, independent, intelligent, and sexually conscious woman ( $\mathrm{Li}, 2011, \mathrm{p} .32$ ). Jingyuan Zhang however is troubled by the traditional gender undertones of Xu's narrative depiction of a lovelorn woman who is effectively a slave to her feelings for a man who doesn't even remember her (J. Zhang, 2011, p. 232).

Li's other four film pairs are from the perspective of Hollywood remaking Chinese-language films. In the case of the Hollywood remake of Hong Kong transnational film The Eye (2004), the American film "uses feminism as a ruse to empower the American heroine at the expense of her Othered double" (J. Li, 2011, pp. 87-89). Utilising Laura Mulvey's conceptualization of scopophilia (1975), and building on the findings of Chris Berry and Mary Farquhar, who argue that the gaze in Chinese cinema does not exclusively encourage the audience to identify with a masculine subject position (C. Berry \& M. A. Farquhar, 2006), Li finds that the gaze in the Hong Kong original film is designed to create a sense of disorientation for the viewer, rather than masculine identification. $\mathrm{Li}$ argues that the gaze is restructured in the American remake to emphasise the ethnic dominance of the American over her Mexican counterpart. 
In her analysis of Eat Drink Man Woman (1998) and its Hollywood remake Tortilla Soup (2001), Li focuses on how family, gender and generational discords are represented semiotically through food, with contrasting views on modernity and tradition in a globalized world being played out on-screen.

The aforementioned works by Chan and $\mathrm{Li}$ are very useful in terms of how they reinforce the validity of the methodological approaches already established in gender and remake studies, however, there are additional factors which are yet to receive sufficient attention. What none of the previous studies cover in great detail is the relationship between genre, gender and remakes in Chinese-language film. Yiman Wang is the only scholar who directly uses genre as a method of structuring the analysis of remakes in her discussion of gender in 1930 melodramas. Discussing the category of "maternal melodramas", Wang analyses the Hollywood film Stella Dallas (1925), identifying narrative parallels between this story, the Hollywood remake of the same name (1937), and two 'remakes' by director Wu Yonggang entitled The Goddess (1934) (神女), made in Shanghai and Rouge Tears (1938) (胭脂泪), made in Hong Kong. Wang aims to "unpack exactly how China's semi-colonial circumstances imprint Wu's remaking of Stella Dallas and, conversely, how his remakes envision a more desirable, utopian future, by comparing Wu's different strategies of representing abject female sexuality in The Goddess and Rouge Tears" (Y. Wang, 2013, p. 21).

Wang marks several contributing factors as potential reasons for the changes made to the gender dynamics and the addition of a sequel section in Rouge Tears. Firstly, she argues that the combination of changes in cinematic technologies and access to 1930 s migrant filmmakers, and the tension between Hong Kong's focus on cinema as a commercial enterprise, and the increasing restrictions placed on film by government, all contributed to a much more detailed expression of the experience of prostitution and urbanity than seen in The Goddess. In Rouge Tears, allusion was replaced with direct imagery and overt references in camera angles and mise-en-scène, and the male gaze was inserted to mediate the audience's view of sex and its place in the modern environment, where anything can be turned into a commodity (Y. Wang, 2013). Rouge Tears' modification of the child's gender from a daughter in the original Hollywood film, to a son in the subsequent Chinese versions, emphasised a "traditional gender/sexual politics that privileged male-centered education", a notion that acquired "new urgency and justification in modern China's struggle to transcend its economic and political subjugation by the West and Japan" (Y. Wang, 2013, pp. 19-20). Wang thus highlights the importance of considering genre in remake studies, and the evolving nature of genres across different socio-political and cultural contexts. 
This study will extend upon Wang's discussion of gender representation in remakes of films within the same genre to consider what occurs when remakes do not remain within a single defined generic category. Two out of four pairs of films included in this study undertake a recognizable shift in genre, with A Chinese Ghost Story representing a particular brand of Hong Kong cinematic 'mash-up' which could be labeled a comedy/supernatural thriller/ romance, while Zhang Yimou's $A$ Woman, $A$ Gun and a Noodle Shop, along with its original film Blood Simple, defies straightforward generic categorisation, with its mix of historical drama, suspense and comedy. This work will therefore provide an opportunity to give a more thorough consideration of genre and how different generic conventions across cultural and temporal lines might impact on Chinese-language remakes.

\section{Aims and Structure of This Book}

This book will bring together the different strands of remakes, gender and the family in Chinese-language remakes which have so far been only partially explored in previous studies. The chapters following this will undertake a study of the reformulations of gender and the family in Chinese language remakes of films from the U.s., Hong Kong and pre-communist China from a variety of genres and time periods to look at how and why gender representations change between the source films and their remakes and the implications this might have for what we understand the functions of remakes to be in a Chinese-language cinematic context to be. Eight films, created across different time periods, genres and cultural contexts, will be analysed in order to compare and contrast their representations of gender across the key areas of sexuality, gender roles/expectations, marriage and family. As far as this researcher is aware, these eight films have not appeared before in this way in any other English-language study. The films which will be analysed (in their pairs) are What Women Want (2000 and 2011), Blood Simple (1984) and A Woman, A Gun and A Noodle Shop (2009), A Chinese Ghost Story (1987 and 2011) and Spring in a Small Town (1948) and Springtime in a Small Town (2002).

The focus of each chapter is as follows: Chapter One of this book introduces recent theory on remakes, mapping relevant concepts and methodological approaches, charting the course of remake studies so far through French, Hollywood, and Asian cinematic spheres. Chapter Two introduces the first case study under analysis, with the consideration of the American original film What Women Want (2000) and its Chinese-language remake (2011). Using narrative and psychoanalytic analysis methodologies, the chapter investigates 
variations in masculinity, femininity, sexuality and the family between the two films, with a view to gaining some insight into how these changes might resonate with their respective audiences.

Chapter Three complicates the notion of cross-cultural remaking as a straightforward process of translation, establishing the importance of the mediating factors of genre and auteurism in the case of the Coen brothers Blood Simple (1984) and its remake A Woman, A Gun and A Noodle Shop (2009). While Zhang Yimou maintains the heavy reliance on the theme of failed masculinities seen in the original film, he also significantly shifts the generic bases of his remake to Chinese comedy and performance arts, orienting his film towards audiences with knowledge of these art forms and demonstrating the significance of genre in creating meaning for remake audiences.

The next two chapters shift focus to the "intracultural remake". Chapter Four considers another dimension of genre in its examination of the role of genre and gender as proxies for domestic cultural concerns, specifically, the relationship between Hong Kong and mainland China in the Hong Kong film A Chinese Ghost Story (1987) and its remake (2011). The original film, with its strong themes of political anxiety regarding Hong Kong's handover to China and its casting of bisexual actor Leslie Cheung, presented a chaotic mixed-genre film featuring an array of sexually ambiguous characters. In contrast, the remake, which is a collaborative effort between Hong Kong and mainland Chinese production houses, abandons the gender ambiguity of the original film. These changes reflect a more hetero-normative view of gender, and this chapter explores whether this transformation is just another example of Chinese cinema's transnational dynamics, or whether the remake might be reflective of the complexities of representing the Hong Kong identity in the mainstream Chinese cinematic and cultural landscape.

The idea of the remake as a form of political allegory is explored further in the final chapter, with a discussion of how the mediating factor of temporality influences the similarities and differences between Fei Mu's 1948 film Spring in a Small Town (1948), and its remake Springtime in a Small Town (2002). The remake bears the marks of the past sixty years of literary and cinematic interventionalist national cultural policies in China. Combined with the political inclinations of its director Tian Zhuangzhuang, the remake uses the metaphor of the family home, gender stereotypes from Mao's social realist vision, as well as the semiotic connections of the original film's title, to comment upon China's political past, present and future.

The films in this study were chosen because each pair sheds a different light on the temporal, cultural, generic, political and cinematic dimensions of remake studies. Each pair of films also connects, in one way or another, with 
an overall theme of gender and the family, and the inclusion of both interand intra-cultural pairs of films enables a multi-dimensional approach to film remaking which takes into account the transnational nature of Chineselanguage cinema discussed earlier in this chapter, while still acknowledging the remake's capacity to reflect different audience expectations. Additionally, this study adapts and extends the earlier cross-cultural remake studies methods to consider the relationship between mainland Chinese cinema and the Chinese diaspora, as well as considerations of the same dynamic national culture at different points in history. The study will also identify any factors which are unique or significant to the Chinese remaking context, which may not have been considered due to the field's focus on more Western themes and concerns. 


\section{Remaking the Modern Family}

The case studies within this monograph begin with the examination of a pair of films that initially make the process of remaking a film across cultures look like a very straightforward situation of translation, whereby a narrative is copied and transferred to another language and location. In the case of the Hollywood film What Women Want (2000) and its Chinese-language remake (我知女人心) (2011), indeed, upon first viewing, the remake seems to have made no major changes to the actual plot of the source film. It is not, in fact, the differences between source film and remake which initially strike the viewer of these films, but the similarities. A product of collaboration between us and Chinese production houses, it is easy to assume that the remake is perhaps nothing more than a Chinese copy of the original film.

While the film is now set in Beijing and characters speak Standard Mandarin, the Chinese-language remake readily seems to adopt the original Hollywood film's plot. The film's mise-en-scene is dominated by light, bright and shiny high-key lighting, with skies punctuated by tall, beaming skyscrapers, and spaces framed by sharp, clean lines, presenting a modern view of life in China today. Thematically, dysfunction, divorce, women in the workforce, and the sexual tensions of adolescence all make an appearance in the film. Scenes which seem very direct, including one where Andy Lau's character walks in on his very young daughter, who can't be much older than sixteen, and her boyfriend on the lounge room couch, perhaps indicate that this film might reflect liberal, modern Chinese attitudes towards gender, sexuality and the family. But is this actually the case? This chapter will compare and contrast representations of masculinity, femininity, sexuality and the family in the two versions of the film, with a view to better understanding the role of perceived cultural difference in Chinese-language remakes, and how the representations of gender and the family seen in the remake might connect with current values on these critical social elements.

The us film What Women Want (2000) directed by Nancy Meyers, and starring Mel Gibson, Helen Hunt, Marisa Tomei and Alan Alda, is set in Chicago, and tells the story of a chauvinistic male advertising executive, Nick Marshall, and his struggle to function within a society which is no longer controlled by men. Nick's personal life is dominated by difficulties with his exwife and daughter, and he engages in a string of meaningless relationships. At 
work, an advertising market increasingly dominated by the female consumer means a change of direction for his company, and Nick loses a big promotion to new female employee Darcy McGuire. While attempting to get in touch with his feminine side (part of a professional exercise in understanding the female consumer developed by McGuire), an accidental electrocution gives Nick the power to hear women's thoughts. First seeing this as a curse, his (female) psychiatrist enlightens Nick to the power he could wield should he use this insider information to his advantage. Nick then sets about bringing down the woman who stole his promotion, copying her ideas and undermining her confidence and competence.

The Chinese-language remake (我知女人心), made in 2011, is also a mainstream commercial film, and follows the same plot line, with the male lead Sun Zigang (孫子剛) (played by Andy Lau) directing his new-found mind-reading powers at Li Yilong (李仪龙) (Gong Li). Like the American film, the Chinese remake also features a number of secondary characters, including a male sidekick for the male protagonist, the male CEO of the advertising company, an emotionally unstable coffee waitress, and a female employee with low selfesteem. In both films, by listening to the thoughts of women, the male lead is able to transform himself into a man who understands and appreciates his daughter more, along with winning the love of the female protagonist.

Filled with Frank Sinatra music, Chicago architecture, references to U.s. brands like Nike, and a plot which glorifies the endeavor of personal reinvention, the original film is "a very American movie," according to director Nancy Meyers on the DVD's commentary; "and the characters are very American" (Meyers, 2000). Given this description of the original film as being highly culturally specific, it could be reasonably inferred that it would be difficult to remake such a film in China, where there are different cultural, historical and social forces in action. However, upon viewing the remake, critics from media organisations such as Variety and the Los Angeles Times actually saw few differences in how the story was translated. Julie Makinen's review leads with the title, "What women want translates easily now—in remaking the 2000 film for Chinese audiences, few details had to be changed" (Makinen, 2011). Variety's reviewer Richard Kuipers evaluates the film as a "straightforward remake of Paramount's 2000 money-spinner" (Kuipers, 2011), while Mark Olsen goes further to state that "Andy Lau and Gong Li are appealing leads, but this Chineselanguage carbon copy doesn't find a distinctive voice" (Olsen, 2011). Not only do these reviews identify a lack of substantial plot variation between the two films, but they also reflect the long-held notion that remakes are primarily commercial, sub-quality, unoriginal films with little substance, a myth which 
has already been discussed and dismissed in academia but seems to nevertheless persist in some critical circles.

Arguments regarding originality aside, when the two versions of What Women Want are placed under closer scrutiny, there are, in fact, a number of crucial differences between the two films. This chapter will discuss how gender and the family are constructed in What Women Want, in order to establish where changes are made and speculate as to why these may have occurred. To begin, representations of masculinity and femininity will be examined, and located within the socio-cultural contexts of the films' regions of production. Following this, the chapter will examine how the two films approach the issue of sexuality, before moving to consider how the family is reshaped in the remake.

\section{The Construction of Gender in What Women Want}

\section{Good, Ol' Fashioned Masculinity: Men in What Women Want (20oo)}

In the original film, we are introduced to masculinity through the monologues of three women who know the male protagonist Nick Marshall well—his exwife, his personal assistant, and his daughter. The first image we actually see in the film is of a dirty, sweaty newspaper delivery man, smoking a cigarette while unloading his truck against the backdrop of the Chicago skyline. The voiceover narration from an as-yet unknown woman talks about an American cultural concept: “Do you know the expression, 'a man's man'? A 'man's man' is the leader of the pack, the kind of man other men look up to, admire and emulate. A man's man is the kind of man who just doesn't get what women are about".

We are then introduced to Nick Marshall-"Nick, my ex-husband, is the ultimate man's man. I probably never should have married him. I don't think he understood a thing about me". His personal assistant continues: "So, do you want to check out Nick Marshall's office? Don't worry, he never gets in before ten. He will send you on more errands than anyone else in the office, because he can't do anything for himself. He's a real bachelor, and the least politically correct person in the universe. He's the king of all the T\&A ads that we do. You want babes in bikinis? He's your man". Nick is a man who objectifies women and views them as a collection of sexual body parts. But this attitude is not apparently all Nick's fault-according to his ex-wife, "once you understand Nick's mother, you understand Nick". The viewer is then taken back to Nick's childhood, which was spent in a Las Vegas burlesque theatre, surrounded by half-naked women, pimps, and black money. "While other kids were out riding 
their bikes and playing ball, Nick was backstage, hangin' with the girls". We see Nick beaming as he receives kisses and attention from the female performers.

The introductory minutes of the film thus give a clear impression of Nick's character. He is a "man's man", a big shot, who doesn't understand women and doesn't really want to. He is infantile in many respects, using a baby voice and a pout to beg his housemaid to make him breakfast. We hear in the voiceover that he has a bad relationship with his daughter, who sees him more as an Uncle than a father. The next shot, set to sexy jazz music, is of Nick asleep in bed. Nick rolls over, and we see a lipstick stain on his cheek. We then meet the fourth woman in his life, his Latino housemaid, who spends equal parts of her time chastising Nick, cleaning up after him, and rejecting his sexual advances. Our introduction to Nick concludes with an interaction between Nick and the doorwoman Flo, who gets him a cab to his office every morning.

Nick's problem with women appears to partially stem from his attachment to the 'past glory days'. His behaviour and attitudes are a 'throw-back' to a previous generation, when men were socially and economically dominant, and masculinity was not under attack from increasingly active women. Masculinity in the American original film is thus framed through the male lead's nostalgia for the past-in this case, a past which is unmistakably American. The film strongly roots its version of masculinity in American cinematic culture, through references to Frank Sinatra music (Nick's idea of "an antidote to too much oestrogen"), Vegas showgirls, and recognizable Chicago architecture. The film's verbal sparring between the lead protagonists and the physical comedy of Nick's character harks back to classic Hollywood screwball romantic comedies like The Philadelphia Story (1940) and Pillow Talk (1959).

This connection to memory and nostalgia is a characteristic associated with 1990s America, a part of what Harrison calls a 'crisis of historicity' which was indicative of American anxieties "about the relationship to the past, and a declining ability to imagine the world to come" (Harrison, 2010, p. 2). This period was a time in which America underwent great social change, and identities which were once firmly fixed and united were being eroded by globalisation, resulting in "fragmented communities with their own distinct histories ... (Harrison, 2010, p. 2), and 'culture wars' over issues such as minority rights, multiculturalism and national identity" (Harrison, 2010, p. 18). Harrison argues that as they witnessed the repeated failures of these utopian dreams, citizens became less enthusiastic to engage with unifying narratives of progress. In short, "the 1990s were a period of exuberance and uncertainty ... but while America may have been richer, its citizens were more divided and insecure" (Harrison, 2010, p. 7). 
In terms of women's rights, the 1990s was the decade where standards generally improved, but the goals of the feminist movement were yet to be fully realised. Women's participation in the workplace was ever-increasing, but there were still inequalities particularly in political representation and in relation to race. These social changes manifested themselves in cinema, with "films which produced nostalgic reaffirmations of traditional gender norms of masculinity and femininity, in response to the anxieties created by change, particularly in movies which dealt with the 'predatory woman' or made the reconstitution of masculinity their subject" (Harrison, 2010, p. 16). The American version of What Women Want appears to be consistent with this latter form of film, whereby Nick's crisis and his refusal to let go of past glory days is connected with this broader notion of identity crisis in the face of a changing world for men, where women were expected to now be treated as equals.

The New Chinese Man: Remaking Masculinity in What Women Want (2011)

Rather than affording women the first word, the beginning of the Chinese remake gives Sun Zigang the opportunity to introduce himself to the viewer. He is first seen on the set of an advertising shoot for a luxury foreign car. Dressed in a business shirt, vest and jeans, he sits in the director's chair, smoking a cigar. Zigang observes the shoot with disapproval, before finally interrupting to take command from his younger female employee. He encourages the male model to be more arrogant, more masculine, and the women to be sexier. He justifies this intervention with the statement that his clients are not high-end customers, but coal miners with money- "the car is black. The suit is black. It's the essence of coal. You wouldn't get it", he says to the female employee. We see him receiving praise and support for his work from his male colleague and best friend Tip, and we also begin to see the womaniser in Zigang, as he flirts with the female models. In the following scene, Zigang and Tip drink whisky at a bar and discuss "what women want". Tip is insecure, and functions as a contrasting, effeminate character against Zigang's masculinity. Zigang is confident that he understands both men and women - what women want, in his opinion, is simple- "men with money".

We are then introduced to a somewhat different perspective on Sun Zigang from his ex-wife. Wearing a wedding dress, she is preparing to remarry, and is giving her bridesmaids and the viewers an insight into her ex-husband's personality. Their daughter Doudou (豆豆) is also present. According to his exwife, "Doudou's father only sees himself. Like all men, he never listens, and he never lets people finish a sentence. His ears are just for decoration. Sun Zigang was raised by his father. Even when he was young, he knew how to 
placate women". Her narration is intertwined with a flashback of Zigang being raised by his father. She comes to the conclusion that while Zigang is flawed, "that's just how he is, with the typical faults of any man". The scene cuts to Sun Zigang in bed, being awoken by his landlady. Late for work, a groggy Zigang is framed next to his watch and a near-empty glass of wine, and she questions him over his evening's activities. Unconcerned, Zigang orders her to make him breakfast- "since the management fees on his apartment are so high these days, it's the least you can do". Confident, arrogant, charming and successful, this is a man who usually gets what he wants.

The remake of What Women Want, while maintaining the same masculinity in crisis theme as the original film, adopts a different method of approach for its predominantly domestic Chinese audience. Instead of constructing Sun Zigang's masculinity with reference to the bygone past, it is the present that takes centre stage. Zigang's character is thus surrounded by symbols of a 21st century man, from his uptown lifestyle to his modern workplace and attire. Rather than dancing to an old Frank Sinatra song, Sun dances to an Englishlanguage pop/dance track, and even performs a ballad in English for love interest Yilong later in the film. Rather than attempting to go back in time, Zigang is trying to move forward into a way of thinking which matches his otherwise contemporary lifestyle. The film reflects what Kam Louie has identified as a greater shift in Chinese society, whereby the traditional ideals of wen and wu in China have evolved to more strongly identify business success, wealth and a high-flying, travelling lifestyle as important features of masculinity (Louie, 2014). As will be discussed later in this chapter, Zigang's father provides the counter-point for the past version of masculinity in the film's narrative.

\section{Performing Gender in What Women Want}

A very significant aspect of how gender is constructed in both versions of the film centres around performances. While Nick Marshall has an office full of pictures of women in bikinis, and dances around his living room to an old Frank Sinatra song, the Chinese remake draws attention to the performative nature of gender through the exaggerated notions of masculinity and femininity encouraged by Sun Zigang's coaching of his models. Both films feature drag scenes where the male protagonist dresses as a woman -in the original film, Nick Marshall tests out the beauty products given to him by his new female boss, with comical results. This scene is replicated in the Chinese remake, and an additional drag scene added where Zigang's work colleague Tip arrives in drag at a work meeting. The internal monologues of women throughout the film also serve to highlight the performative nature of gender, contrasting the external appearance and verbalisations of these women with their 'real' 
gendered characteristics revealed through their thoughts. Important aspects of characters' personalities are therefore conveyed through various performances within the film, and in general, gender is shown to be a form of performance, in the sense that men and women both perform the perceived qualities of their gender at different points throughout the films.

This exploration of masculinity and femininity raises deeper questions of how gender is in fact constructed in the films, and the use of drag scenes to interrogate gender strongly connects with the theory one of the most significant post-feminist scholars, Judith Butler. Butler, in her works Gender Trouble (Butler, 1999a), Bodies that Matter (1993) and Undoing Gender (2004), discusses the theory of 'performativity', articulating how gender is not a pre-ordained, natural category, but is instead discursively constructed; through the use of certain statements, gender is brought into being, and it is in this sense, 'performative'. In Butler's theory, "gender is not to culture as sex is to nature; gender is also the discursive/cultural means by which 'sexed nature' or 'a natural sex' is produced and established as 'pre-discursive', prior to culture, a politically neutral surface on which culture acts" (Butler, 1999a, p. 11). Thus, the performative nature of gender makes the traditional binary gender system open to challenge from groups that do not conform to hetero-normative standards. Butler uses the example of the drag queen, who becomes another gender through the performance of behaviours associated with that other gender (Butler, 1999a). In this way, gender "becomes a free-floating artifice, with the consequence that man and masculine might just as easily signify a female body as a male one, and woman and feminine a male body as easily as a female one" (Butler, 1999b, p. 346). However, importantly, a drag queen who mimics perfectly the female gender does not deconstruct the binary of gender but rather reinforces it.

As already mentioned, the two versions of What Women Want both feature a drag scene involving the male protagonist. Through this scene, we gain an understanding of some of the rituals involved in being a woman (and conversely, the rituals not involved with being a man). Waxing, using sanitary pads, and applying make-up, all form part of the social rituals involved in distinguishing women from men-from a young age, these acts are signifiers of gender difference and thus, as Butler argues, contribute to the construction (and maintenance) of gender itself. By unsuccessfully and humorously performing 'woman' through this drag scene, both the male protagonists establish that the differences between the genders are in part, attributable to learned behaviours-behaviours these men never engaged in, and are therefore not very skilled at. However, there is a slight difference in the use of the male body which speaks to the broader issues of gender construction that appear across the two films. 
While Nick Marshall's masculine, hairy body only emphasizes the difference between his masculinity and the female body, Sun Zigang projects a slightly different form of masculinity, which is more consistent with the remake's Jungian approach to gender. While his conversion of a tampon into a toy cigar could be read as an attempt to masculinise a very feminine product, this initial desire to dominant the feminine fades over the course of this scene-Zigang struggles less with the application of makeup Nick Marshall did, and after an initial period of hesitation, seems to relish the opportunity to engage in some of the behaviours and rituals that are associated with the 'anima'-a point which will be explored further later in this chapter. However, while the gender boundaries in the Chinese remake are redefined, they are nevertheless also reinforced by a second scene where Zigang's workmate Tip misunderstands a directive and appears in drag to a work meeting. The subsequent ridicule and embarrassment he suffers makes very clear the attitudes towards this alternative construction of gender. In practice, none of the men in What Women Want genuinely have their sexuality questioned through the way the films' construct their gender.

\section{What Do Women Want? Femininity in What Women Want}

Both versions of What Women Want have introductions that use female characters to induct the viewer into a certain view of masculinity-the premise being that we are introduced to the male characters from a 'feminist/feminine perspective'. But through these introductions, we also gain an insight as viewers into the construction of femininity. In the original film, we meet no less than six female characters in the first ten minutes of screen-time. The ex-wife, the personal assistant and the daughter all seem to have particularly scathing opinions of Nick, drawing upon anti-male sentiments and notions of female superiority with comments such as "he can't do anything for himself" or otherwise employing sarcasm to describe his personal behaviours and values. He is, according to them, incompetent, sexually promiscuous, and totally incapable of maintaining what these women consider to be quality relationships. Child-like, in the past he has been totally dependent on them, and is thus rather pathetic.

But, in the introductory monologue of Nick's ex-wife, it is also evident that femininity also involves an element of criticism directed at women by other women. Nick's mother is derided for her unorthodox lifestyle-her openly sexual behaviour is condemned, and she is ridiculed in her role as mother, by another woman. Thus while Nick himself is subject to some criticism throughout the film, his mother is condemned for being the source of Nick's behaviour. She has displayed what is clearly considered to be an inappropriate version of 
femininity and of motherhood in particular. The acceptable form of femininity, as defined by those women whose behaviour is not questioned or is condoned within the film, is sexually chaste (or at least, keeps her thoughts to herself), insecure and dependent. These women supposedly both love and hate Nick Marshall, and are easily fooled by his charms. At one point early in the film, Nick accidentally spills coffee on a woman's breasts and subsequently gropes her under the pretense of helping her. From her reaction, we can see that this behaviour is interpreted naively by the woman as him kindly helping her clean herself up, rather than as sexual assault. Thus for a film which purports to be about what women want, the American original is very male-fantasy oriented, with little room for substantial female characters.

Further evidence for this view can be found in the most important vehicle the film has for constructing femininity - the thoughts of women, as overheard by the male protagonist. As the women in the film do not know that Nick is able to hear them, their thoughts are presented as being unfiltered, authentic female thoughts. In the context of the original film, American women have thoughts which are primarily neurotic or sexual. Neuroticism appears primarily in the form of anxiety over how colleagues or other people perceive them, for example "I hope I am doing this right, Oh God, what am I doing? This is so embarrassing" and similar ideas. There are also a number of thoughts which relate to the performance of simple, everyday domestic tasks, such as "Did I remember to turn the oven off?" Finally, the bulk of the rest of female thoughts are concerned with sex, involving fantasizing or concealing one's desire for another person-apparently women have sexual thoughts too, but often do not, or cannot, express them. The one woman who isn't discreet is the coffee waitress, who sleeps with Nick and as the film goes on is portrayed as a desperate sexual predator. Anxieties about the increasing role of women in external society, and the desire to re-affirm traditional gender roles in response to this threat, are thus again reiterated through the construction of femininity.

\section{What Do Chinese Women Want?}

In the Chinese remake, what is interesting but almost goes unnoticed is an early scene in a bar, where Zigang casually writes on a bar napkin the words “What do women want? What do Chinese women want?" (“女人要什么? 中国女人要什么?”). It seems there is a clear distinction being made here between women broadly and Chinese women particularly. In this film, while recognizing that there are common desires shared by all women, the viewer is directed to note that there is something specific about Chinese society and culture which warrants a separate category addressing the expectations and goals of Chinese women. In the Chinese remake, these expectations and goals are 
framed through the representation of a number of female characters, particularly the ex-wife, the protagonist Li Yilong, and the coffee waitress Yan Yi, but also significantly by several of Zigang's female co-workers. Aside from Yilong, who is depicted as being relatively strong, reasonable, intelligent and classy (albeit rather sentimental), the remake follows a similar depiction of femininity to the source film, where women perform a version of femininity that is shallow, self-obsessed and gullible. There is, however, a definite change in focus between the themes featured in the American source film's female monologues and those in the Chinese remake.

Zigang's best friend Tip acknowledges this change in his response to Zigang's musings about what women want-what women want is "money". What Chinese women want is "men with money". The Chinese film, in contrast with the American original, emphasizes women's internal thoughts as being highly materialistic and consumerist. It is of course necessary to acknowledge that the Chinese remake of the film would have been subject to more strict censorship rules than its American counterpart, and it was tailored for a broader audience, therefore the sexual content which could appear in the film would have been restricted. Many of the sexual thoughts which were a feature of the original film would have been removed as a consequence of this. However, in re-writing the script, there was a decision made to replace these thoughts with materialistic ones, driven by issues of self-image, rather than other themes.

Woman, as she appears in the Chinese remake, is a very vain creature. Many of the thoughts of everyday women, even as they pass by Zigang in the street, are aspirational and revolve around buying or receiving material possessions. When he is first discharged from the hospital, he overhears the thoughts of women who want to be bought cars if they aren't going to be bought houses (“不买房也得给我买辆车”), and later, women who are overspending on their credit cards comparing notes and judging others on their purchases. The thoughts of these women are less related to a fear of doing things right or wrong, and are instead much more heavily oriented towards self-image, materialism and status than what is conveyed in the original film. Many internal thoughts involve criticizing the female body (both self-criticism and criticism directed at others), with references to poor women dressing like "peasants", women who wear a lot of make-up as "working girls", and plastic surgery as an option for unattractive women. Interestingly, these comments are not only about self-image, but are also embedded with a form of class elitism.

If Shuqin Cui's argument that 'woman' in Chinese cinema acts as a "visual and discursive sign in the creation of the nation-state in twentieth-century China" (Cui, 2003, p. xi) is applied to this 21st century remake, the representation of women could be read as indicative of the nation suffering from a 
self-image issue. The characterization of the remake's women as shallow and vain is symbolic of the increasing influence of the discourse of consumerism that has become associated with the rapid economic and social changes which have occurred in China over the past thirty years. Thus, the Chinese woman in What Women Want fiercely defends her right to her new-found materialism and prides herself on her appearance, but at the same time, worries about being 'overweight' - an allegory for over-consumption. The changes that have been enacted upon femininity in the remake thus could be read as the cinematic manifestations of these cultural and social changes in China more broadly.

\section{Sexuality in What Women Want}

As can be seen in the different versions of masculinity and femininity presented in the two films, much of the narrative of What Women Want is fundamentally concerned with defining and re-defining gender. In both films, what was seen as a legitimate form of masculinity, with its misogynist tendencies and societal dominance, is established as being no longer the appropriate approach for modern men in contemporary society. However, while the primary plot remains the same, the two films tap into two distinct psychological concepts to explain the behaviour of their protagonists, which again reflect perceived differences in cultural approaches to gender.

\section{Freud and What Women Want}

The American source film, set in the 199os, is built on a structure which very closely follows Sigmund Freud's understanding of gender and sexuality. The most obvious acknowledgement is in the film's title, a reference to an unanswered question purportedly posed by Freud himself- "What do women want?" The Freudian interpretation of human behaviour centred on the belief that the driving force within all humans is the libido. Freud argued that the life energy of humans originates from, and is shaped by, sex. Every personality or physiological disorder suffered by individuals is the product of a traumatic sexual event or unfulfilled sexual desire/s, often stemming from childhood, where limitations or prohibitions on sexual behaviour from adults influenced the sexual development of children (Kline, 2014).

In the Hollywood film, it is the absence of a father figure that defines Nick Marshall's attitudes towards women. It is established early in the film that Nick suffers from a complex related to his mother. This stems from her not providing a strong male role model for him, and raising him in an overtly sexualized environment. The American film is built around this Freudian 
interpretation of parent-child relations, which vilifies the mother for her incompetence and for the subsequent failings of her son. Nick's ex-wife gives us a detailed explanation of this attribution of blame in her opening monologue- - Once you understand Nick's mother, you understand Nick. Nick was actually born and raised in Las Vegas. Nick's mother was a real, honest-to-God Las Vegas showgirl. When other boys were outside riding their bikes and playing ball, Nick was backstage, hangin' with the girls. He was their mascot, their little pet. They couldn't get enough of those baby blues. If you ask me, Nick's mother just about killed it for any other woman Nick would ever meet. She had a lot of sugar daddies in her life, but only one true love- the boy with the family jewels. And since Nick didn't have a father, his mum made sure he was always surrounded by strong male role models that her little boy could really look up to. There is nothing normal about the way Nick Marshall was raised. So what do you expect? You don't have to be Freud to figure out that this was one cock-eyed way to enter the world."

The visuals of this scene make it clear that these comments are sarcastic. The conditions described have actually stunted the normal process of Nick's sexual growth, and he seems to be unable to progress beyond what Freud called the 'phallic stage' of development. In this stage of development, Freud theorized that the libido found expression through the subject becoming obsessed with matters concerning the phallus. As can be seen throughout particularly the early stages of the film, all of the film's characters, but most especially Nick, are highly concerned with sex, and there are frequent references to the phallus in terms of size and performance. In just the two minute monologue above, there are already two references to 'the family jewels' and a 'cock-eyed' way to enter the world used to describe Nick. The coffee shop where we meet Lola (the unstable barista) sets up a gag about the size of Nick's 'coffee'- "grande, or at least I like to think so". Nick is thus clearly very 'tuned in' to matters relating to the phallus, and failing to progress beyond this point of development has, according to Freudian analysis, resulted in him becoming an aggressive, overambitious, vain man (Kline, 2014).

In representing women, the film also filters female characters through a Freudian lens. The women in What Women Want also have sexual thoughts and needs, some of which we are privy to in their internal monologues. Many of these needs go unexpressed, which Freud believed led to personality disorders such as neuroticism, obsessive behaviour and sexual repression. All of the female characters in the film, from the lead protagonist through to the coffee waitress and the doorwoman, display these qualities to some extent. They frequently question themselves, and are highly concerned with what other people think of them. Lola, while having sex with Nick, is unable to express her 
sexual needs, and is fortunate that he is literally a mind-reader at this point in the film. Protagonist Darcy is even caught by Nick at one point looking at his crotch while they are in a professional setting, for which she must immediately (mentally) chastise herself. But while Nick's sexualised behaviour is seen as misogynist but somewhat 'natural', women have been most affected by a social context which has shaped them to be ashamed of these kinds of thoughts and desires. The women are thus conflicted and often unable to express themselves clearly to get what they need in a relationship, and it is up to Nick instead to give them what they need by 'reading' them.

For the period from his first significant lecture in 1909, through the translation of his works in the early twentieth century, to the peak of his popularity between the 1940s and 1980s (Ross, 2012; Skues, 2012), Freud's theories became a very significant part of American approaches to understanding the psyche. According to Elizabeth Lunbeck, despite the American obsession with "distinctively optimistic mental therapies-touting self-esteem, enjoining self-help, promising self-actualization ... paradoxically, America is the nation in which, among all others, Freud's science of psychoanalysis has arguably enjoyed the greatest purchase, the most far-reaching cultural influence, the most powerful institutional instantiations" (Lunbeck, 2012, p. 209). With the decline of his work in the 1970s and 1980s, American psychology saw the rise of narcissism as an ideal. The prioritization of love of the self over love of others became the focus of rhetoric about a culture of rampant individualism which was seen to be becoming a feature of American culture (Lunbeck, 2012, p. 217).

Freud's psychoanalytic approach to gender and sexuality, while useful in some contexts, also had a significant weakness, in that it was reliant on the concept of inherent, hierarchical gender binaries. In the case of the Hollywood film What Women Want, the film's narrative is structured around this gender binary, with the male and female assigned certain qualities which should not overlap. When they do, this is considered 'strange', a transgression of the socially accepted gender boundaries. Darcy McGuire, with her career focus and single status, is thus considered a transgressor until she shows the empathy and caring qualities expected of a woman towards a man. Nick is certainly out of his depth wearing female clothing and performing female routines such as waxing, and his attempts to empathize with women are initially met with strange looks and derision (for example, when he tries to steal a colleague's idea for marketing a female product, which ends in all of the women being offended by his bumbling attempts to relate to their needs). Both characters are positioned as somehow 'abnormal' if they demonstrate characteristics which are associated with the opposite sex. Research on remakes and gender has shown 
that this binary approach is often evident in Hollywood films, and is connected to particular social, political and cultural factors in America. The American version of What Women Want is thus both simultaneously a tribute to Freud's work in as much as it replicates his method of constructing gender and sexuality, and a critique of his theories, as was fitting for a film produced after the perceived decline in his relevance. Thus, despite the criticism of Freud, his theory remains a highly valuable tool in reading this film's representations of gender.

\section{Jung and What Women Want}

In the Chinese-language remake of What Women Want, we also see a re-orientation of gender, with the introduction of theory which is not as binary-oriented as Freud's work. In the remake, while the English name of the movie remains the same, the reference to Freud in the Chinese name has been removed, with the title instead literally translating as 'I Know a Woman's Heart'. Lead character Sun Zigang's main problem is that he has failed to reconcile himself with his 'anima' - that is, the feminine which exists within the masculine, thus he is unable to understand the world from a woman's perspective.

The theory of contra-sexuality, attributed to Carl Jung, states that anima and animus are complementary parts to a healthy whole. The remake overtly references this theory through Li Yilong, when she explains it early in the film as a part of her first speech to her new employees. Gender, according to Jung, is a much more fluid concept than Freudian psychoanalytic theory recognizes. Jung argued that individuals constantly engage in a process of Individuation, the "development towards a wholeness that necessarily remains a potential state". According to this theory, an individual is sexually and psychologically healthy when they acknowledge and accept both the masculine and feminine sides of their psyche. Unlike Freud, Jung's theory argues that the 'masculine' aspects of the psyche such as autonomy, separateness, and aggressiveness were not superior to the 'feminine' elements such as nurturance, interrelatedness and empathy" (Ward, 2006, p. 16).

That Jung is substituted in favour of Freud in the Chinese remake is perhaps an indicator of the perceived difference in how gender is constructed in Chinese culture more broadly. Carl Jung was in fact influenced by the Eastern philosophy of yin and yang, which emphasizes balance between energy and forces. He perceived these Chinese Taoist concepts as forms of precursors to his own theory of individuation, with "re-establishing a balance between the opposites of yang (warmth, light, maleness, heaven) and yin (cold, darkness, femaleness, earth) in the Tao and the goal of the individuation process, 
a balancing of compensating psychic opposites in the experience of the self, being parallel processes" (Schlamm, 2010, p. 485).

Sun Zigang's process of transformation is reflective of a Jungian approach to gender, with the incorporation of the feminine into the masculine in a balanced way being the goal. His characterization moves towards acknowledging the feminine aspects of his personality such as empathy, kindness, and the ability to listen. The anima and animus are neither positive nor negative, rather, they reflect continually changing states of being based on "whether the opposite sex is feared or idealized" (Ward, 2006). From a Jungian perspective, the thoughts he hears which are negative are in fact projections of his own fears relating to the opposite sex, rooted in his own anima. This Jungian perspective may be another explanation for the significant amount of criticism we hear from women in the film, as Zigang may actually be projecting his flawed understanding of his anima onto the members of the opposite sex that surround him.

\section{The Paratextual Construction of Gender in What Women Want}

The varying approaches to the representation of gender discussed in this chapter are aptly symbolised by the paratexts of the What Women Want films, specifically, their DVD covers and advertising posters.

The cover of the American What Women Want, which was widely distributed for European, American, Australian and New Zealand audiences, features a head shot of Mel Gibson smiling directly at the camera, his blue eyes shining. Helen Hunt is captured in profile, eyes closed, with an affectionate smile directed towards Gibson. Both are dressed in black. While Helen Hunt's body might be positioned in front of his, the focus of this picture is squarely on Mel Gibson. He is afforded a front-on view, while Hunt's body language is that of supportive female. The back of the DVD cover is dominated by another image of Hunt and Gibson, this time backlit in a romantic embrace. Hunt leans into Gibson's strong frame, and he grips her arm as if to support her.

The second cover is a variation on the first, using a similar image of Hunt and Gibson in an embrace. This time, their relationship is located against the distinctive Chicago skyline, and they become the image of the quintessential American couple. Hunt's face is partially obscured and her body positioned side-on, while Gibson again dominates the image through the opening of his shoulder and face toward the camera. Taken together, these images strongly evoke the traditional happy couple, one in which the male is dominant. They play down the manipulation and exploitation undertaken by the male lead against the female protagonist within the film, and emphasise the unity and love within the couple. This is echoed in the phrase, "a naughty and nice 
romantic comedy", implying that Nick's behaviour, while childish, is essentially harmless.

The Chinese remake's DVD covers feature the lead couple of Andy Lau and Gong Li, but the way they are positioned gives a radically different impression of their relationship compared to the American source film. Using a back-toback medium shot of both Andy Lau and Gong Li, and a shot of them beside each other, these images present the lead characters as equals who share both a connection and a rivalry. The balancing of their bodies against each other also reflects the theme of the balancing of anima and animus that the film focuses upon. The second image similarly achieves this through its symmetry, both characters posed with their legs and arms in complementary positions. The representation of the Chinese couple thus emphasises balance, rather than idea of the male being dominant and the female supportive which form the basis of the advertising of the source film.

\section{The Family in What Women Want}

In the process of constructing the gender relations and sexualities that have so far been described in this chapter, both the original and remake films also strongly relay ideas pertaining to the family unit. Perhaps the most obvious social issue raised in the films is divorce, through the representations of 'broken' families-parents who are divorced, and children who relate more to their mother, and have difficult relationships with their father as a result of his absence. This issue, however, is treated differently across the two films, and how and why this occurs is important in understanding how perceptions of cultural difference may impact upon the construction of the family in the context of Chinese-language cinematic remakes, as well as how these depictions might tie into social and political discourses on the family.

In the American film, divorce is culturally and socially no longer considered to be a taboo subject. While it is an obvious and continual indication of Nick's failure to understand women, being divorced is not a barrier to him establishing a relationship with someone else. Communication with his ex-wife, who has since re-married, occurs on a number of occasions, both in person and on the telephone, when his daughter is having difficulties. Divorce itself, however, is not the subject of criticism via any attempt to actually re-unite the parents or preserve the structure of the traditional family. Darcy, Nick's new love interest, never meets Nick's daughter, and Nick's roles as father and lover are allowed to exist more or less simultaneously in two separate and distinct familial/ relationship contexts. 
While the Chinese film seems to also be relatively accepting of divorce, the relationship between Zigang, his daughter and ex-wife, and Li Yilong, the new love interest, is of a different tone to the source film. Zigang and his ex-wife (who has re-married) seem to have a much greater sense of distance between them, with direct communication (on the telephone) only occurring once during the film. While there is also no attempt to re-unite these two parents, there is a distinct sense of closure associated with their relationship which is established before Zigang and Yilong's relationship starts to develop. The incorporation of Sun's daughter into this new relationship via a chance meeting between her and Yilong, and the establishment of these two women as friends or 'allies' through their mutual dislike of Zigang's behaviour, points towards an underlying discomfort with the issue of divorce, particularly when children are involved. Rather than operating in two different contexts simultaneously, Zigang must consolidate his role as father into his new relationship. While the right to divorce has been enshrined in law in China since before the 1950s, the representation of divorce in the Chinese-language remake of What Women Want is consistent with a society in which the familial structure of mother, father and child (and grandparent) is still considered the ideal.

\section{The 'Traditional' Chinese Family}

These family-related discourses within the Chinese-language film can be read with reference to some of the most salient points in the historical development of the Chinese familial system. From the early 20 th century, and culminating in the Communist Party's takeover in 1949, a number of drastic changes occurred within the structure of the family within China. Traditionally, families had been multi-generational households, and for the upper class, also included extended family members and concubines (Yang, 1959). All members were governed by "a principle of dominance by the parents, and stratification of status and distribution of functions by sex and age" (Yang, 1959, p. 10). It was this patriarchal, feudal family structure which was identified as being incompatible with the modern, industrialised state imagined by China's leadership after the May Fourth Movement in 1919. Successive governments capitalized on broader changes which were occurring in social structures, and with the arrival of the Communist regime, attempted to usurp the family and replace it with its own bureaucratic structures (Xiao, 2014). In this way, "state power inserted itself into the private sphere to revolutionize people's everyday practices" (Xiao, 2014).

While divorce was already legal in Republican China in the 1920s, it was not until the $195^{\circ}$ Marriage Law that a nation-wide push towards reshaping the family system occurred (Xiao, 2014). This law made arranged marriages, 
child brides and polygamy illegal, and gave women the legal right to property and the ability to initiate divorce proceedings. This was part of a coordinated effort to break down (or accelerate the breakdown) of the traditional family system, first by removing the patriarch's power to choose family members and consolidate power through arranged marriage, and then by a system of state allocation of jobs in the new collectivized and nationalized industrial and agricultural sections which further weakened the power of the family and often caused the involuntary physical separation of family units. These conditions often resulted in extended families no longer being able to reside in the same house, and the One Child Policy implemented in the 1970s, further restricted the ability of the family unit to gain power and influence within wider society.

This is not to say that the power of the family has entirely disappeared within modern Chinese society; it is important to acknowledge that a class system whereby family ties and 'connections' (guanxi) are pillars of success is still in effect, and many powerful people in China have family members who also have significant related business interests. There is also a great divide between rural and metropolitan areas on their adoption of modern ideals of the family. It is more accurate to say that the influence of the family has been weakened in comparison to its position in traditional China, and that current public opinion reflects a change in attitude towards previously accepted behaviours. Reflecting on these changes, it can be argued that "[n]o institution has experienced the vicissitudes of the political, economic, and social changes that have marked the PRC's first half century more sharply than the family" (Alford \& Shen, 2004, p. 238).

\section{The 'Modern' Chinese Family}

While the majority of characters from the original Hollywood film are retained in the remake, there is a significant addition of one character who does not appear in the original film-Sun Zigang's father, Sun Meisheng (孫美聲). So what happens when the Chinese remake presents us with a living father figure for its male protagonist? At first glance, very little. Sun Meisheng's character is an unremarkable one. Throughout the film, he appears five times, with two of these occasions involving very little dialogue, and a third mostly seeming to be for comic relief. He does not drive the narrative, and earlier in the film seems to just be there to give the audience an understanding of where Zigang's attitudes might have come from. Later, he acts more as an enabler to the main protagonist, telling him to be honest with Yilong. The Hollywood film shows that neither of these activities is necessary for the general plot of the film to work, and there is no equivalent figure in the original movie. This added character does not have a great deal of screen-time, so the question is, why include him? 
Sun Meisheng's role can really only be understood with reference to the preceding discussion of the changing nature of the Chinese family. At around seventy years of age, Sun Meisheng would have borne witness to a period of great social upheaval in China, and his characterization is a poignant reflection on the tension between traditional and more modern discourses on the family, and the re-negotiation of ideals within Chinese society. In the film, he lives in a nursing home on the outer rim of Beijing. His son visits his father a few times over the course of the film, both alone and with his daughter. In the nursing home, Sun Zigang's father is seen teaching other residents to sing, and seems, for the most part, to be sociable and healthy. On the surface, it seems that this process of children leaving home and the patriarch living in a nursing home is being normalised. There are no overt objections or accusations of abandonment from anyone over this issue within the narrative. The separation of the family, physically and emotionally, is portrayed as being a feature of a modern Chinese lifestyle.

The audience first meets the character of Sun Meisheng as a young man through a flashback. In this scene, he briefly shows his hardline approach to discipline and parenting, which has left a deep impression on Zigang. A later flashback strengthens associations with the past, with the setting of a traditional building shot in dark lighting, in a kitchen with paper latticed windows and an outdoor stove. Costumes are from the 1950s, and there is an argument between Sun Meisheng and his wife about his participation in a Communist choir. Sun Meisheng still participates in a choir in the nursing home, and listens to Chinese folk songs from the traditional era. In his characterization, we see a blurring of traditional and Communist time periods, whereby both preCommunist and Communist China are categorised together under the banner of 'the past'. While mostly seen in modern, informal clothes, and being technologically adept enough to use an iPod, Sun Meisheng is, for the best part of the film, living in the past, and most of his dialogues are concerned with his treatment of his wife and son in a period long ago.

Zigang, on the other hand, is more closely associated with 'modern China'-divorced, employed in the fast-paced advertising industry, listening to and performing songs in English, smartly and formally dressed in a suit for the majority of the film. As we know though, despite Zigang's criticisms of his father, in many ways they are very similar in terms of their attitudes towards relationships and family. His relationship with his daughter, like that of him and his father, is strained, and he is accused of the same crimes as his father (failing to listen) by his ex-wife in the film's opening scene. The responsibility for Zigang's wayward lifestyle shifts from the mother figure to the father in the remake, however, this is done more delicately than in the source text. In place 
of the sardonic criticism of Nick's mother, the remake uses implication, filmic montage and flashbacks within the opening scenes, combined with the statement "Zigang was raised by his father", to establish the role of the male parental figure in shaping Zigang's attitudes and behaviours. It is left to the viewer of the Chinese remake to conclude whether this constitutes blame or is merely a representation of how sons follow in their fathers' footsteps.

The comparing and contrasting of father and son comes to a head in a scene where they argue at the nursing home. Sun Meisheng is bragging about his "special gift" of being able to understand what Zigang's mother was feelingshown to be a lie through a flashback from when Zigang was a young boy, watching his parents argue. Through stepping back in time here, it is obvious that Sun Meisheng's view of their family history is very different from his son's. But we can also see the origin of Zigang's attitudes towards relationships and family, and the root of the problem between him and his father. While Sun Meisheng states "like father like son", and tries to draw parallels between them, the two men are contrasted in their clothing (Zigang is very formal, wearing modern business attire, while Sun Meisheng is dressed informally). An initial connection is established between father and son in body language, as their seated positions mirror each other. But distance is created between them through the positioning of the characters apart from each other in the frame. The prop of an iPod is used by Sun Meisheng to further alienate Zigang by having both earphones in and not listening as they argue. The scene ends with Zigang speaking on behalf of his mother, saying "What was she thinking then? She was thinking 'why did she marry such a selfish and arrogant man?" Zigang gets up to walk away before the conversation has even finished, with Sun Meisheng calling out- "she may have married a man like me, but look what kind of son you are"-implying Zigang has somehow failed his father.

In Sun Meisheng's representation, China's traditional and Communist eras are compressed together. The difference in values between father and son are a comparison of the concepts associated with 'traditional' China of the past, as compared to 'modern' expectations of how men and women should relate to each other. In a later scene in the film, Sun Meisheng and Zigang meet again, with Zigang again creating a link to traditional Chinese culture by passing on a gift of a CD of old Chinese folk songs from his daughter. Sun Meisheng chooses this time to expose his true feelings about his own management of his role as father and husband: "I admit I was a bad father, and a bad husband. I never knew what your mother was thinking, and I didn't want to know. My only regret in my life is that I didn't listen to anything your mother said". Sun Meisheng thus creates a link between traditional culture and the treatment of women - and becomes a representative of a whole system of cultural practices 
and attitudes towards women which are now judged to be inappropriate. The son is in danger of continuing such ideas, and both must reform in order to function in the contemporary social and familial context. This revelation is an important step for both men, and the audience gets to see Sun Meisheng in particular in a new light - literally, as the lighting in this scene is much warmer than the two earlier scenes featuring these men. The dialogue is much softer and more melancholy, compared to the anger and bitterness of their earlier confrontation. The men are situated in a closed, private space, emphasizing the increased intimacy of their relationship.

Sun Meisheng further instructs his son in their final dialogue on how he should be honest with Yilong about stealing her ideas- "unless you want to regret it your whole life like your father, you will go and tell her the truth". The father's inclusion in the film thus serves a secondary function as educator-he has learned the secret of 'what women want' (which is to be listened to, and to be talked to honestly), and is thus compelled to teach (or re-educate) his son. The traditional function of the parent as teacher is thus reinforced, as Sun Meisheng provides the encouragement needed for Zigang to be honest with Yilong. As a result the couple eventually reconciles, and the film ends neatly with all three generations-Yilong, Zigang, and his daughter, attending Sun Meisheng's choir performance.

The cultural and social implications of the father figure in the Chinese remake are brought even more sharply into relief when one compares the two versions of What Women Want. The Hollywood source film has no older male character who acts, as Sun Zigang's father does, as a point of reference to traditional views on the family. Instead, Mel Gibson's character functions as part of a couple, as opposed to part of a family unit. Unlike Yilong, Gibson's female counterpart Darcy never meets his daughter, so there is no implied affirmation of the traditional family as appears in the Chinese remake. Instead of relating his behaviour to a wider social problem or need for reform like the Chinese film, the Hollywood original focuses more on Nick Marshall as an archaic man who is out of touch with contemporary values. The Hollywood film is, in essence, the story of one particular man who treats women in a particular way. This particularist approach of American cinema has already been associated with America's (and Hollywood's) fascination with 'the couple' as an independent unit, rather than 'the couple' as a part of broader society as it appears in, for example, French film (Durham, 1998, pg. 65-58). By introducing the figure of the father, the Chinese film takes the investigation from one specific person to a whole cultural tradition of attitudes to, and treatment of women. The father character plays a significant role in the film remake that 
results in the restructuring of the entire narrative around the family rather than the couple.

Despite the film's modern façade, the inclusion and representation of Sun Meisheng thus still reflects some very traditional Confucian views on the family. To respect and care for your elders is paramount in the Confucian moral order-to relegate them to someone else's care is shameful. Despite the earlier mentioned breakdown of the traditional family system, the importance of filial piety still lingers over Chinese society. It is therefore interesting to consider how the Communist Party has reconciled itself with this issue. After helping to break down the family system as the main structure of society, the Party has struggled with the economic and social burden of taking responsibility for the elderly ("Fulfilling promises," 2012, 11 August). The consequence of the elderly receiving inadequate social support has resulted in a high suicide rate among the older demographic in China ("Alarming elderly suicides in rural China," 2014). The Party is thus in the process of shifting responsibility back to the children to care for their parents, despite the fact these children now work full-time, and have less time than ever to devote to caring duties. The administration has recently legislated to make it mandatory for children to visit their parents 'often', or else risking being sued by them for neglect ("China: Parents can sue children for neglect" 2012). Sun Zigang's regular visits might be read as a moral guide for how a busy person should behave towards their parents. The difficulties in their relationship perhaps in part reflect the difficulties of negotiating between Confucian ideals of respecting one's elders, and more modern interpretations and pressures on the family.

\section{Commerciality and the Modern Family}

In bringing into the spotlight the "modern" Chinese family (in all its paradoxical forms), the remake also introduces a distinctly commercial aspect to gender and the family which is not evident in the original film. Aside from a prominent feature on Nike, the original What Women Want does not feature a large degree of product placement or advertising. The Chinese version of the film, however, again reflects a change in emphasis between source and remake, whereby advertising has become much more prominent. Products are directly linked to expressions of gender and the family in ways which create associations between femininity, masculinity, family, success, love and consumption.

Examples of these connections can be seen from quite early in the film, such as Zigang's ex-wife wearing jewellery by ${ }_{3} \mathrm{D}$ Gold at her wedding, making sure the logo is visible when she takes it out of the box. When Zigang and his daughter visit the shopping mall (a bonding experience), we see the storefronts 
of $3 \mathrm{D}$ Gold (a Chinese jewellery store), Five Plus clothing, and Costa Coffee. Exactly the same sequence in the original Hollywood film does not feature any overt branding at all—only those who were very informed would know which brands were on the shelves. Zigang and Yilong's romantic interludes almost always feature alcohol with labels prominently displayed, with red wine and champagne being two of the film's sponsors. Cars are also prominent, with Zigang's chase of Yilong to the airport featuring him driving his Renault. The Apple iPhone features in an interaction between Zigang and an unknown woman at a bar. His comparison of her highly embellished phone is used as an allegory for her appearance, and his reference to his phone as 'naked' might be as close as the film comes to sexual innuendo.

Both the director and the producer of the remake have been interviewed on record saying that these commercial aspects of the film reflect the significant changes which have occurred within China in relation to attitudes to consumption in the last twenty years. They both point to a "convergence" between American and Chinese lifestyles, and position the film as a form of "satirical", self-aware social commentary on this phenomenon (Makinen, 2011). However, the film doesn't show any obvious indications of being a satire. There is no humour associated with the use of particular products to speak of, nor are there any consequences for the lead characters for living such overtly consumerist lifestyles. It seems that rather than satirizing consumerism as an ideology, the film is actually just a vehicle for promoting consumerism.

According to Shuyu Kong, this consumerist approach may be related to developments in the 'Chinese New Year comedy' genre over the past decade (2007). Through her study of Feng Xiaogang's films, Kong shows how "the advertising business is now so close to film production and consumption, that advertising has become an integral part of the formal features and content of commercial films" in China. New Year comedies, like other genre films in China, have "evolved into brand name products following a Hollywood-style marketing strategy, carefully tailored to satisfy the entertainment needs of domestic and international audiences" (Kong, 2007, pg. 227). This evolution has only been able to occur since the strict state-controlled film industry has broken down in favour of a more market-based approach, in line with the overall economic and cultural opening up of China (Kong, 2007, pg. 240).

What Women Want, while technically of the same genre, is quite different from the first Lunar New Year films created by Feng Xiaogang, which were commercial films that simultaneously undercut their own commercial agenda by using comedy to highlight serious social and cultural issues such as infidelity, the poor/rich divide, the Chinese diaspora and criticism of rampant consumerism (Berry, 2009; R. Zhang, 2008). The list of sponsors involved in What Women Want is comprehensive and diverse in its range of products, and 
extremely interesting, with brands that combine to create a very particular vision of China. What Women Want could be described as 'aspirational' in terms of its social function, encouraging viewers to associate consumption of certain products with success and happiness, as well as legitimising certain products as being for the modern Chinese man, woman and family. As Chris Berry notes:

One form of realism in contemporary Chinese cinema manifests a new faith in modernity-however, instead of class-based revolution, it is driven by material acquisition ... The dominant genre for this mode of realism is the romantic comedy, set among 'ordinary people' who live a lifestyle considerably more affluent than that of real ordinary people, but not beyond their imagination. This could be called 'aspirational cinema'it encourages not only the dream of finding the perfect partner, but also the perfect car, the perfect dress, the perfect sofa, and so on.

BERRY, 2009, P. 117

Within the film's narrative, women are presented as the new powerful consumer, and the target of today's advertising. The film thus directs its own advertising towards female viewers by constructing a particular view of femininity which associates consumption with success. As mentioned earlier in this chapter, the inner thoughts of women, aside from Li Yilong, are almost totally concerned with issues of consumption and the judgment of others based on material possessions. On several occasions, female-oriented products are associated with happiness and positive new beginnings, such as $3 \mathrm{D}$ Gold Jewellery at the wedding at the beginning of the film, and the bonding shopping trip between Sun Zigang and his daughter. What the remake of What Women Want thus presents is the myth of modern China, a nation which is highly competitive, capitalist and consumerist, while still attempting to maintain its traditional family ideals. It is an aspirational film, encouraging Chinese viewers to continue to support 'Socialism with Chinese characteristics', an idea promoted by Deng Xiaoping, to build a stronger, united, successful Chinese nation-part of which currently involves generating domestic consumption to support a slowing Chinese economy. Overall, What Women Want strongly encourages consumption and consumerism, but moderates this with Chinese cultural and political traditions. While using and purchasing international brands, the characters are not also buying into a capitalist ideology. They are in fact, as Mao would say, "using the foreign to serve the Chinese" (洋为中用). Thus, in today's modern transnational, post-socialist China, the remake's lead protagonists, and even minor characters, are adept at using foreign products, technologies, and languages, but they themselves are nonetheless distinctly Chinese, particularly in their loyalty to the traditional family structure. In 
promoting this particular vision of China to a primarily domestic, Mandarinspeaking audience, the remake also connects with a broader "meta-narrative of the Chinese renaissance that is visible in the cultural industries that is not only leading China's global soft power offensive-shaping how the world sees China-but is also helping to shape how China sees itself"(Rawnsley \& Rawnsley, 2010, p. 6).

\section{Reflections}

The difficulties in translating the gender and family values embedded within the source film are no more apparent than in the remake's slightly forced ending. Zigang goes to Yilong's apartment to admit that he has been stealing her ideas, and at the same time, he extends an invitation to Yilong to attend his father Sun Meisheng's concert. Through this invitation, he and his father both demonstrate a remarkable lack of foresight regarding Yilong's likely reaction towards Zigang's confession. Yet, Yilong does eventually attend, and so the film seems compelled to reinforce the continued legitimacy of some of the more traditional aspects of the family. As a consequence, the film's contrived ending sees Zigang, Doudou and Yilong, who are all predominantly associated with modernity, tied together into a traditional Chinese multi-generational family structure. Filial piety, a very long standing cultural value, is affirmed as a crucial part of maintaining good familial relations. The patriarch appears as educator, as seen in the reconciliations and advice between Sun Meisheng and Zigang, and Zigang and his daughter. The inclusion of the patriarch Sun Meisheng is imperative for this to occur, and thus the Chinese-language remake restructures the original film to accommodate these traditional Chinese family values. Simultaneously, the family is mobilized as a commercial unit, with key characters and events connected with aspirational consumption. As discussed throughout the chapter, these families are made up of individuals whose gender roles and sexualities are altered across the two versions of the film. The analysis of the two versions of What Women Want in this chapter thus provides an example of how Chinese-language remakes approach perceived cultural difference and questions of social change through the (re)construction of gender and the family. The following chapter will complicate this picture through the discussion of how other factors such as genre and the auteur might be influential in reshaping a source film into its intercultural remake in the Chineselanguage cinematic context. 


\section{Gender, Genre and the Auteur}

The previous chapter's analysis showed how changes in gender representations within a remake's narrative can reflect the new audiences' different cultural, social and political values, in particular, in conceptualisations of gender and family. While the transformation of What Women Want into its Chineselanguage counterpart appeared a somewhat straightforward process of cultural translation (albeit as the analysis showed, there were more differences than initially appeared), the following chapter will examine a pair of intercultural films, Blood Simple (1984) and A Woman, A Gun and A Noodle Shop (2009), in which the source film undergoes a much more striking transformation. With the 1980 s Texas of the original film replaced by ancient China bursting with the vibrant colours of the Gansu desert, it is difficult to imagine how the two films might look more different. This chapter will investigate the factors which have contributed to the changes observable between the original film and its remake, framing this analysis through the transformations which have occurred in the depiction of genre-specific forms of masculinity and femininity between the two films, and contextualizing this within the frameworks of the films generic and directorial influences.

The focus on the connection between gender and genre stems from the overt shift in setting and style that occurs between Blood Simple and $A$ Woman, A Gun and a Noodle Shop, which brings to bear questions regarding the role of genre in shaping remakes. As Felicia Chan and Angelina Karpovich highlight, the development of genres is a complex web of interactions between the political, social, cinematic and historical contexts of film production and film spectatorship (F. Chan \& Karpovich, 2011). As discussed in Chapter One, genre is a topic which has not yet been fully addressed in Chinese-language remake studies. While the earlier chapter on What Women Want outlined how representations of gender and the family changed from the original American film to the Chinese-language remake, that pair of films did not have to account for the effects of a significant shift in genre between source film and remake. However, as genre is an important factor in defining a film's plot and characters, it is important to consider how a radical change of genre might in turn affect representations of gender within a film. In this chapter's pair of films, there is also the additional factor of the director's influence, with the Coen brothers considered to be auteurs with their own style. Likewise, Zhang Yimou, director of the remake, is one of China's most prominent directors, and in a scholarly 
environment where the study of the auteur has been identified as an area which requires re-thinking based on the particularities of Chinese-language cinema (S. H. Lim, 2007), this chapter makes an important contribution to the understanding of how a Chinese auteur might approach the remaking process.

In this chapter, discussion of each film will be divided into four parts, considering the auteur, genre, masculinity and femininity respectively. The original film's plot, directors and significant generic properties will be introduced, before an investigation of how the change in genre identified in $A$ Woman, $A$ Gun and $A$ Noodle Shop has impacted on the representations of gender within the film. With all of these variables potentially at work, can the changes between source film and remake be attributed to the kind of gender-based cultural difference seen in What Women Want? This chapter's analysis and discussion of Blood Simple and A Woman, A Gun and A Noodle Shop will consider how remakes might offer the opportunity to reflect upon the influence of other factors such as the auteur, gender and genre on shaping remakes across different audiences, in particular, focusing on the Chinese-language cinema audience.

\section{The Coen Brothers' Blood Simple}

The original American film Blood Simple tells the story of a woman, Abby, who is married to bar owner Julian Marty. She has an affair with Ray, a bartender at Julian Marty's establishment. The husband decides to hire a local private detective, Loren Visser, to have the lovers killed. Instead, Visser tampers with photos of Abby and Ray in bed to make it look as though he has carried out his task, takes payment and shoots the husband with Abby's gun, to ensure Julian Marty doesn't betray him and go to the police. While trying to break into Julian Marty's safe, Visser is interrupted by Ray, who finds Marty's body. Ray finds Abby's gun and assumes that she has killed her husband. He decides to help her by cleaning up the crime scene and disposing of the body. Unfortunately, Marty isn't actually dead, and so after driving him into the desert, Ray has to bury him alive. With Ray thinking Abby killed Marty and vice versa, the film is a story of infidelity, impulse, and miscommunication, where the clarity which finally comes at the end of the film comes too late.

\section{The Coen Brothers-American Auteurs}

In its approach to genre, Blood Simple draws heavily on American film noir, a group of films that have their roots in American crime literature, particularly the works of Dashiell Hammett and James M. Cain (Conard, 2006). The 
original film noir of the 1940s was born out of the post-war era, and the themes of these films often reflected the concerns of the time- "the Depression, war homelessness, the experience of veterans, the post-war gender backlash, the post-war expansion of corporate culture and the growth of consumerism" (Bould, 2013, p. 38). Later, the neo-noir movement ${ }^{1}$ emerged as change swept through America in the 1960s, and people became more mobile, society more multicultural, and the "locus of community" began to dissolve. "In place of the family, the community, the nation-state, or the church, a new king emerged in the form of the 'self'" (Abrams, 2007, p. 9). As Visser narrates, "what I know about, is Texas; and down here, you're on your own".

Across their careers, the Coen brothers have relied heavily on noir film as the basis for much of their oeuvre, focusing on the philosophical themes that have emerged in this genre, including "moral ambivalence, alienation, paranoia, crime, violence, disorientation and the inversion of traditional values", and adopting cinematic techniques including "oblique camera angles and an exaggerated emphasis on light and shade" (Conard, 2009, p. 1). However, the brothers also self-consciously draw attention to cinematic conventions by adopting and adapting them in strange ways, and their films go against the grain of well-known generic tropes, featuring characters such as the gangster with "heart", the virtuous lazy man, a variety of failed masculinities and the not-quite femme fatale. The nihilistic comedy that is a feature of film noir is taken to the extreme, such that the pointless attempts of the main characters to affect their own fate often leads to comic absurdity and unexpected, shocking violence (Hibbs, 2009).

Blood Simple also sets the precedent for another feature that would become synonymous with Coen brothers' films - that is, the use of quintessentially American locations. The Coen brothers have in fact set many of their films in recognisably American locations, whether they be Texas, New York or Los Angeles (Redmon, 2015). In the case of Blood Simple, the setting of the plains

1 "Neo-noir" is a loose generic term used to describe films made from the 1970s onward which follow in the footsteps of the classical Hollywood noir film style of the 1940s and 1950s. Neo-noir films can be identified through a shared set of themes and cinematic techniques similar to those of classical noir films, but in addition, the films consciously refer to these cinematic conventions. Neo-noir films also adapt the morality of classical noir films to suit contemporary audiences. Mark Conard's edited work The Philosophy of Neo-Noir (Conard, 2006) provides a comprehensive description of neo-noir film through the analysis of numerous contemporary films of this category such as Chinatown (1974), Blade Runner (1982), and LA Confidential (1997). 
of Texas also locates the film within a tradition of Western noir films dating back to the post-World War II era, when the conventions of the quintessential American Western genre began to mingle with noir themes.

Within American cinema, the Western genre "has long been regarded as the most endemically American genre, not only because of its literary and cinematic origins, but also because of its tendency to tell a deeply conservative utopian story about the civilising process" (Sharrett, 2012, p. 165). The Western is also a very masculine genre, which creates interesting character variants when these conservative generic tropes come into contact with noir elements. Blood Simple adopts the setting of the wide, open landscape of the Texan plains, and all the promise of the new frontier, but emphasizes instead the noir side of this environment - the violence, isolation, greed and abandonment of morality in the Wild, Wild West.

This interpretation of the Western also has significant implications for gender representation in the film. At the heart of many films noir is a battle between the sexes. The emergence and resurgence of the film noir genre has been closely linked to social adjustments in the balance of power between men and women, first in the 1940s, in the post-war period of male psychological trauma, and again in the 1970s with the emergence of the second wave of feminism in America, when anxiety about women's roles in society seemed to peak (Studlar, 2013). As a result, characters appeared on screen that reflected this social upheaval-men became more fallible and more easily manipulated by an increasingly powerful female presence. The representations of the dynamics between male and female characters are thus a crucial element of film noir, with many films focusing on topics such as infidelity, betrayal, and love triangles. Blood Simple adopts the approach of the early Western noir, where the key stereotypes of the "private detective", "the tough guy" and the "femme fatale" (Doom, 2009; Newman, 2011, p. 155) collided with the Western genre, to create a bleak vision of the deterioration of the traditional family and morality in America (Luhr, 2012).

The genre-mixing and self-aware style of the Coen brothers bring together these cultural influences which impacted the brothers' cinema- "we grew up in America, and we tell American stories in American settings within American frames of reference" (Joel Coen as quoted by Gilmore, 2009, p. 7), and a postmodern quality that exists in their films. "Films labelled postmodern ... frequently embrace strong undercurrents of mayhem, satire, irreverence, and irony, revealing at the same time a milieu in which social and personal relationships often enter into a process of breakdown and collapse. Although enormously diverse, postmodern films tend to borrow stylistically and thematically 
from earlier works and genres as part of the modality of pastiche ${ }^{20}$ (Boggs \& Pollard, 2003, p. 445). As Joel Coen states:

We did not deal with the real Texas, but an artificial version of it, an assemblage of texts and mythologies. The subject is 'murderous passion'. There have been so many cases of this sort that have occurred in Texas that it has become a part of the public imagination. But what resulted from that was important to us because the film was imagined as a slice of life, a deliberate fiction that it was normal to set within an exotic locale.

PALMER, 2004, P. 160

Postmodernism draws attention to the fact that what the viewer is seeing is a fictional construction, like the Texas which exists only in cultural and cinematic myth. To emphasise the fictionality of the environment, Blood Simple uses highly symbolic and at times, ironic, motifs. Ceiling fans, curtains, venetian blinds, and snap-brim hats function like inside jokes for cinema-literate viewers who know that these images have been used in Western and noir films of the past (Newman, 2011, p. 143).

Understanding the filmic language of the Coen brothers thus requires a significant amount of background knowledge on cinematic culture, as well as American cultural stereotypes, in order to understand the allusions and adaptations they make to American myths and settings. In Blood Simple, we can see the unravelling of these stereotypes in the lead characters, and in the comedy which manifests itself in verbal wordplay and physical forms (such as the unexpected shooting of one of the main characters, only for him to survive and later be buried alive) (Hibbs, 2009, p. 137). The Coen brothers thus create "unpredictable" films that question stereotypes within film noir as well as investigate greater issues such as self-identity, the pursuit of the "American dream", history, and humanity in modern society (Conard, 2009), and their penchant for genre mixing, or "generic incongruity" (McFarland, 2009, p. 42), makes their work difficult to classify in strict generic terms. In addition to this reinvigoration the Coen brothers provide for the study of genre, "those intent on

2 "Pastiche" is a term used to describe a particular form of filmmaking, which is "critical in the sense of exercising judgement, selecting and emphasising, and of having an analytical perspective" (Newman, 2011, p. 154). As Michael Newan elaborates, "the Coen brothers' pastiches do a critical job of selecting, collecting, foregrounding, curating, preserving, archiving, interpreting and re-imagining the media that have been significant in their lives and in the lives of the community that shares their specific cultural literacy" (Newman, 2011, p. 154). 
understanding American culture through film do well to turn to the Coens. The duo's films trek through, seize and witness nearly every aspect of twentieth century America, from the 1920 s through to the present day" (Redmon, 2015, p. x).

\section{Genre and Gender in Blood Simple}

In engaging with genre, the Coen brothers have also "repeatedly and explicitly raised questions of gender" (Redmon, 2015, p. 113), both in Blood Simple and more broadly within their oeuvre. Their films demonstrate how gender is a constructed concept through their manipulation of cinematic tropes of masculinity and femininity (Redmon, 2015). The following section of this chapter will explore how these tropes are articulated in Blood Simple, and how they are subsequently transformed for the eyes of the Chinese-language remake audience.

\section{The Failures of Masculinity}

Whether a tough guy or mild-mannered everyman, self-loathing loser or psychologically unstable loner, the male protagonist of noir, even if ostensibly innocent of a crime he is accused of committing, usually ends up being guilty of something, most of all, of failing to live up to masculine ideals.

STUDLAR, 2013, P. 369

Consistent with themes of deterioration and bleak pessimism, at the heart of many noir films lies the concept of failed masculinities. Masculinity in the traditional Western genre is predicated on the trope of the "strong, silent" male who "talks with his fists and guns rather than his words"-either in the hero figure who "is emotionally healthy because his emotions are in check and his sexual needs are directed towards either labor or the family", or the "anti-social villain — a psychopath but not an anguished soul" (Sharrett, 2012, p. 166). While outwardly projecting strength and virility, the depiction of the Western man is underpinned by the "acceptance and even idealisation of the repression of the male", and the male hero uses this stony-faced façade to "create armour from his very musculature, channelling emotional repression to a point that the body is refashioned as an instrument in service of state power and bourgeois sexual mores such as marriage and family" (Sharrett, 2012, p. 167).

Specific to Western noir, of which Blood Simple is representative, is the breakdown of these traditional Western tropes of masculinity. While Ray and 
Julian Marty are surrounded by symbols of traditional Western man, neither of them has the physical or moral strength characteristic of this figure. Instead, they are beholden to the "laws of noir violence, allowing passion and greed to overtake them" (Doom, 2009, p. 2). There are in fact, no heroes in Blood Simple, and "in film noir, not only are individual men revealed as sick, but also male-dominated institutions are frequently subjected to challenging critiques" (Studlar, 2013, p. 369). As is often the case in the noir world, each man is motivated by his own self-interest, or at least, self-preservation, and the great masculine institution of the state is totally absent in this place where there are no police and no noble causes to advance. "Films noir therefore offered a field of resistance to Hollywood conventions by inscribing masculinity as a problem to be diagnosed and solved rather than admired and emulated" (Studlar, 2013, p. 370).

When we are introduced to Ray, he is wearing a checked shirt, work boots and jeans. Tall and fit with a masculine hairy chest, out of all the men in Blood Simple, he most closely resembles the hero we are accustomed to seeing in Western films. Ray is driving Abby to Houston to escape her husband, and is trying to avoid discussing Abby's marital problems with her on the way. $\mathrm{He}$ says with a thick Texan accent, "I ain't a marriage counselor". He is a man of few words, initially seeming to be the man who talks less and acts more-a man who is unable to express his emotions verbally, but nonetheless conducts himself with a quiet sense of morality (Doom, 2009).

However, we quickly find that this isn't the case. Ray is really the one who starts the affair when he tells Abby that he likes her, a point he reiterates when she asks why he is helping her. He asks a series of open-ended questions, "what's the matter?", "what do you want to do?", and gives a half-hearted rejection, "Abby, I like you, but there's no point starting anything now". This encourages Abby, and instead of leaving, she and Ray go to a hotel where they start an affair. When Ray is presented with an opportunity to sleep with another man's wife, he takes it, and from the beginning of the film he is already morally compromised. Ray later buries Abby's husband alive, too afraid of the consequences of allowing him to live.

The image of the Western tough guy further deteriorates when we are introduced to Julian Marty. The first shot we see is of his cowboy boots, the second, a pair of male hands with a horseshoe-shaped ring. At the same time, we hear a few bars of a country ballad song. When we meet him for the first time, he has just been given photo evidence of his wife's affair. He is upset that he has been proven right, but he is also disgusted that the private detective Visser took photos of his wife, in what could be a "cinematic first, where a client doesn't want or expect photographic proof of the affair" (Doom, 2009, p. 6). The sexual obsession Julian Marty and Visser each have with Abby are the first indicators 
that they are losing their grip on reality and descending into psychological instability (Studlar, 2013).

But as his face is revealed, we see that Julian Marty is clearly not a "local". His physical similarity to an Italian immigrant or second-generation ItalianAmerican, emphasized by his clearly foreign accent, appears to also connect him with stereotypes of the Italian-American male in Hollywood gangster films (Cavallero, 2004). As the film progresses, we come to know Julian Marty as suspicious, jealous and possessive like the stereotypical Latin man. Julian Marty acts as though his greatest failure is his inability to control his wife. But he does not have the cool composure normally associated with a Mafia Don, instead, he plays to the most emotional and volatile Italian male stereotype. While it is true that he orders a hit on his wife and her lover, Julian Marty conducts this business in an old car, unable to clearly articulate what "the job" is, while sweating profusely and barely holding his nerve. This scene, when contrasted with the images associated with a figure such as the Godfather, who sits in his plush office surrounded by his followers, only emphasizes Julian Marty's lack of leadership ability, power, and charisma. Julian Marty only manages to engage the services of Visser because he pays (Doom, 2009), such is the lack of respect everyone has for him. His employees and his wife see no reason to be loyal to him. Not only is he not the respected leader, he is not even capable of the violence required to be one of a Mafia boss' employees; the muscle who perform the dirty work. The ring he wears on his little finger, which often symbolizes membership of a mafia organization is bereft of meaning-Julian Marty has no family, no friends, and no followers, and his posturing and bravado indicates he is acutely aware of his failure to live up to these ideas of masculinity.

The private detective Visser, the third male protagonist, is a testament to the moral deterioration of the detective figure from noir to neo-noir films. His role is still essentially what it was in the classical noir, "to attune audiences to complex psychological issues and to an impression of life as it is lived, and to certain atrocities that actually exist and that no good purpose is served in hiding" (Frank, 1995, p. 133). In Blood Simple, he achieves this by both lacking a moral compass himself (Doom, 2009) and by providing the opportunity for Julian Marty and Ray to demonstrate their flawed interpretations of masculinity and its associated morality. The difference between Visser and the traditional detective is that he isn't even pursuing a criminal, nor is he an "antihero".

Returning to the scene of Julian Marty's meeting with Visser in the car, we first see Julian Marty approaching Visser's vw, and again his right hand with his pinky ring, but now, his broken forefinger has a cast on it-the result of his botched attempt to abduct Abby in the previous scene. To reach Visser, 
Julian Marty must put his failure on display in front of a crowd of locals, who have obviously heard what happened, and expose himself to their derision, as they ask him what happened to his "pussy finger". Visser is chatting up a young girl at his car, something that Julian Marty failed to do at his bar earlier after finding out his wife is cheating on him. The private detective again draws attention to his finger, laughing and asking if he "stuck his finger up the wrong person's ass", and telling an anecdote about a friend who broke both his hands. Julian Marty's shame is highlighted by Visser's behavior, and he is stony-faced throughout the whole interaction. "I got a job for you", he finally says. "Well, if the pay's right and it's legal, I'll do it", Visser responds. "It's not strictly legal". "Well, if the pay's right, I'll do it". Julian Marty looks distraught as he asks Visser to commit murder, but his pride has over-ruled his morality, and it seems he feels to prove his masculinity he needs to punish Abby and Ray for their disloyalty.

While Doom argues that Visser has lost his moral compass, in many instances, this only serves to draw attention to the immorality of the characters around him. He is, at the very least, aware of what constitutes right and wrong, unlike those around him, who seem to have "gone simple" and merely react to events rather than control or manage them (Doom, 2009). In the car with Julian Marty, he calls him an idiot for proposing murder as a means of dealing with his cheating wife and her lover. While agreeing to do it, Visser later changes his mind, protecting the couple by doctoring photos of their dead bodies. Later in the bar, he looks disgusted as Julian Marty pushes over the money. Visser killing Marty is not just to get to the safe and rob him, but is also to mete out punishment for his weakness, his moral failure. In doing this, Visser stands opposed to Julian Marty's version of masculinity, which is underpinned by pride, possession, and control, and for a brief moment, Visser seems almost morally superior in his actions. However this quickly comes undone as he subsequently murders Ray to protect himself from being implicated in the killing of Julian Marty, and he also attempts to kill Abby.

\section{Approaching the Femme Fatale}

So far, Blood Simple has read as a very masculine-oriented film, in its heavy focus on the notion of failed masculinities. However, Abby is also a significant character, particularly in her association with the figure of the femme fatale - as "the woman to die for" - the desire to possess or protect her is what drives both Ray and Julian Marty to their deaths (Doom, 2009). The traditional femme fatale role was often that of the instigator of a plot to murder her husband, or more broadly, a woman whose pursuit leaves a man broken, or worse. She posed a threat to the established patriarchy through her wanton disregard 
for established norms of female behaviour (Tasker, 2013). She also was often childless, making her a threat to social stability, as she rejected the role of mother and loyal wife that was so crucial for maintaining the family as the most sacrosanct social unit. Therefore, in classical film noir, the femme fatale was often punished for this deviance, either by being killed, badly injured or going insane (Tasker, 2013). As is characteristic of many Coen brothers films, while drawing inspiration from this femme fatale character, Abby's character has been adapted quite significantly from this role. Instead of being aggressive and manipulative, naïveté, sexuality and vulnerability are Abby's defining qualities (Doom, 2009, p. 7). She also “doesn't actually suggest Ray should do anything, instead hinting at her own desire to take action ... to remove her husband from the picture" (Doom, 2009, p. 7). The gun which she carries in her purse has an interesting dual symbolism, being both a gift from Julian Marty and a weapon which she might use against him. But unlike Julian Marty, when it comes time to decide what to do, she chooses not to use violence, and to leave him instead.

Julian Marty implies that he has been the subject of numerous similar humiliations, and that her innocence is an act, but it is impossible for us to know for sure whether this is the truth or a product of Marty's paranoia. It is not difficult to imagine how Marty's behaviour might drive Abby into the arms of another man. Marty's failed attempt to rape Abby after dragging her out of Ray's home rubs salt into his wound while simultaneously highlighting exactly why Abby would want to leave him. It also isn't surprising that under these violent conditions, Abby remains opposed to the idea of having childrenthough, this also may connect with her desire to continue conducting affairs and not be house-bound by the duties associated with caring for a child.

Perhaps it is the fact that she is not necessarily a heartless manipulator that spares Abby the fate usually assigned to the femme fatale. While she must witness the death of her lover Ray, and commit murder herself, her crimes against morality are not in the same vein as those of the men. She kills to defend herself, which is justifiable, and otherwise, her greatest sin is infidelity. As such, while she is punished, in the sense that she loses her lover and is traumatised by her experiences, she escapes with her life. Moreover, Abby is not a stereotypical victim character, she "accepts her situation and acts" rather than "crawling, screaming and wailing to her freedom" (Doom, 2009, p. 8). She manages to show her defiance by shouting "I'm not afraid of you Marty!" after she shoots the man she thinks is her husband through the bathroom door. The fact that it is not Julian Marty but Visser is only a minor detail which does little to undercut the gravitas of this show of strength. 
Reading femininity and gender more broadly in Blood Simple is a complex task. From one perspective, Abby could be read as the first in a long line of unconventional female characters portrayed by the Coen brothers-women who offer an alternative to the deteriorating system of masculine institutions. However, as Redmon highlights, Abby is also a vehicle through which the story of masculine crisis is portrayed (Redmon, 2015), and so her representation is still defined very much by the masculine world that she inhabits. She still is passed between men, reminiscent of the woman as object of exchange who is traded from one man to another as a means of establishing and reinforcing patriarchal systems. Abby subverts both the femme fatale role and the role of woman solely as victim, but only because she is partly responsible for what has occurred-it is her "weakness and dissatisfaction that are responsible for setting the story into motion" (Barton Palmer, 2004, pp. 16-17). While she doesn't kill, she is nevertheless, surrounded by death.

The lack of clarity regarding Abby's past makes her enigmatic and unpredictable, and it is often unclear whether she is genuinely naïve or being deceptive. This ambiguity in gender representations also connects with the manipulation of genres performed by the directors, as they empty the Western and noir films of their "generic conventions and their strict adherence to masculine codes ... and the male subject must confront his altered social position as one who is no longer the sole possessor of power, exposing his impotence by adhering to an outdated and outmoded social system" (Johns, 2009, p. 141). The representation of Abby's character combined with the negative meditations on masculinity in Blood Simple give the film a feminist twist, which provides an interesting point for discussion of how this issue might be treated in the film's remake.

\section{Blood Simple Remade-A Woman, A Gun and a Noodle Shop}

Blood Simple heavily reliance on detective noir films and Westerns, which largely dictate the style, settings, dialogue, costumes and plot of the film, along with the postmodern approach of the Coen brothers, involving mixed genres and violated stereotypes, makes a remake of this film an intriguing prospect. If this now cult classic film was re-created in another time and place, what would it look like? Thankfully, China's most famous director Zhang Yimou has provided an answer. Given the Coen brothers' status as auteurs, the connections they create between their films and American culture, and their strong reliance upon American genres and the cinematic canon, how has Zhang's remake re-imagined this kind of story? 


\section{Zhang Yimou-China's Most Acclaimed Director}

Zhang Yimou, China's most internationally and domestically acclaimed director is, like the Coen brothers, considered to be an auteur in his own right. To date, he is one of a very select group of Chinese directors who have seen their films released in mainstream cinemas in the Us, Australia and other nonChinese speaking regions (X. Zhang, 2008). As part of the Fifth Generation of Chinese film-makers, which included also the director Tian Zhuangzhuang, (who will be discussed in more detail in Chapter Five), Zhang began his career as a cinematographer before moving into a directorial role. His initial films, like those of his Fifth Generation compatriots, were read as part of a wider social movement which was concerned with "historical/cultural reflection and a search for the roots of Chinese culture" (Lu, 1997, p. 108).

As his career developed, Zhang's films became larger in reach and scale, and he transitioned from "alternative cinema" into the mainstream cinema industry. The criticisms which he drew for his early films, for appearing to endorse the rule of the Communist Party, became more pronounced as Zhang's films "went global". While being praised for developing his own visual language and for putting Chinese cinema on the global stage, he drew particular criticism for his later commercial films, especially Hero (2002), for demonstrating a form of "fascist aesthetics that supports totalitarianism in general and the Chinese authoritarian state" (Larson, 2008, pg. 181). Reading Zhang's films has thus always been a highly politicised process of negotiating between his seemingly humanist and personal approach that exposes the flaws of the Communist Party rule, and the simultaneous romanticisation of rural Chinese life, which appears to support the leadership and its agenda (X. Zhang, 2008).

At the same time, Zhang's particular style has also been criticized as a form of self-Orientalisation, whereby Chinese culture is misrepresented for the benefit of Western audiences and the associated commercial gain (Dai, 2002). His later films emphasise visually appealing stunt work, vibrant colours, and spectacle, in contrast with his early inclinations towards stories which represented women who were oppressed by strange feudal traditions (Chow, 1995). As such, there is an ongoing academic debate as to whether Zhang deliberately distorts 'Chineseness' for the visual pleasure of non-Chinese audiences. These criticisms have only gained momentum the further Zhang progresses in his career, with his latest release The Great Wall (2017) drawing raised eyebrows from leading Chinese film scholars such as Ying Zhu and Stanley Rosen, with Zhu describing the latest Zhang creation as "simply a dazzlingly bad film", and a consequence of the "eagerness to feed China's bloating ego and market, where Hollywood and its Chinese partners have concocted a colorfully synchronized mess devoid of genuine human touch and investment in real 
feelings and imagination" ("Can China expand its beachhead Hollywood", A China File Conversation, 2017). While Zhang has produced many film adaptations from novels, which give his works a strong literary connection, $A$ Woman, A Gun and A Noodle Shop is his first acknowledged film remake. Given his significant role in contemporary Chinese cinema, it is therefore a fascinating case study to analyse how Zhang has approached the work of his American counterparts, and how his directorial style might have influenced the Chineselanguage remake.

Zhang's film transports the viewer to ancient China, in Gansu Province, somewhere along the Silk Road. It is here that we find a noodle shop, owned by Wang Mazi (王麻子 also called 老板 or “Boss”) and his wife “Laobanniang” (老板娘, meaning proprietress) whose name we never actually learn. Also living and working there are Li Si (李四), Zhao Liu (赵六) and Chen Qi (陈七). After being told that his wife has been "going around" with Li Si by Zhang San (张三), a local police officer, Mazi hires Zhang San to kill the adulterers. Zhang San instead fakes their deaths and after receiving his payment, shoots Mazi with the wife's gun. He is interrupted while trying to break into the safe, and has to leave the body behind. Li Si finds Mazi dead with the gun, and assumes that his lover has killed her husband. He endeavours to protect her by covering up the crime, and takes the body into the desert to bury. He has a close encounter with the police, and is horrified to find Mazi still alive when he starts to bury him. Zhang San returns to the crime scene to find Mazi's body gone, and realises that someone else is also trying to break into the safe. He then resolves to kill off those in the compound who are a threat to him, which results in the deaths of Zhao Liu and Li Si. Chen Qi manages to flee before she can be murdered. Laobanniang survives by shooting through the wall at her unknown attacker, killing him.

The remake thus very broadly follows the original film in terms of its major plot points, and the themes of infidelity and miscommunication are present in both original and remake. More specifically in the Chinese case, the name of the film as well as those of the characters, also reinforce these themes. Zhang San, Li Si, Wang Mazi, Chen Qi and Laobanniang, are the Chinese-language equivalent of the English 'Tom, Dick and Harry' - the non-descript everyman and every-woman, subject to all those weaknesses which we characterise as part of being human. The film's title, 三枪拍案惊奇, literally translates as 'Three surprise shots', referring to the three bullets fired by the film's gun-one shot for each of the lead male characters, whose sins of greed, jealousy and infidelity do not go unpunished. However, what is also apparent is that Zhang's remake has undergone significant changes in visual style and narrative indicative of a shift in genre between source film and remake, and it is these aspects of the remake that are in focus in this chapter. 
Zhang himself has gestured towards these alterations, commenting in a press release on the key elements which influenced him in this production:

I love all the works by the Coen Brothers. Some twenty years ago at a film festival, I saw their directorial debut Blood Simple, which left me with a great impression. The film keeps coming back to my mind, although I haven't seen it for a second time.

One day, a curious idea struck me: what would it be like if Blood Simple was made as a Chinese story? That was how A Woman, A Gun and A Noodle Shop began to take shape. I gave the remake a rich Chinese flavor, casting Xiao Shenyang - a young comic actor who recently shot to fame in China - to add in a sense of farcical humor at the beginning. The fun soon turns into riveting suspense. I also adopted the aesthetic style of the old Chinese opera piece, San Cha Kou. The result is the confinement of all the characters within the same space, each of them shifting roles with one another and making similar mistakes. This lays bare the absurdity of life-something ironically repetitive, always beyond our control

“A WOMAN, A GUN AND A NOODLE SHOP PRESS KIT," N.D.

As he makes clear in the above statement, Zhang Yimou's directorial style draws on different cinematic and cultural traditions from the Coen brothers. He has his own particular formula for making films, which is well-documented in the literature on Chinese cinema. Zhang's references to a particular style of comedy exemplified by Xiao Shenyang, the Chinese sketch or skit comedy, and his mention of Chinese opera, are all significant factors to consider in how the remake was created. The following section will therefore discuss the changes in visual style and narrative that are apparent in Zhang's remake, through the lens of gender representations, in order to understand the role of genre and the auteur in shaping the Chinese-language remake.

\section{Making Audiences Laugh: Humour in China}

The most striking thing about comedy is the immense variety and range of its forms ... from the variety show to the short, from the sketch to the narrative feature, from cartoons to sitcoms and from double-acts to standup comedy, the range of forms it can encompass is probably greater than that of any other genre.

NEALE \& KRUTNIK, 1990, P. 10

While broad categories of humour such as the situational comedy, or the cartoon, may appear in many cultures, comedy has also been described as a 
cultural product, with different peoples and regions exhibiting particularities with respect to the development of humour in their society (Neale \& Krutnik, 1990). The first of the two most overt shifts that occur between Blood Simple and its remake is the second film's much stronger comedic overtones. While the Coen brothers' humour has elements of the neo-noir interpretation of nihilistic humour, A Woman, A Gun and A Noodle Shop has undergone a generic shift towards a different form of comedy in the process of being remade.

Zhang's remake initially seems to employ a somewhat universal form of cinematic physical humour which would not be out of place in a Charlie Chaplin or even a Jim Carrey film. However, Zhang's humour is also culturally specific, particularly in its verbal wordplay. Jokes have been re-written to be tailored to audiences who have been exposed to different genres of Chinese performance, such as xiangsheng, or "cross-talk", as well as their modern re-incarnations. The film thus strongly connects with long-standing comedic forms in China as well as their contemporary expressions, such as television sketch/skits like the New Year Gala variety show. The reception of the remake therefore depends on the level of understanding viewers have of these cultural practices.

From the beginning, we can observe that Zhang has shifted the balance of casting from primarily dramatic-oriented actors and actresses in the original film, such as Dan Hedaya (Julian Marty), Francis McDormand (Abby), and M. Emmet Walsh (Visser), to a cast dominated by comedy performers. Xiao Shenyang (小沈阳), Zhao Benshan (赵本山) (the police chief) and Mao Mao (猫猫) are all from the same school of comedy, and are well known in China for their participation in New Year's Gala comedic skits. Yan Ni (间妮) (Laobanniang) has previously starred in a New Year's release comedy film, as well as being known for her role in the television comedy My Own Swordsman (武林外传). Julien Gaudfroy, who plays the Persian trader, is a French-born television host and xiangsheng performer in China.

For the remake, Zhang has collaborated with Shang Jing, in the role of Assistant Director-Shang is none other than the Director of My Own Swordsman (武林外传). Upon closer investigation, there are actually quite strong similarities between A Woman, A Gun and A Noodle Shop and My Own Swordsman, particularly in their narrative structure and expressions of humour. In the television serial, Ni Yan plays the owner of an inn, and she is joined by her workers-a young girl, a skittish young male waiter, a wushu warrior, and an overweight cook. The plot centres around the inn, which is set to be demolished as part of a land ownership conspiracy. A wealthy man sends two assassins to eliminate the innkeeper and her workers, who oppose his take-over. A Woman, A Gun and a Noodle Shop is structured like a long episode of this serial, with several skits or sketches stitched together. The narrative is interrupted three times with the headings "Day One", "Day Two" and "Day Three", 
adding to the impression that the film is a series of sketch performances or acts in the theatre, rather than a continuous work.

Both the TV series and A Woman, A Gun and A Noodle Shop have similar devices such as puns/idioms, first person camera angles, and "tu hua" (土话) or dialectal Chinese, substituting Standard Mandarin with forms of vernacular language such as 咱 (za), 啥 (sha), and 哎呀妈呀 (aya maya). Many of the expressions of humour also have their origin in the older forms of Chinese jokes such as those presented by xiangsheng or opera performers. In the process of remaking the Coen brothers film, Zhang has shifted the form of humour in his remake to better match the cultural background of a Chinese audience. There are a number of examples of such changes within the remake. One such instance can be found when Li Si and Laobanniang are discussing the punishment they might receive if found guilty of adultery, where there is a joke which hinges on the misinterpretation of a Chinese character:

李四: 你们看见那几个犯人啊, 多年轻, 多水灵, 可能以前没有遭过 啥罪, 这回可惨了, 听说男的得受宫刑, 女的得骑木驴。

老板娘: 为啥骑母驴呀? 以后要是有个公的就不让接触了?

李四: 木驴, 不是母驴, 木头做的驴, 骑那玩意, 颠哒死。太惨 了, 怎么有这么恐怖的刑法嗯? 咱不能学他们, 咱得好好活着。

While the male punishment for adultery is straightforward, castration, Laobanniang becomes confused when she interprets the punishment for adulterous women as being "骑母驴”, "riding a female donkey". She asks why women would be made to ride only a female donkey — is it because in the future they won't be allowed near anything male again, not even a male donkey? Li Si corrects her, “木驴, 不是母驴”, “a wooden donkey, not a female donkey”. He is referring to an ancient brutal form of punishment where women were made to sit on a spiked saddle. In this conversation, there is both a play on words and a historical reference, both of which need to be identified in order to understand the humour in the conversation.

Later in the film there is an energetic dialogue between Chen Qi and Zhao Liu which references another form of humour popular in China, xiangsheng. Xiangsheng is a form of comic debate which has been dated as far back as the Ming Dynasty, which draws upon the traditions of the stage with the specific aim of making audiences laugh. Xiangsheng usually involves two people, but can also be in the form of a monologue. We are exposed to both forms in A Woman, A Gun and A Noodle Shop, firstly with an energetic debate between Chen Qi and Zhao Liu regarding the morality of stealing. The dialogue 
resembles a serious debate, in the sense that each speaker is trying to argue their interpretation of a point of morality, but it is made humorous through the fast and energetic delivery of lines. There is a definite structure, with each person first addressing the other with the statement “陈七/趙六: 请注意”, “Chen Qi/Zhao Liu, please take note:" before making their point or arguing the weakness of their opponent's statement. Each person then closes their turn with “回答完毕”, “my answer is complete”. However, Chen Qi then breaches the barrier between film world and real world, otherwise called "breaking the fourth wall”, by stating “我不回答; 此外可以插播广告...", “I won't respond, here are some commercials".

The film also features a monologue where Li Si plays both roles in a discussion with Laobanniang. He is talking to himself about the three stages of a relationship, but is interrupted at various points by Laobanniang commenting crudely that she needs to pass wind. He then makes reference to a Chinese colloquialism to make a point about her infidelity:

李四: 你是有家的人, 这就跟一个夢卜盯一个坑是一样的, 你想把我 这棵夢卜栽进去, 就得把原先那个萝卜起出来, 你想没想过, 把你家 那棵老萝卜起出来以后, 扔哪儿? 再者说, 我也不适合当填坑萝卜, 我这夢卜，没长成呢?

老板娘：你还没长成呢？你都快糠了, 还没成呢?

“一个夢卜盯一个坑” translates approximately as “a turnip for every hole”, metaphorically meaning that every person has a corresponding perfect partner. The phrase also has a sexual implication in how the turnip and the hole are analogous to the male and female genitalia. Li Si argues that as a married woman, Laobanniang already has her "turnip", and that if she wants to plant another turnip instead, then she first has to dig up the old one. But she might not have considered that after she digs up the old one, then where will she put it? And will a different turnip be able to grow in the same hole? He then follows by saying he can't replace the old turnip because he is still young and not yet fully ripe; to which Laobanniang retorts, "You aren't ripe yet? You're almost a dried turnip, but you think you aren't ripe yet"? This monologue wouldn't be fully understood or humorous without an awareness of the meaning of the original colloquialism.

The situations analysed above speak to the cultural specificity of the humour found in Zhang's film. A Woman, A Gun and A Noodle Shop references the Chinese tradition of xiangsheng and combines this with the more contemporary form of television serial humour, particularly the program My Own 
Swordsman. The stars of Zhang's movie are also regular guests on the New Year's Gala program broadcast every year during the Lunar New Year celebrations, and their brand of humour is therefore familiar to a very wide audience, making their casting financially profitable while giving the film the best possible chance of entertaining viewers. There is no overlap between the verbal jokes made in the original film and those in the remake, because both films have their own set of social, cultural and performative models which inform their expressions of humour.

This is not to argue that humour within China is a homogeneous entity that is shared and understood by all across the different regions of China. As mentioned in the opening line of this section on humour, humour is, by its very nature, varied across these very lines of geography and linguistics. The kind of humour mobilized by Zhang may be more familiar and humorous for certain groups within the broader audience that is it targeted towards. However, what is evident is that there is a perception that underpins that remake that the kind of humour depicted is intelligible by those viewing the film -in this instance, the domestic Chinese cinematic audience. That is, the audience shares a form of cultural capital which allows them to decode the symbols and utterings within the film's narrative structures and images. The film would not have seen a New Year's release date if this was not the case. It is this cultural capital, or lack thereof in the case of the film's international audiences, that Zhang draws upon to refashion the remake into his desired form.

\section{Symbols of Beijing/Peking Opera}

The significance of the audiences' cultural capital in reading Zhang's remake becomes further apparent when the second generic shift in Zhang's film is considered. This second shift relates to Zhang Yimou's deployment of the traditional performance mode of Peking/Beijing Opera. In the press statement released earlier, Zhang names a specific opera as his inspiration: San Cha Kou (三岔口). By giving this information to viewers, Zhang directs his audience towards a preferred reading of his film involving this particular operatic work. In comparing San Cha Kou to A Woman, A Gun and A Noodle Shop, it is fascinating to see how Zhang has incorporated elements of this opera piece into his remake.

Like the notion of 'Chinese humour', 'Peking Opera' does not, in fact, come in a one-size-fits-all form; rather, it has evolved and adapted over much of its existence, having emerged at a time of "colonial modernity" and subsequently been used as a political apparatus on many occasions (Goldstein, 2007, p. 2), where its form and messages have been brought into alignment with the prevailing political ideologies, such as in the yangbanxi works that were heavily influenced by Mao Zedong's wife, Jiang Qing during the Cultural Revolution 
(Roberts, 2010). Those who are not familiar with this art form in great detail, including audiences whose only exposure to Peking Opera is through films that refer to it, would not be aware that it has such a diverse and intricate past. However, despite this clearly heterogeneous history, Goldstein argues that Peking Opera throughout the 2oth century has been subject to a "powerful impetus to construe it as wholly traditional and purely Chinese ... amid the multiple crises of foreign imperialism, regional fragmentation, economic upheaval, and political and cultural revolts" that China has faced (Goldstein, 2007, p. 3). That Zhang Yimou has chosen to reorient his film remake towards a form of art which is under such pressure to be considered as a representation of Chinese culture on a national and international stage is not a coincidence. It is therefore in the following section that Zhang's depiction of Peking Opera will be analysed in more detail, with a view to understanding how he has mobilized this 'Chinese' mode of performance for his film's audience.

Perhaps the most overt aesthetics in the film are present in the costumes, which are a key tool that Zhang uses in many of his films to reference Beijing Opera. In A Woman, A Gun and A Noodle Shop, the colours of the costumes in the film are vibrant, with bright greens, pinks, reds and blue all dominant hues. In San Cha Kou and other opera works, the colours of the costumes are quite important in establishing which role (sheng, dan, chou or jing) is being performed by which actor (Bonds, 2008). Sheng roles are leading men, who are further broken down into sub-categorisations such as laosheng (elder statemen), xiaosheng (young scholar), and wusheng (martial artsmen) (Bonds, 2008. p. 245). Dan roles are the female leads. Depending on status and age, this character can be a young unmarried woman (qingyi), a married older woman (laodan), or a "lively young female companion to the qingyi", referred to as a huadan (Bonds, 2008, p. 247). Chou characters are the comedic roles, and they span a wide range of ages, physical abilities and types of humour. Finally, the jing have painted faces, and are "male characters with rough, bold and uninhibited characteristics" (Xu, 2012, p. 54).

Within this complex system, costumes are also indicative of gender and hierarchy, with these clearly marked by different characteristics. ${ }^{3}$ Make-up is also a crucial part of an opera costume-painted faces usually also indicate who is who. However, this isn't the case in A Woman, A Gun and a Noodle Shop. Zhang is liberal in his interpretation of opera costumes, abandoning the rigid symbolic use of colour seen in traditional opera in favour of a more chaotic approach. Chow identifies these cinematographic markers in Zhang's trilogy of

3 The gendered aspect of costumes will be discussed in more detail in the later section 'Gender and A Woman, A Gun and A Noodle Shop'. 
films, Judou, Red Sorghum, and Raise the Red Lantern, outlining how Zhang uses the vibrant colours of his costumes to contrast against the "morbid oppression" and "backwardness" which is also on visual display in his films (Chow, 1995, p. 145). While it is clear that Zhang was inspired by operatic traditions, there is also no attempt to replicate the heavily painted faces seen on the stage. Only in one moment does the remake allude to this aspect of operatic style, in a shot of Laobanniang applying make-up with an eyebrow pencil while she watches Li Si. Nevertheless, these costumes draw their inspiration from their operatic predecessors and some aspects of the costumes are not easily read without knowledge of Peking Opera conventions_-nor, without knowledge of Zhang's oeuvre.

In reference to Zhang's second point on the use of confined space and how the body is used, gestures and use of space are very important aspects of opera storytelling. If we refer to Yang Donghu's version of San Cha Kou (杨东虎, 2011) broadcast on CCTV 11, the official government platform for traditional Chinese operatic works (Goldstein, 2007, p. I), Zhang refers to one specific scene where the sheng and chou characters misidentify each other at an inn, and a fight ensues in a dark room. Zhang's remake interprets the confined space of the inn instead as a courtyard, surrounded by a desert, leaving his characters both physically isolated and psychologically trapped by the constant presence of others. However, if we look in more detail at the actual style of movement used by Zhang's characters within this space, there are departures from the conventions of opera. In the film, the characters all move in a familiar, contemporary way. Their gestures are expansive and imprecise; people stumble, fall, wave their arms frantically, creep loudly, and struggle through small windows and spaces without grace. There is really only a moment in the film, the Persian trader's early performance with a sword, where the use of movement in opera and the film seem to meet. Otherwise, the Chinese remake exaggerates its comedic physicality, demonstrating a style which is quite different from opera, which requires precise, structured movements, and often spectacular feats of acrobatics and skill (Bonds, 2008).

It appears that Zhang has transformed the remake from its noir and Western origins to generic categories which are more familiar to his audience, while at the same time continuing, as he has done throughout the course of his career, to adapt and adopt these genres to suit his auteurist inclinations. The gestures he makes towards both the visual style and use of space of Peking Opera are but shadows cast on the wall; they are neither accurate in detail nor substantive in their historical accuracy. Zhang thus shares this approach to the use of these cinematic constructs with the Coen brothers' version of 'Texas', despite the obvious differences in generic origins of their works. 


\section{Gender in A Woman, A Gun and a Noodle Shop: A Lesson in 'Zhangification'}

\section{Zhang Yimou and Gender}

As touched upon earlier in this chapter, gender is a crucial facet of Zhang's filmmaking, and gender representations have been read with reference to the complex issues of China's past. As already briefly mentioned in Chapter Five, the films of the Fifth Generation group of directors, including Zhang, often dissected the traumatic past of the Chinese nation, including the period from 1949 onward after the Communist Party took power. The films of this generation are discussed as a form of counter-narrative to official discourse on the politics of the People's Republic of China. In Zhang's oeuvre, gender plays a key role in the disassembling of power structures. Gender representation is also where Zhang's films often express their literary origins, through characters who hark back to earlier Chinese literature. Zhang has attacked the concept of feudal patriarchy as a source of power cinematically through the reshaping of lead character gender roles, as can be seen most clearly in his famous trilogy, Red Sorghum (1987), Judou (1990) and Raise the Red Lantern (1991) (Farquhar, 1993).

In many of Zhang's films, old men "personify a system that never relinquishes power, and freedom only comes from real or symbolic patricide that is carried out by the son, but instigated by female desire" (Farquhar, 2002). Thus the faults of masculine-oriented institutions are laid bare through their often old, cruel and impotent lead male characters (Chow, 1995), who are replaced by the new generation of sons who reject the principles on which the previous generation's power was based. However, significantly, Zhang's films reorient true power not towards the sons, but towards courageous and determined women, whose desires "whether for love, sex, sons, justice or simply survival challenge the systems that threaten them" (Farquhar, 2002). While he may sexualise these women, he also gives them sexual agency. Zhang thus complicates a trope of rebellious womanhood which has existed in Chinese cinema since the early 2oth century by aligning collective "patriotic endeavour" with individual sexuality instead of pitting the two against each other (C. Berry \& M. Farquhar, 2006, p. 125). In his early films, the social change that is ignited by the actions of a defiant woman exposes the individual's role in a society which previously admonished the pursuit of one's own desires lest they undermine the community.

As mentioned earlier in this chapter, Zhang's more recent films have been more exaggerated in their scale, but at the same time less politically disruptive. In films like Hero (2002) and House of Flying Daggers (2004), gender 
representations were considered in terms of how closely the lead figures related to traditional wuxia roles, including the image of the woman warrior. This figure is "traditionally an integral support for the patriarchy, as she temporarily steps into a position of power to defend the patriarchal family order" (Edwards, 2010, p. 69). However, Zhang complicates her representation by stripping her of her masculine costume, which simultaneously frees her to explore experiences of romance and sexuality, while at the same time sexualising her for the audience (Edwards, 2010). Across his career, Zhang has shown a propensity to manipulate gender tropes of Chinese cinema and culture, and the following section will explore how this might be evident in the remaking of A Woman, A Gun and A Noodle Shop.

\section{Masculinity 'Zhang-ified' \\ Mazi}

Mazi, the husband of Laobanniang and the owner of the noodle shop, is quite a different man from his corresponding character Julian Marty in the original film. In his sixties, he is around twenty years older than Julian Marty, and thirty years older than Laobanniang. Unlike in Blood Simple, where Julian Marty is introduced through his interaction with Visser, Mazi is introduced independently and prior to his interaction with the corrupt officer Zhang San. While Julian Marty is introduced in his place of work, we first meet Mazi in his bedroom. The camera lingers over his shoulder, and we see a head, with wiry hair and balding in the middle, and a hand holding a pair of scissors, cutting out the face of a plump baby on a poster. There is no sound, other than that of the scissors tearing through the paper. The camera changes angle to look up at him - he is an old man, with puffy eyes, a stringy moustache and goatee. One of his front teeth is solid gold. He seems to be very involved in the task of carefully cutting around the baby's face, and his facial expression is one of both concentration and pleasure. If Mazi's behaviour seems a little strange, this is only emphasized when Zhao Liu knocks on the door, and Mazi quickly gathers together the many baby faces he has cut out and hides them under a blanket. Mazi then feigns illness, lying down on his bed, his pock-marked forehead ("Mazi" being a nickname meaning "pock-faced") adding to his aged and decrepit look.

A central tenet of Mazi's masculinity is his wealth and the power over others that this affords him. Mazi is very tight with his money; he is wealthy, but stingy. We first see this quality when Zhao Liu visits his boss to report that Laobanniang has bought a gun. There is confusion when Mazi throws money at Zhao, seeming to pay him for the information, but it turns out he is merely paying him his wages - less than the agreed amount of course. Zhao Liu leaves 
cursing his boss. From this conversation, Mazi shows himself to be a cruel and unjust man-he uses his position to exploit his workers, not paying them a fair wage and treating them poorly. This behaviour opens him up to a workers dispute, where the lower class workers Zhao Liu and Chen Qi plot to take what is rightfully theirs from Mazi's safe.

Like Julian Marty, Mazi also reveals himself to be obsessive and perverted. While we do not immediately understand the significance of the baby posters, looking around the room during his conversation with Zhao Liu, we can see there are also baby statues lining the shelves of his bedroom. We later come to understand is that Mazi has no children, and he has become fixated on this issue. He blames his wife, saying that she must be infertile. He feels cheated that he paid so much for a woman who will not give him an heir, and therefore subjects her to humiliating punishment by pushing her face through the holes on the baby posters and burning her on the bottom with his smoking pipe. He is also extremely suspicious, and when he finds out that she has bought a gun, he assumes it is to kill him, before he has even found out she is having an affair.

While their qualities of jealousy, possessiveness, and wealth seem to overlap, Julian Marty and Mazi differ in where they take their models of masculinity from. While Julian Marty takes many of his qualities from film noir, Mazi seems to draw upon multiple sources, most clearly the figure of the 'miser' in Chinese literature, and in Beijing Opera, the characters of the jing and the sheng. The miser character of Qing and Ming dynasty literature is broadly characterised as an "economising and pleasure-deferring" character (McMahon, 1995, p. 14). Mazi connects with the frugal, nasty, miserly attitudes of this figure - the safe in his office perhaps being the most obvious sign of the hoarding of money which typifies the miser. His over-arching attachment to money and his own survival make him neglectful of his wife (McMahon, 1995), and might also explain why even as a wealthy man, he has not moved to secure another wife to bear him an heir.

The comparison with Beijing Opera's sheng and jing characters may appear initially to be counter-intuitive, as the jing character was a strong, powerful figure who dominated the stage with a larger-than-life physical presence, stocky build and face, and commanding singing voice (Bonds, 2008, p. 15), while the sheng was a noble figure, a "dignified and decent man" (Bonds, 2008, p. 3). Mazi clearly does not have many of these characteristics, but he does have the characteristics of the male figures Zhang has employed in many of his films, most notably his trilogy — wealthy, impotent, old and cruel.

Mazi could thus be read as a deliberately corrupted version of these male figures, and thus another expression of Zhang's notion of failed patriarchy. The 
proud, dominating body of the traditional jing is transformed into a scrawny, limping old man. There is nothing left of the jing makeup, traditionally brightly coloured to indicate emotions; ugly pock marks take its place. Mazi wears the maroon short-sleeved top symbolic of the jing, and the olive green trousers of a laosheng (older man of good character), but his costume is ragged and unrefined. He has been stripped of his padded vest, used to emphasise his physical prowess (Bonds, 2008), leaving his chest totally bare. In its place, he wears a red scarf, perhaps another hint towards the traditional red mang robe worn by the sheng character as an indication of "his importance to the plot" (Bonds, 2008, p. 245), but equally an early symbol of his murderous intent and his own death, as red "reflects passion at different levels, and when worn by court officials as well as executioners and criminals, it represents the deprivation of life" (Bonds, 2008, p. 73). He thus neither has the good character of the sheng or the influence of the jing.

Mazi effectively dies two deaths, one for each character-first at the hands of Zhang San, and then finally, Li Si. Further supporting the argument that Zhang is continuing his cinematic criticism of the patriarchy is the change in circumstances regarding Mazi's death. As we recall, in Blood Simple, Ray buries Julian Marty alive in a field. In Zhang's re-imagining of the story however, Li Si actually shoots and then buries Mazi. This key event within the remake is thus altered to incorporate the theme of symbolic patricide of the older male figure by the "son" and love rival, consistent with Zhang's other films.

\section{$\mathrm{LiSi}$}

While Julian Marty and Mazi may share some common characteristics, the form of masculinity expressed by the lover $\mathrm{Li} \mathrm{Si}$ is quite different from the silent, tough guy Ray. Li Si is introduced in public, under pressure and confronted with an intimidating form of violent foreign masculinity. The first time we see Li Si's face is a slow-motion shot of him leaning away to narrowly escape the swipe of the sword of a Persian trader. Terrified, his eyes open wide, he stumbles backward and shouts for help from his friends, "Murderer, murderer! Zhao Liu, Chen Qi!" While he seems to have initially put himself between the trader and Laobanniang to protect her, he quickly crumples back towards her, and she seems more impressed by the trader's wild behaviour than afraid. Li $\mathrm{Si}$ is definitely not a warrior, and our initial impression of him is that he is a coward and a little bit ridiculous. However, $\mathrm{Li} \mathrm{Si}$ is also not the type to let anyone else have the final word, and once the sword is sheathed, he chastises the trader, stating that Laobanniang should not buy anything from someone who behaves so ostentatiously with a large sword. We could say that Li Si's strong point is his words, but unfortunately, on a few key occasions these also fail 
him - particularly when he is confronted by figures of authority such as Mazi or the police.

After Laobanniang buys a gun early in the film, we find out $\mathrm{Li} \mathrm{Si}$ is having an affair with her. Unlike in Blood Simple, we don't see the beginning of the affair unfolding, and the sex scene is removed. Instead, their relationship is revealed when $\mathrm{Li} \mathrm{Si}$ questions her motives for buying the gun, something he would not be able to do if the power distance between boss and employee was being maintained. He asks her, "what do you intend to do with that?" When she replies "Can't I have a gun just to have a bit of fun?" he scoffs at her, "Who would believe that? What are you really thinking? Do you want to make me worry to death?" Laobanniang replies, "You are always worried. We have been together for so long, and yet, this hasn't changed/there has been no progress on this". Li Si responds by saying they have been together for actually only 71 days in total, and Laobanniang laughs at him for keeping count.

Li Si's costume is particularly striking; he is dressed almost entirely in pink, which closely aligns his character with the Beijing opera role of the wenxiaosheng - the young male lover, and is symbolic of his romantic nature. His cotton top and trousers, with turned over fabric at the waist, indicate he is of a lower social status, the working class - in this instance, a waiter (Bonds, 2008). He also wears a poorly fitted red midriff top, marking him, like Mazi, with the colour of passion and death-this is the article of clothing Zhang San uses to prove to Mazi that he has killed Li Si. His ill-fitting costume also makes him look slightly ridiculous, which emphasizes the elements of the chou in $\mathrm{Li}$ Si's character-he often plays a comedic role particularly in the beginning of the film. Earlier in this chapter we discussed the example of Li Si's monologue, but there are other moments where Li Si provides comic relief. For example, in one scene after the three love triangle members have had an argument, Li Si shouts provocatively at Mazi across the desert dunes, only the find the sound carries further than he imagined when Mazi hears him and stops to gesticulate back in response.

\section{Zhang San}

While Abby may have been the most mysterious character in Blood Simple, with viewers having little information about her past (Doom, 2009), the most enigmatic of all those who feature in A Woman, A Gun and A Noodle Shop is Zhang San. His character deviates quite markedly in a number of ways from the original private eye Visser, and from the versions of masculinity portrayed by the other men in the remake.

Zhang San's apparent anti-social behaviour, lack of morals, and diminished empathy and remorse, are all classic characteristics of psychopathy. It would 
be easy to interpret his behaviour as cold-blooded, calculating and cruel-he bargains over the price of murder, and then double-crosses Mazi. He murders three people in his attempts to steal the riches from Mazi's safe. However, while Visser is a character who is easy to dislike, Zhang San is more complex. To begin with, Zhang San demonstrates none of the lasciviousness of Visser. While we meet the original private eye when he is spying on Abby and Ray, and taking photographs of them in bed, Zhang San does not demonstrate any of this sexual depravity. In fact he displays no sexual interest in Laobanniang whatsoever, which severs his connection to one of the key noir themes of sexual obsession and possession. This change also makes Zhang San less repugnant than his Blood Simple counterpart. In direct contrast to Visser, who took pleasure in telling inappropriate stories or jokes, Zhang San very rarely speaks, and when he does, he certainly does not joke. His lack of sexual lecherousness and his silence combine to create a character who is highly enigmatic, and almost meditative in his demeanour, not dissimilar to a monk or martial arts master. At other times, his silence almost seems remorseful, or hesitant, and it seems Zhang San is not convinced that he is pursuing the right path.

Perhaps the most significant change of all to Zhang San's characterisation is that in the remake, he is not a private detective, but a member of the local constabulary. He is, according to his superior officer, the most famous detective in the team, but not the highest ranking one. Zhang San's position as a police officer of middle rank is crucial in guarding him against suspicion when he decides to become a rogue operator and assassinate Laobanniang and $\mathrm{Li} \mathrm{Si}$. We thus always see him wearing his police armour, the outward symbol of the institution within which he hides. His corruption, combined with the representation of his superior officer as incompetent and ridiculous, gives a cynical interpretation of authority and again contributes to the notion that the film attacks patriarchal institutions.

\section{Femininity 'Zhang-ified' \\ Laobanniang}

As the only significant female character in the film, like Abby, Laobanniang is a character who was at risk of being overwhelmed by masculinity. But while Abby is naïve, sexual and vulnerable, Zhang has chosen a different approach to his female lead. He instead has created a strong character who has evolved from the women he has represented across his career as a director.

While Zhang Yimou's female protagonists are already known for being resolute and speaking out against injustice, Laobanniang is more open, brash and aggressive than women in his previous films. This is reflected in her first line of 
dialogue in the film—she asks the Persian trader, "Do you have anything that is particularly effective at killing? (你有没有那种用起来特方便而且沾边就死 的?)". She doesn't need permission from her husband to own a gun-unlike Abby, who was given hers as an anniversary gift from Julian Marty. Laobanniang instead seeks one out of her own volition, and she does not care who sees her buy it. She is a provocateur, and she enjoys the attention she receives for owning "one of the most high-tech products in the world" that gives her the power to "bring thunder down on all living beings" (这辈子, 我能拥有一件世界上最 高端技术的产品。我也能雷倒众生了). Zhao Liu mishears the trader saying the gun can "kill horses fast and people even quicker", and passes this information to Mazi, who understands that his wife intends to kill him, the character $m a$ (马) for horse being a homonym for the $m a$ (麻) in Mazi's name.

In fact, Laobanniang's motive for buying the gun is much closer to selfdefence than cold-blooded murder. The audience comes to appreciate why Laobanniang needs to defend herself fifteen minutes into the film, when we see an interaction between her and Mazi in the bedroom. Mazi describes how he bought her ten years ago for the sum of 3 guan 800 wan, and over that time she has been unwilling to give him a son. Her husband demonstrates strange sexual inclinations where he takes pleasure in hurting her. Thus at this point, Laobanniang resembles the female leads we have seen on many occasions from Zhang Yimou, to the extent that there has been a model developed for his films revolving around trapped and abused women, which will be described in Chapter Five.

However, the next part of the dialogue indicates that there is far more to Laobanniang's character than this model allows, and she breaks the mould through her ability to defend herself. During this scene in the bedroom, Mazi also confronts her about the gun, asking whose money she used and why she bought it. Despite her position of vulnerability, with her hands tied and having been beaten, she responds fiercely "with my own money", and threatens him "I'm telling you Mazi; this is the last time you will torture me like this". Mazi then burns her repeatedly with his smoking pipe. Throughout $A$ Woman, A Gun and A Noodle Shop, Laobanniang always says what she needs to say, regardless of the punishment or consequences. In this respect, she is quite different to Abby, who rarely verbally defended herself, and even after fighting off Marty's physical assault, needed a man (Ray) to physically stand beside her to make Marty leave. Laobanniang's rage is instead more characteristic of the shrew, who in Chinese 18th century literature is often the wife of the miser. This woman is "especially effective with her mouth, which she uses to vent rage upon her husband or other adversaries, whom she 'curses in the open street'” 
(McMahon, 1995, p. 84). Later we see her skills on display when she takes aim at cowardly Li Si for failing to stand up for her.

Laobanniang is also different in that she has a plan for the future, and while this explicitly involves $\mathrm{Li} \mathrm{Si}$, the film does not clearly indicate who is rescuing whom. When Abby moved out of the house she shared with Julian Marty in Blood Simple, her plans were ambiguous - we don't know if she intends to stay with Ray, particularly after things start to go awry and there is miscommunication and confusion between them. Also in contrast to Zhang's earlier female leads who suffer in silence (such as Ju Dou in Ju Dou, or Fengxia in 1994's To Live) or free themselves only through death (Songlian in Raise the Red Lantern), Laobanniang intends to free herself through getting a divorce and moving on with her life. She explicitly states this to $\mathrm{Li} \mathrm{Si}$, saying that she is already his, and if Mazi won't sign the papers, she will sign for him. So despite, or perhaps even because of her experiences with her husband, Laobanniang cannot help but be hopeful of finding love and a new life. It is this hope that leads her from her current doomed relationship into the next.

Laobanniang's relationship with Mazi is an abusive one, but her situation with Li Si also has its own obvious flaws. The power imbalance between Mazi and Laobanniang is reversed between Laobanniang and $\mathrm{Li} \mathrm{Si}$, with her dominating personality at times threatening to crush him. When Mazi is again violent toward her later in the film, she again fights back, defending herself and chasing Mazi away by running at him with her gun. In the very next breath, she takes aim at Li Si, calling him the "number one coward on the southern slopes" for not stepping in to defend her. When Li Si runs away from her, in fear of the consequences of returning home where Mazi waits for them, Laobanniang starts to cry, and bitterly criticizes him for disappointing her: "You let me hope for too much. As a woman I dreamed of having a shoulder to lean on, but I could not find this. Then I met you, and I thought I had found that shoulder. Now I find out this is false-you lied to me, and I really believed you. I don't want to listen to any more of your lies, you just stay here". Furious and hurt, she rides off without him, leaving him in the desert to walk home.

Laobanniang displays a wide range of emotions, giving her a strong presence to balance the masculinity in the remake. Outwardly, she resembles the coquettish huadan, or young, flirtatious woman, beautifully adorned and on display, but personality-wise, she also shows that she can fight and beat "the boys" - in one scene, we see her rolling around in the dunes fighting Mazi, her hair a tangled mess, her clothes red with dust. Her depth of character, and her array of personality traits take her quite far from the original Abby in Blood Simple, and she instead extends upon the model of femininity that director Zhang has built over the past twenty years. 


\section{Reflections}

A Woman, A Gun and A Noodle Shop demonstrates the significant role genre and the auteur can play in the reformulation of a source text into a remake and how films function on multiple levels, narratively, visually and symbolically. Unlike in the case of What Women Want, where the two films appearing to be similar actually ended up being quite different, Blood Simple and A Woman, $a$ Gun and a Noodle Shop began looking visually very different, but on closer analysis, genre and auteur considerations are very important for both films. The differences between the source film and remake lie instead in how each film puts into practice the directors' interpretations of cinematic and cultural traditions. Both films strongly connect with the indigenous aspects of genre, and both are led by directors who have, over the course of their careers, raised questions about gender through the incorporation of atypical characters who do not fit with stereotypical models of masculinity or femininity seen in cinema or society more broadly.

From a narrative perspective, the woman as the only survivor appears in both films, with the Coen brothers inverting a film noir trope, while Zhang seems to be extending upon his own trope of female suffering to include a woman who actually survives relatively unharmed. In Blood Simple, along with the failed masculinities represented by the male leads, the Coen brothers also use genre, or more specifically, the mixing of genres, to further confuse and break down the masculine codes of institutions such as the state or the law. Zhang Yimou achieves this in his remake by incorporating the figure of the corrupt policeman, and emphasises it through the location of the film narrative in the middle of the desert. Visually, Zhang utilises distorted or empty symbols of Chinese culture, including Beijing Opera costumes and an unremarkable courtyard, which lack any kind of definite historical reference point for the viewer.

By shifting the generic basis of the original film from noir and Western films to Beijing Opera and Chinese humour, the director tacitly acknowledges that the film's domestic audience in China does not have the same cinematic cultural capital that connects them to a tradition of American film noir and other indigenous American film genres. To keep all of the references to these genres strictly intact would mean that some aspects of the remake would have been lost in translation.

Symbolically, while the remake looks vastly different on the surface to the original film, the film is imbued with the same tensions that have been present across Zhang's career, of what it means to represent 'Chineseness'. The symbols and settings in Zhang's film are markers of cultural and cinematographic 
ideas - "the use of things, characters, and narratives not for themselves but for their collective, hallucinatory signification of 'ethnicity"' (Chow, 1995, p. 144); in this case, 'Chineseness'. Chow argued that because Zhang's depictions were not connected with any real or tangible reality, it was not the content of his trilogy of films that pitted him against the Chinese authorities, but the fact that his films were pure spectacle devoid of meaning, as this violated Chinese literary and cultural linkages between "fullness", cultural production and morality (Chow, 1995, pp. 152-154). At the same time, Zhang's symbolic visual language can be read as a concrete representation of the kinds of gender and social issues which have been the subject of analysis in this chapter.

There is no clearer indicator of the remake's deep connection to these different audience needs than the fact that there are two versions of the same remake in circulation. Zhang cut nearly five minutes from the internationally screened version of his film, removing some of the more colloquial jokes, editing shot lengths, angles and music; a very clear case of appealing to (at least) two distinct audiences - one the New Year's comedy domestic audience, who favoured the local eccentricities of the film, and one for international viewers, who were searching for references to the cult classic original film. Zhang's remake therefore attempts to position itself relative to the traditions and expectations of a domestic, New Year's comedy Chinese-language film audience, while at the same time making some further adjustments which emphasise the remake as homage to the original film, enhancing Zhang's status as a contributor to global cinema, a space in which film functions as the universal language of communication among the cinematic elite. In this way, the Chinese-language remake represents something of a break from the style of Zhang's other films, which incorporated multiple levels of address within the same film - this remake required two cuts to reach its audiences. This chapter identifies a different approach to remaking than has been described previously both in this book and in earlier remake studies more broadly, highlighting a situation where a remake has effectively been remade-bringing the importance of genre and the director in creating meaning for remake audiences into even sharper relief.

Given the significant changes in the social dynamics between China and the rest of the world over the past thirty years, and the changing nature of Zhang's relationship with the authorities over this period, the attitudes within and towards Zhang's remake no longer reflect the anxieties and difficulties that his film trilogy may have inadvertently expressed. While the depictions of cruelty and backwardness in Chinese society in Zhang's early films may have represented the perpetuation of a sense of inferiority between China 
and more developed nations (Chow, 1995), Zhang is now a poster boy of global Chinese cinema, and with the Coen brothers selling the rights to the film to Zhang and congratulating him on a successful remake, Zhang reinforces his position among the global elite of cinema and reinforces the idea of Chineselanguage cinema as an influential transnational entity. The differences that can be observed between the Coen brothers' Blood Simple and Zhang's $A$ Woman, A Gun and A Noodle Shop indicate there is no gap between Hollywood and Chinese directors, or developing and developed nations. Zhang's retention of some of the more distinctive actions taken by the original film's characters, such as Li Si banging the shovel on top of Mazi's grave just as Ray did on Julian Marty's, create a very clear association with the Coen brothers film which would be recognisable for those who had seen Blood Simple; that is, the international film viewer. These differences instead speak to the fluid nature of genres, both when they are adapted by auteurs, and when they shift from one audience to another. 


\section{Ghosts of Chinas Past and Present}

The previous two chapters have illustrated how remakes can be shaped both by notions of socio-cultural difference, and by cinematic cultural difference in the form of different generic standards and directorial styles. From considering the questions involved with remaking in a cross-cultural context, the following two chapters will now shift the analysis and discussion to the intercultural remake. In doing so, changes between source film and remake can be looked at from different perspectives, with a view to understanding how remakes manifest cultural change across genres, different times of production, and different locations of production within the region currently known as "China".

This chapter will begin where the previous chapter left off; extending the focus on gender, genre and remakes to the intracultural remake, through the analysis of the Hong Kong film from 1987, A Chinese Ghost Story (倩女幽魂), and its 2011 remake of the same name. What factors may have influenced the very clear differences observable between these two films, and what are the implications for the study of Chinese-language remakes? Furthermore, what possible perspectives could this pair of films bring to bear on the question of how remakes might reflect greater concerns of disputed or fractured notions of social and political identities, particularly in reference to the precarious relationship between mainland China and Hong Kong? The following chapter will endeavour to answer these questions through a comparative analysis of source film and remake.

The 1987 Hong Kong original, directed by Ching Siu-tung, and produced by Tsui Hark, follows the relationship between a young tax collector, Ning Caichen, and a female ghost, Nie Xiaoqian. The film is considered to be a classic of Hong Kong New Wave cinema, with its hybrid blend of Hollywood-style special effects and Chinese ghost story plot, along with Hong Kong Kung-fu and comedy (Teo, 1997). The remake, created in 2011, is a co-production between mainland Chinese and Hong Kong production companies, directed by Wilson Yip, and retained the same Chinese title (倩女幽魂). Both the original film and the remake find their inspiration in the Pu Songling short story 'Nie Xiaoqian' (聂小倩) from his work Strange Tales from a Chinese Studio, and thus draw on a long tradition of ghost tales in historical China featuring female ghosts and living men.

The following analysis will compare and contrast the two films, focusing on five dimensions. Firstly, the two films' generic categorisations and plots, with consideration for how the remake and source film address the same source 
text. Following this, an analysis of representations of masculinity, including how the star persona of Leslie Cheung influenced the male image in the original film. The gender-oriented analysis will then turn to femininity, investigating the changing representation of the monstrous-feminine across both films. The psychoanalytic concept of the gaze will be drawn upon to discuss how sexuality is realigned in the remake, before the final section addresses how the remake's metaphor of memory loss might come to represent a broader allegory for the relationship between Hong Kong and China.

\section{Locating A Chinese Ghost Story (1987) in Hong Kong Cinema}

At the time cinema was introduced to Hong Kong, the region was colonised by the British (from 1841-1997), and with Hong Kong and mainland China separated, the different conditions in the two regions affected the development of their respective cinemas. Hong Kong cinema of the "first period, from the introduction of cinema in 1897 to the geopolitical division of several competing Chinas in 1949 is seen as an offshoot of mainland Chinese cinema ... marginal and secondary to the cinematic centre of mainland China, Shanghai" (R. Chi, 2012, p. 77). During this period, cinematic talent and ideas were exchanged between mainland China and Hong Kong, as Hong Kong served as "a source of labour and technology, a branch office for expanding business operations, or a refuge from political instability" for mainland Chinese artists and directors (R. Chi, 2012, p. 77).

Hong Kong's cinema industry developed through the incorporation and adaptation of a variety of cultural influences, and Hong Kong's position as an "open port" meant that there was a free flow of techniques, ideas and styles from Hollywood, Europe, Japan, Korea and mainland China, as well as local pioneers, that all played a role in shaping Hong Kong's cinematic productions. After the Communist Party victory in 1949, the relationship between Hong Kong and mainland Chinese cinema changed, and separate "Chinese cinemas" were emphasised, as mainland Chinese film production became more introspective and state-controlled up until the 1980 os reform period, while Hong Kong cinema turned towards other markets in South-East Asia to support its industry (R. Chi, 2012). The cinema of Hong Kong, like the city itself, came to be considered part of the Chinese "diaspora" (Ma, 2010), where cultural displacement created "new modes of expression and exchange" as well as "anxieties over identity and belonging" (Yue, 2010, pp. 8-9).

During the 1980 s and 1990 in particular, Hong Kong cinema represented "one of the success stories of film history" (Bordwell, 2000, p. 1), with a vibrant 
cinema which had both artistic value and mass appeal. ${ }^{1}$ Blockbuster films in Asia also found audiences (albeit smaller ones) as cult cinema in the West, and thus Hong Kong cinema had both local and international followings, as it combined Eastern and Western stories and cinematic techniques. At this time, "Hollywood served more like a model and a partner than the 'Other' to be resisted or repelled ... it was more complicit than oppositional to Hollywood" (Chu, 2004, p. 5). The original Chinese Ghost Story's particular style reflected the extravagance, inventiveness and careful craftsmanship which have become synonymous with Hong Kong cinema of that period.

The combination of a variety of styles and aesthetics also impacted upon the generic features of films created during this era. A Chinese Ghost Story (1987) is one such film that is difficult to classify, with David Bordwell labelling it both "a costume fantasy", and a "ghost romance" at different points in his work Planet Hong Kong: Popular Cinema and the Art of Entertainment (Bordwell, 2000), while Stephen Teo calls the film a "horror" movie (Teo, 1997). Esther Yau (2001) argues that the generic schizophrenia which typifies Hong Kong cinema is indicative of Hong Kong's "androgynous" film culture, a space in which films cite "diverse idioms, repackage codes and combine genres that are thought to be culturally, aesthetically or cinematically incompatible ... using wit, hyperbole and sentiment to break down the notions of bounded cultures, so that the cultural entities that once appeared to be historically and geographically intact are often taken apart and reassembled". Through this approach, which refuses to engage with notions of "cultural authenticity", Hong Kong cinema "positioned itself as a (post)colonial cinema that evaluates and counteracts the cultural regimes of both the British and the Chinese" (E. Yau, 2001, p. 7).

The deployment of this mixed-genre approach in many films produced in Hong Kong in the 1980s and 199os has been read as reflecting strong themes of anxiety regarding the possible outcome of the handover for "Hong Kong identity" (E. Chan, 2000). Stephen Teo specifically flags Tsui's Chinese Ghost Story films ${ }^{2}$ as being significant in the way they "summarise a feeling of impending doom as Hong Kong faces up to its destiny" (Teo, 1997, p. 229). One of the most prominent themes of this period in the cinematic genre of horror was the

1 By contrast, mainland Chinese films were just starting to emerge on the international scene, with the first appearances of Fifth Generation films at international film festivals occurring in the early 1980 .

2 There were three films in total in this franchise; A Chinese Ghost Story I (1987), followed by A Chinese Ghost Story II (1990) and A Chinese Ghost Story III (1991). All three are taken to reflect these themes of anxiety about cultural identity. 
notion of reincarnation, which Teo interprets to be reflective of the struggle of Hong Kong cinema and culture to reconcile with the continued presence of seemingly contradictory cultural and social values from other times and places (Teo, 1997). Dale Hudson discusses how the plethora of 1980 "goeng si" films featuring corpses and vampires (Hudson, 2000, p. 203) were partly a product of Hong Kong's "crisis of modernity" and "coincided with accelerated awareness of uncertainties and certainties regarding Hong Kong's future" (Hudson, 2000, p. 204).

A Chinese Ghost Story induces a feeling of disorientation using a number of techniques, including dark and misty locations, wild, twisting camera shots, disembodied voice-over narration and strange supernatural creatures. Works which are strongly connected to Tsui Hark are well-known for their heavy nationalist themes, often tied to the identity crisis associated with Hong Kong's return to China (Teo, 1997). Tsui's films are read as being heavily symbolic and at times, chaotic, and "what matters is not an entry into the past or a return to a cultural and national origin - to a homey Chinese place that guarantees stability and certainty - but a retroactive reduction of everything in the past to the giddiness and uncertainty of the here and now. His early films reflect the dangerous and dizzying disclosure of rootlessness experienced in pre-1997 Hong Kong" (Lo, 2006, pp. 55-56).

Interestingly, this generic schizophrenia is also a marker of the wuxia genre (Teo, 2009), and thus A Chinese Ghost Story can also be located within the broader Chinese genre of wuxia; that is, films or literature which refer to "a tradition of sword-wielding, swordfighting, horse-riding or gallivanting warrior figures who stand and fight for honour, chivalry and righteousness" (Teo, 2009, p. 3). Cinematically, this wuxia genre is also connected with nationalism, as the protagonists often participate in battles which shape the future of the nation. Wuxia's connection with nationalism made it the perfect vehicle for expressing concerns regarding the relationship between Hong Kong and China, particularly in the lead up to the handover of Hong Kong back to China in 1997. Testament to how the genre has evolved over time, "the wuxia film was and is now regarded as a national form, fulfilling nationalist desires for self-strengthening at times when China was weak. In the present, as China has become a rising world power, the wuxia film seems to have become an instrument of the state: wuxia as a means to maintain the myth of the warrior tradition and its historicist concepts of chivalry and knight-errantry in order to justify the modern concept of the nationstate" (Teo, 2009, p. 8). These generic concerns are very relevant for the reading of the remake, in how it engages with stereotypes within the wuxia genre to express ideas about the current politics of national identity. 


\section{Remaking A Chinese Ghost Story (2011)}

While the remake of $A$ Chinese Ghost Story shares the same lead characters and the same broad plotline as its source film, from the first scene, it is immediately clear to the viewer that there has been a marked shift in tone between the two films. Perhaps even more significantly, there are narrative differences, such as a re-ordering of character introductions and changes in the emphasis and amount of background detail given about main protagonists, which in turn influence the course of the rest of the film. By comparing and contrasting the two opening scenes, gender representation reveals itself as a crucial facet to be understood in how the Chinese-language remake can be representative of the constantly shifting terrain between Hong Kong and mainland Chinese cinemas and histories.

The original A Chinese Ghost Story opens with an eerie sequence, with the wind blowing at night and a lone scholar in a run-down temple. The windows blow open, and he sees a woman dancing in white. She draws him over to her, and his lantern falls into a bucket of water. The woman is on top of the man, and when he reaches for her ankle, the bells on her anklet ring, and call forth something sinister from the misty forest. While the woman pins him down, something comes through the open door, and we see the man scream and writhe, before the candle in the lantern goes out. A vibrant red silk cloth flows up to fill the screen, and the title “A Chinese Ghost Story" (倩女幽魂) appears.

We are then introduced to the tax collector Ning Caichen (寧采臣), who stumbles his way through the rain and survives an encounter with fighting warlords to make his way into a village. Unfortunately, his records are ruined by the rain, and he is unable to collect on any debts. The locals around him are a little paranoid, constantly living in fear of the police, who check everyone overzealously in their pursuit of a dangerous fugitive (who we later find out is Yan Zhixia, 燕赤霞, a Daoist warrior). In a series of comedic errors, Ning wanders through the village, drawing ire and ridicule wherever he turns, due to his clumsiness and poverty. Looking for a place to stay, he is directed by a stallholder to Lan Ruo Si (兰若寺), and he naively takes this advice. He survives the night through sheer luck, without even realising that the temple he slept in is full of zombies, victims of the temple's other inhabitants, the ghosts. On that night, Ning also meets Yan the Daoist warrior, and has his first encounter with the beautiful ghost, Nie Xiaoqian, who tries to seduce him unsuccessfully at a pavilion by the river.

When Ning returns to the village the following day, the villagers are shocked to see him alive. The people who previously mocked and ridiculed him instead 
crowd around behind him and whisper; the shopkeeper who refused to hand over money now stammers in disbelief "Did you really stay in Lan Ruo Si?" before giving over handfuls of currency. A Daoist religious procession suddenly makes its way through the village, and Ning sees Xiaoqian in the centre, carrying a scroll in her hands. Ning calls out to her, and the villagers flee in fear. He searches for her in vain as the authorities disperse the members of the procession. Now with money, Ning returns to a stall where he had previously admired a watercolour painting of a beautiful woman washing her hair in the stream, only to find the picture is gone.

This short opening sequence, and the atmosphere which is created by it, with its mix of physical comedy, absurdity and horror, is radically altered in the 2011 remake. Instead, it is replaced with melancholic music over a computer-generated imagery (CGI) landscape background, with the muted colour palette resembling a traditional Chinese painting. The remake does not begin with Ning Caichen's story; instead, the film introduces an extra-diegetic element—narration by the Daoist warrior Yan Zhixia, who we see in tears, standing with a dagger held over his head (just out of the frame). He narrates the beginning of the story, while the audience is taken through a flashback to see the relationship between the ghost Xiaoqian, and Yan Zhixia unfold.

He philosophises, "Life requires us to make choices. When this feeling is destined to disappear, the only thing you can do is forget her, or make her forget you. I am a ghost hunter. One day my master sent me to Black Mountain to catch a ghost". During this scene, we see the ghostly figure of Xiaoqian flying through the dark forest in slow motion, pursued by Yan. He fires an arrow, which releases her hair from her top knot, and we see a glimpse of her sharp teeth. Yan grabs her dress, and when she spins to free herself, her dress comes away in his hands. The ghost flees up a tree, watching Yan's reaction. He looks away, but then returns his gaze to her. They study each other for a moment, and we see in Yan's eyes surprise, and the awakening of desire. The glimmer of a smile on Xiaoqian's lips acknowledges her psychological victory, and she climbs down from the tree, running naked into the forest.

Yan continues, "Only afterward did I understand that what my master was testing wasn't my kung fu-it was my heart. The most frightening thing about ghosts isn't that they kill people; it's that they make you lose yourself". At their next meeting, Xiaoqian attacks Yan, but holds back from taking his life. Instead, she again studies him closely, before reaching into his bag to take a sweet-something which she has never eaten before. We see their innocence as they sit in a tree while they talk about her love of sweets. This is also our first glimpse of the inconstant nature of Xiaoqian's affections - when Yan tells her he can't afford to buy her as many sweets as she wants, she replies casually that 
in that case, she will like/love whoever can give her these sweets. Things do not remain innocent for the pair, as Yan watches while Xiaoqian consumes a victim, and what quickly became love just as quickly turns bitter, as we see the lovers quarrel about the futility of the relationship between man and ghost. The climax of the argument comes with her ordering him to kill her, since man and ghost can never be together. We then return from the flashback to the first scene of the film, where Yan stands over the kneeling body of Xiaoqian, before he brings the dagger down. "From today, you won't suffer again, because you won't be able to remember me", he narrates. The screen whites out just before we see him strike.

The remake then uses jump-cuts to move to an action scene, with Yan running towards four fighters, who are in a battle to the death with the Tree Demon, Laolao (姥姥). In the fighting, two of the men die, and the last remaining warrior forces Yan to cut off his arm so he can break free from Laolao's grasp and complete the incantation needed to drive her away. This last man standing, Xia Xue Feng Lei (夏雪风雷), disowns Yan for not arriving in time to save his "brothers". Through lightning and wind, we then see the temple of Lan Ruo $\mathrm{Si}$, where the roots of a tree grow up through the inside of the dilapidated building and over the roof. This is the home of the Tree Demon and the spirits. Yan's voice-over continues, "I finally understood, that men and ghosts cannot be together. I decided to use magic to seal off any memories she had of me, so she could not recall this feeling - so she would forget me forever. But I never imagined that when that young man came to the mountain, we would begin all of this again". After this, the film title is introduced, and the remake picks up from where the original started. The familiar theme song of the original, performed by Leslie Cheung, accompanies the character Ning Caichen as he walks through the misty forests and mountains.

\section{Manifestations of Gender and Sexuality in A Chinese Ghost Story}

\section{The Legacy of Leslie Cheung}

From this opening scene, with its clear focus on relationships, sex and desire, it is clear that the films' meanings are heavily bound up with questions of gender representation and sexuality. The hugely popular but controversial figure of Leslie Cheung, who was bisexual, in the lead role of Ning Caichen only further emphasizes this, and has resulted in the study of gender and star persona becaming a central feature of the analysis of the original A Chinese Ghost Story. Cheung was a star of Hong Kong New Wave and Second Wave cinema and a pop icon until his suicide in 2003, and he has been the subject of intense 
scholarly attention for his exploration of gender representation in his films, most notably Farewell My Concubine (1993), He's a Woman, She's a Man (1994), and Happy Together (1997). These films, with their overt blurring of gender lines and homosexual themes have been associated with Cheung's acknowledged bisexuality, ${ }^{3}$ though Cheung in fact played a diverse array of roles in his sixty-movie career, from policeman to scholar to Peking Opera performer, which multiplied and complicated interpretations of him as an individual both on and off the screen. Analysis of Cheung's films is therefore almost always connected with his personal life and his image as celebrity; how he had lived many of the experiences of the characters he played, particularly in relation to his sexuality. Cheung's ability to rewrite the definitions of masculinity and femininity through his cinematic performances as well as his music career is seen as being one of his defining contributions to the Hong Kong arts.

Descriptions of Cheung in reference to this perceived ambiguous sexuality abound, often emphasising the queer aspect of his performances:

Leslie begins the concert with the monkey-suit section of the evening: Canto-pop crooning. All around, multi-generational families from the 8o-year-old grandmother to the toddler are swaying and stick-waving. Lulled, we are sucker-punched by what is to follow. Lights dim. A figure shadows stage-front and lies down, head pointed towards the ceiling. A single spotlight. Disembodied shoes. Red, bejewelled, high-heeled, sexy, Dorothy-in-the-Wizard-of-Oz-all-grown-up shoes. Leslie's shoes. One normally doesn't use the phrase "collective intake of breath", but let's reserve it for this moment. Leslie proceeds to enjoy some very explicit dancing with a bevy of beautiful boys, displaying remarkable enthusiasm for a man who is not Out, performing in front of a Family Crowd.

BIRD, 2003

Natalia Chan discusses Cheung in her chapter "Queering Body and Sexuality: Leslie Cheung's Gender Representation in Hong Kong Popular Culture" (2010), explaining that his androgyny enabled him to play "feminine masculinity and masculine femininity" and thus created a space where bisexuality could be

3 For detailed discussions of Cheung's career, see, for example, Firelight of a different colour: The Life and Times of Leslie Cheung Kwok-Wing (Collett, 2014), "Queering Chineseness: The queer sphere of feelings in Farewell My Concubine and Green Snake" (Hsu, 2012), "A star is dead, a legend is born: Practicing Leslie Cheung's posthumous fandom" (Y. Wang, 2007), and Helen Hok-Sze Leung's chapter “In Queer Memory: Leslie Cheung (1956-2003)" (Leung, 2008). 
performed. Cheng's acting thus signified a "certain kind of doubleness. $\mathrm{S} / \mathrm{he}$ is the woman who sacrifices him/herself for the King onstage, and at the same time, he is also the man who adores Xiaolou off-stage. Acting a man within a woman, or a woman within a man, Cheung is both Dieyi and the concubine in the androgynous sense"4 (Chan 2010, p. 136). Chan argues that Cheung represented a form of "camp androgyny in which the most refined form of sexual attractiveness consisted of going against the grain of one's own sexuality", and Cheung became an icon of style, prosperity and popular culture in a way which was unprecedented in Hong Kong cinematic history. Chan argues that Cheung's drag performances were good illustrations of Judith Butler's central argument that gender is "culturally and socially constructed, and ready for any kind of disruption, interruption and intervention ... gender is transient, creative and symbolic"(Chan 2010, p. 143).

The contested sexuality of Leslie Cheung is a strong element of the original Chinese Ghost Story film. It is difficult to ignore the symbolism in an early scene when Ning Caichen is caught standing, terrified, between the sharp ends of the opposing swords of two men; or his lack of immediate sexual drive towards the female lead ghost, who has otherwise been seducing men with ease. How Leslie Cheung represented sexuality has thus become inextricably linked with the film's representations of gender, and this raises interesting questions regarding how the 2011 remake of $A$ Chinese Ghost Story might re-present the same story, minus this iconic figure.

Remaking Gender through Ning Caichen, the Fragile Scholar The male lead protagonist Ning Caichen is strongly connected to the romantic scholar figure, the caizi, who appears in Chinese literature and film (McMahon, 1995). This character is feminised "in his fragile, pale-faced appearance, and his overly-emotional personality" (Chen, 2011, p. 78), and links with the scholarly man of mid-seventeenth century literature whose virtue and passiveness are represented as their most endearing qualities. He is the character who usually has the love affair with the beautiful girl, that often ends in tragedy (Chow, 1991) — as we see in Caichen's case, where he is separated from Xiaoqian by death.

Before we even arrive at the remake, in the conversion of the original text Strange Tales from a Chinese Studio into Ching Siu-tung's 1987 film, there has already been a major shift in the interpretation of masculine and social norms. What the original text represents is, in fact, a polygamous relationship. Ning

4 (Cheng) Dieyi is the male stage name of Leslie Cheung's character, while the concubine is one of his female roles. 
Caichen is an honourable, righteous man, who is already married when he meets Xiaoqian. While the story is still concerned with Ning releasing Xiaoqian from the grip of a demon who forces her to seduce men, in the story, after he finally retrieves her ashes, Xiaoqian neither dies nor becomes human; she remains a ghost. In this form, she offers herself as a live-in maid to Ning's mother. After earning the respect of this woman, she is finally permitted to become Ning's second wife, and she dutifully bears him a son, one of three he sires in total.

Instead of a duality represented by polygamy, Ching Siu-tung's film changes the focus to insert Leslie Cheung's bisexuality, which in turn emphasises the homosexual possibilities of Ning Caichen's character. This is particularly visible in the complex application of the gaze to his character which is described in further detail later in this chapter. Cheung's Hong Kong film thus enacts a change in orientation towards gender and sexuality, drawing on a time when the female/male heterosexual relationship was not as influential as class and power bonds between men (Song, 2004). Cheung's interpretation of Ning's ambiguous sexuality is therefore much more aligned with these later, premodern notions of Chinese masculinity and sexuality, where gender was not necessarily divided along binaries of heterosexuality or homosexuality, but instead by class and power structures. Bisexuality was not necessarily considered a threat to Confucian values during this period in history, as long as it did not compromise these established power hierarchies or prevent the male from producing children with a woman (Song, 2004). Cheung's portrayal of Ning Caichen was thus subversive in its deployment of this historical interpretation of gender as opposed to his own era's homophobic discourse.

Ning Caichen's character in the 2011 remake of $A$ Chinese Ghost Story now reflects a dichotomy which now exists in contemporary Chinese cinema between the masculine and feminine, particularly in regards to sexuality and sexual monogamy. In the remake, the emphasis has been placed on different dimensions of the caizi-his innocence and virtue, and unlike Leslie Cheung's representation, he is not sexualised. Physically, he resembles a boy rather than a fully grown man, with his small body and youthful face. He is noticeably terrified by the rampant sexuality demonstrated by Xiaoqian, cowering away from her advances, evident in his first meeting with Xiaoqian at the temple. In a long sequence, Ning's sexual inexperience is contrasted with Xiaoqian's emotional inexperience-while he has never known physicality with a woman, she has never known emotional connection (that she can remember). As a result, when she touches him, he asks her, with a mix of fear and indignation, what she thinks she is doing. Thinking he is playing games with her, she responds "I am doing what you men all like to do". She tries to undress him, 
but he protests; "Miss, you can't do this!" She responds: "I was also told to be welcoming towards guests. You don't like me?" "I have never done this before/I have no experience", he replies. "Saying you have had no experience is not the same as saying you don't like it. You will like it". She tries again to tear off his clothes, but he refuses her again. During this interaction, Xiaoqian is controlling the position of Caichen's body-first she is on top of him before she then pulls him down on top of her. Caichen however, controls the moral direction of the interaction, showing Xiaoqian that she is behaving immorally and also that there are honourable men who will refuse to treat her as merely an object of pleasure. Xiaoqian is thus put on the path to redemption by Caichen, who shows her that she is worth more than what she thinks. The homosexuality, bisexuality and polygamy of the original texts have been erased, in favour of a focus on Caichen's "good heart", clean morals, and pure love.

\section{Yan, the Daoist Warrior in Love}

Like in many traditional Chinese caizi tales, there is almost always a secondary male character who complements the masculinity demonstrated by the lead protagonist (Song, 2004). The character of Yan in the 1987 film offers the viewer this alternative version of traditional masculinity; he is the $w u$ to Caichen's wen (Louie, 2002, 2014). He is portrayed as a model Daoist warrior, and his ability to destroy malevolent ghosts is contingent on the channeling of his masculine yang energy towards this task. Like the great warriors of the past, he practices celibacy; he instead trains his body to be disciplined and skilled in the martial arts and swordsmanship (Boretz, 2011; Song, 2004). This is why the original Yan had no sexual interest in Xiaoqian-his task was instead to eliminate her, as she represented the threatening forces of yin, "that which is shadowy, insubstantial, female" (Boretz, 2011, p. 10) - her womanly charms were lost on him. In the film, he also make ritual sacrifices and chants incantations to purify that which has become polluted - if he is successful in his training, he transcends the base instincts of humanity, to become an instrument, a weapon, against evil cosmic forces (Boretz, 2011).

The 2011 remake of A Chinese Ghost Story completely rewrites the masculinity of the character of Yan for contemporary audiences. From the very first scene when he is chasing Xiaoqian through the forest and her clothes come away accidentally, Yan deviates markedly from the model Daoist warrior that we see in the source film. His desiring gaze shows a re-orientation of his role to become the ill-fated first love of Xiaoqian. As a consequence, narratively speaking his purpose for remaining in the forest is vastly different from the spiritual quest his original character is engaged in. Haunted by her presence in the shadows of the forest, Yan is the only one of the pair who can remember 
their love, and the only one to feel jealousy when Ning appears to compete with him. The significance of the change to the structure and purpose of the narrative cannot be underestimated; to begin with, a relationship that never existed between Yan and Xiaoqian in the original film has been created for the purposes of the remake.

This change necessitates other alterations in the narrative, significantly that of the relationship between Ning Caichen and Yan. While described earlier as one of homosocial/homosexual bonds, this dynamic is completely transformed by the Yan/Xiaoqian dilemma into one which is primarily concerned with heterosexual competition rather than companionship or cooperation. A narrative shift has occurred, transforming what was essentially in the original film a story about pairs (two lovers, two male companions with homosexual undertones, and perhaps two enemies in Yan versus the Tree Demon), into a love triangle story. Yan's new character thus violates the code which dictates he should not fall in love, and as a consequence, he also abandons the ideal of subordinating heterosexual love to homosocial brotherhood (Boretz, 2011; Song, 2004), spending his time chasing Xiaoqian when his fellow warriors are in need. One of the men dies as a result of his absence. At the end of the film, Yan sacrifices himself to defeat the Tree Demon, but his reasons for this are ambiguous-is he making the blood sacrifice required, is he redeeming himself for his earlier failings, is he dying to save his brothers in arms, or is he committing suicide because he can't be with Xiaoqian?

Yan's character appears to have been reimagined to connect with a contemporary cinematic trend of masculinity. The new Yan falls in love, cries, and is wracked with indecision at crucial moments. However, he is also definitively masculine, as his muscular physique demonstrates. This combination of characteristics appears to connect him with other male warriors who have been "feminized" in mainstream contemporary Chinese cinema, where the male functions both as an erotic object for the female character/spectator, while simultaneously catering to the female desire for romantic male lovers. Yunxiang Chen highlights another example in the case of a Buddhist monk, Sanzang (三藏), in A Chinese Tall Story (2005), who changes from invoking the traditional "pious monk devoid of all secular desires to a passionate lover" for the female protagonist (Chen, 2011, p. 129). This transformation is achieved through the depiction of the "male body as spectacle and the manifestation of feminine characteristics in the male warrior" (Chen, 2011, p. i).

To reinforce this shift in masculinity in A Chinese Ghost Story, an entirely new character has been introduced in the remake in the form of Feng Xue, who is, by comparison, far closer to the traditional representation of the male warrior. He is a hardened fighter, to the extent that he actually cuts off his own arm 
to increase the chance of defeating the Tree Demon early in the film. In the final battle scene, we see Feng Xue shirtless, flexing his muscles, with Daoist incantations literally carved into his body in the form of tattoos. Yan's masculinity is thus constructed through his contrasting personality traits and less extreme physicality, making him an appealing potential romantic interest and placing him on the more obtainable end of the scale of masculinity than he was in his previous moral, celibate monk form.

\section{The Monstrous-Feminine and Dangerous Female Sexuality}

While all of these changes have been occurring in masculine representation in the remake, a discussion of sexuality and gender in A Chinese Ghost Story is not complete without consideration of the two female protagonists who feature in this pair of films, beginning with the film's villain, the Tree Demon, who provides perhaps the most overt expression of sexuality within the films through its connection to the monstrous-feminine.

In the original Chinese Ghost Story film, the audience sees the manifestation of the monstrous feminine in both the Tree Demon and Xiaoqian through their roles as the villains consuming male energy. All cultures have expressions of the monstrous-feminine; she can appear in many forms, including "vampire, witch, female monster, beautiful but dangerous woman, or aged psychopath" (Creed, 1993, p. 1). Her power is rooted in the fear of castration that she provokes in the male character and spectator (Creed, 1993, 2002). In the specific context of the horror film, the horrific or monstrous aspect of the feminine is also connected with the fear of the abject, that which does not "respect borders, positions, rules and disturbs identity, system, and order" (Kristeva, 1982 p. 4). The figure of the Tree Demon is the overseer of the Lan Ruo Si temple, and Xiaoqian and the other young spirits seek out male life energy to feed it. It is also Yan's nemesis. Though we are made aware of its existence by the other characters, at first we only hear it speaking to Yan, its disembodied voice alternating between masculine and feminine registers. According to Sheng-mei Ma, this vocal technique "is often deployed to render transvestite or impersonator as a misshapen and grotesque spectacle" (Ma, 2010, p. 43). The Tree Demon does not physically reveal itself until forty minutes into the film, at which point we see that it is clearly a man dressed as a woman. While cross-dressing is not a new phenomenon in China, dating back to Chinese operatic tradition where men would play female and male roles, the Tree Demon's character subverts this convention through his obvious maleness. Whereas in Beijing Opera the male features would be concealed by make-up, make-up is instead used on the Tree Demon figure to emphasise the fact that the actor is male. ${ }^{5}$

5 See Chapter 5 for more discussion of the role of make-up in operatic performance. 
In a Butlerian sense, this form of cross-dressing, where both male and female attributes are present, works to subvert the formation of strict gender boundaries. ${ }^{6}$ This gender questioning is underpinned by the apparent bisexuality of the Tree Demon character-its sexual orientation throughout the film is unclear; while we know that it consumes virile men, we get no indication that its sexual interest is limited to these men. The additional inclusion of the Tree Demon's tongue as a weapon, simultaneously resembling a phallus, but under the control of a male-female, further destabilises the relationship posited by Freud between male/phallus and female/castrated. The Tree Demon's tongue is an effective device to convey the monstrous, as it invokes the fear of castration by dripping and spraying liquid all over the male characters during battle, before penetrating their bodies to kill them. In one instance, the camera acts like the tongue, entering the wide open mouth of the dying man-we see his internal organs and blood vessels contracting - before emerging to see his body being sucked dry from the inside. Interestingly though, the fluid which the tongue is associated with later in the film also closely resembles semen (Yue, 2000). Audrey Yue therefore argues that this tongue also resembles the act of sodomy in the way it penetrates the male body (Yue, 2000, p. 371). Thus, this tongue serves a dual function, connecting the character with "temptress women who threaten to disperse semen, the source of male power" (Ma, 2010, p. 41) as well as a masculine sexual penetration which reinforces the bisexual aspect of this character (Yue, 2000, p. 371).

By contrast, the gender ambiguity of Tree Demon's characterisation is less pronounced in the 2011 remake. The same character remade is clearly a female actress playing a woman, making her character immediately less confronting to gender binaries than the original figure. She is given the name Laolao (姥姥), meaning grandmother, which not only identifies her as being purely female, but also positions her in a maternal role. Furthermore, her sexually charged reaction when she consumes male energy indicates a more heterosexual orientation - though some of her sexual energy is also displaced onto the female body in a scene where she whips Xiaoqian as punishment for being disloyal. The remake brings forth another expression of the monstrous-feminine in its reference to the Western mythological figure of Medusa (Creed, 1993), whereby the most dangerous part of this Tree Demon is her hair. While the use of CGI enhances the terribleness of Laolao's long, flowing hair, it also seems to have enhanced the character's femininity. So although it is still deadly, this hair seems to be a less potent symbol than in the Medusa figure, and it does not appear to bring forth the same threat to the male sexual identity as the original Tree Demon's tongue and cross-dressing. Feng Xue loses his arm in an

6 See Chapter 2 for further description of Butler's theory. 
early battle because he is attacked by her, but it is in fact his decision to ask Yan to cut off his arm; it is not severed by the Tree Demon in a symbolic act of castration or emasculation. In the Tree Demon character, we can therefore perhaps see two different approaches to the monstrous-feminine- the first film employs this concept with an emphasis on gender ambiguity, while the second emphasises the facets of her characterisation which make her figure less disruptive to stable gender roles than the original film's penetrating, crossdressing Tree Demon.

\section{Looking and Being Looked at - the Gaze within A Chinese Ghost Story}

The Tree Demon's two different expressions of sexuality tie in with broader differences in how the source film and its remake construct sexual identities for their protagonists. These expressions can also be analysed in terms of how the characters are 'looked upon' or positioned by the camera within the film's actual frames, referred to as 'the gaze'. In her analysis of 193os and 1940s Hollywood film, Laura Mulvey found the way women were framed often reflected a form of scopophilia, whereby women were eroticised and/or objectified by camera angles and shots which emphasised the masculine viewpoint. Through this method, women became the passive objects of the male's active gaze, and were thus denied their own subjectivity. While Mulvey's work has since been criticised for its limited applicability within different cultural boundaries and lack of ability to incorporate lesbian/homosexual spectators, subsequent research has nuanced and adapted Mulvey's initial argument to incorporate instances where the gaze might not be considered strictly masculine, including in relation to films by female directors (Flitterman-Lewis, 1990; Modleski, 1999; Vanderstaay, 2010), different genres and different audience genders and sexual orientations (Clover, 1987, 1992; Hollinger, 1998).

In applying the gaze to Chinese-language films, Chris Berry and Mary Farquhar's work has shown how women in Chinese cinema can be the object of the gaze while still demonstrating a form of agency. They note "the divergence from Mulvey's model within the literature on gender in Chinese cinema, which highlights the libidinal gaze as present but not dominant" (2006, p. 111). They also raise another function for the gaze, particularly in revolutionary and Cultural Revolution period cinema, whereby the camera positions the counter-revolutionary or feudal forces as feminine and passive, while affording agency and the active gaze to the positive revolutionary/Communist forces. On the other hand, the gaze has also been associated with an increasing level of sexualisation of women in certain genres of contemporary Chinese-language 
films, by scholars such as Louise Edwards and Dai Jinhua (Dai, 2002; Edwards, 2010). Yunxiang Chen's work further complicates the gaze through its consideration of the relationship between the gaze, the spectator, power and pleasure. She argues that the gaze is not strictly masculine nor is it always synonymous with a position of power, particularly in the case of the male as he appears in contemporary Chinese cinematic expressions (Chen, 2011). Given the variety of perspectives within the literature on the role of the gaze, it is significant to consider in the case of A Chinese Ghost Story how the source film and remake might express this concept.

As discussed briefly earlier in this chapter, in the opening scene of the film, Xiaoqian calls forth the Tree Demon to kill a scholar. This scene features a number of different camera angles, which combine to create a balanced view of the action on-screen. We look down on the scholar in his room, and then switch to what appears to be a first-person view from Xiaoqian's perspective, as she approaches the door and comes in with the wind. Then, a medium shot where we see the full figure of Xiaoqian dancing is followed by a close shot of her hands, before a shot of the man being lured towards her and knocking over his lantern into a bucket of water. The following close-up of Xiaoqian's face and her hand putting the man's hand into her robe cuts away to a medium shot of Xiaoqian on top of the man, flicking her hair and pinning him down.

At the last moment his pleasure turns to fear as the camera changes to the perspective of the unknown force (which we later find out is the Tree Demon) as it lunges forth to kill him. While the scholar is being murdered, we see Xiaoqian looking on, her face devoid of expression. From gazing upon her face, it is clear that she derives no personal pleasure from the act- she is just unable to put up any opposition to what is happening. So while she might be the instigator of this murder, she is not a murderer. Consistent with the findings of Berry and Farquhar and others, the gaze in this scene is not categorically masculine. There are sequences where the female perspective and the camera's view are one and the same, as well as third-person angles where both characters are equally gazed upon. There is also the perspective of the Tree Demon in the final shots of the sequence. Each time we see Xiaoqian with another victim, she is more eroticised, more brazen, and more remorseful over the death. As she watches the second man die, we understand that this creature coming out of the forest is literally sucking the life from its victims. Xiaoqian stands nearby in the forest, shedding tears. At the scene of this death, Xiaoqian tries to flee from the scene before the Tree Demon arrives, but something within her compels her to stay and watch events unfold. Despite the fact that she is only acting on the will of the Tree Demon and that Xiaoqian knows what will 
happen next, she is compelled to bear witness to the consequences of her deviant sexuality. We, as the audience, also see that she is capable of remorse, making her character somehow more redeemable.

In a later scene, the naïve Caichen is captivated by the beauty of Xiaoqian, and his innocence is compromised through the acts of looking and being looked at. This occurs in a beautifully choreographed scene where Xiaoqian must hide Caichen in a bathtub from her sisters and the Tree Demon. About to drown, Caichen comes up for air just as Xiaoqian takes off her clothes to bathe, and the two look at each other, mortified. Surrounded by the other women, Xiaoqian is powerless to stop him looking, and he is caught between where his gaze falls and where he knows he should look. As the women approach, Xiaoqian throws off her top and pushes Caichen under the water, giving him a breath of air as she simultaneously plunges her torso into the water. They look at each other underwater, lips locked, and there seems to be an awakening in Caichen. The awkward situation is made worse after the sisters and Tree Demon depart, when one of the sisters who is suspicious, returns without warning, and Xiaoqian must undress and climb into the bath on top of Caichen to conceal him. We see him underwater, eyes wide. After the threat has gone, Caichen surfaces and says “I won't look at you, put your clothes on". The futility of that sentiment is written on both their faces as they stand back-to-back, too embarrassed to say anything else, before the need for Caichen to escape takes over.

The complicated nature of the gaze is brought to the fore in this sequence of events. Initially, it seems that the gaze in this instance is quite clearly masculine - the young Xiaoqian is effectively cornered by the camera in her efforts to protect Caichen. She is surrounded by the Tree Demon and her sisters, forcing her to strip off her clothes, and expose herself in a humiliating fashion, first by exposing her bare breasts underwater and then by climbing naked into the bath on top of him. This appears to be the controlling, voyeuristic aspect of the gaze in action. However, the straightforward depiction of woman as sexual object is subverted through the obvious discomfort of both the main characters, which complicates the pleasurable or voyeuristic elements of the scene. This discomfort connects both with Caichen's sexual innocence as well as his disputed heterosexuality, as his awkwardness could be symptomatic of either or both aspects of his character. It also is heightened by Xiaoqian's embarrassment, which is also conveyed in her eyes, as she desperately looks around, and at Caichen, looking for a way to escape. In crucial moments of the scene, the film cuts from a shot of Caichen's face, to Xiaoqian's, both with wide eyes in panic and shock. 
This scene illuminates the reliance of the gaze on inherent ideas of power and pleasure. As Yunxiang Chen states, the pleasure of the gaze may not only be located in the act of looking, but also may be derived from being looked at, from being the object that is pursued, rather than the pursuer (Chen, 2011). This conceptualisation seems to strongly correlate with the way the gaze functions between Caichen and Xiaoqian in this scene. In this case, neither of them derive pleasure from the interaction, despite the opportunity for sexual gratification and objectification. There are other examples of this throughout the film, such as Xiaoqian and Caichen's interaction at the river pavilion, where Xiaoqian's attempts to seduce him are lost on the naïve man, who clumsily keeps falling into the river, literally pouring cold water on any potential fire between them. The audience therefore has their pleasure subverted, or perhaps diverted, by the humour of the scene and the reaction of the lead characters to each other.

\section{The Gaze Remade}

In the case of the 2011 remake, the gaze is deployed differently to the original film. Masculine subjects are the focus of the female gaze, as argued by Chen (2011), but this does not necessarily equate with the film becoming more gender neutral. As described earlier, the lead male protagonist Yan has adopted more traditionally feminine personality traits, and this is reflected in how he is framed by the camera. There are more close-ups shots which linger on his face in the remake than in the original film. There is an attempt to portray his feelings through his facial expressions; his pain, specifically, which was simply absent in the original film due to the non-existence of the relationship between him and Xiaoqian. This feminisation of his character may be reflective of a change in his characterisation to appeal to a female audience, who are looking for a sensitive, "New Age" man. But, the camera does not sexualise him - on a personality level, he is made weak by his love for Xiaoqian, yet his body does not become the subject of the gaze in any significant way.

Nevertheless, there is a power imbalance between Yan and Xiaoqian, which reflects a greater issue of the complex relationship between gazer and recipient of the gaze. Their very first interaction, where he pursues her through the forest, is perhaps the most powerful demonstration of the power/pleasure dichotomy. Xiaoqian, after being stripped of her dress, holds Yan's gaze, and when she turns to leave, there is a flicker of victory in her eyes. After all, her task is to seduce men, and the first step in this process is to get them to look at her. When we first see Xiaoqian kill someone in the remake, we see this happen through the eyes of the character Yan. Instead of looking remorseful, 
Xiaoqian's facial expression is one of defiance, as if challenging him to accept the reality of who/what she is. This is despite the fact that her behaviour in acting on behalf of the demon is more aggressive, and less remorseful than her original film counterpart- there are no more tears over the deaths of her victims. In the remake, Xiaoqian is directly responsible for the deaths of men, rather than calling on the Tree Demon to commit the murders.

This is not to argue that Xiaoqian in the original film is not a sexualised character. In the source film, Xiaoqian uses erotic, playful behaviour and tricks such as dancing, bathing in the river alone, and acting cold or injured, to seduce men. She represents the dangerous female sexuality associated with the monstrous-feminine. When she is onscreen, we often hear soothing female singing, and thus she calls to mind the western Siren who lures men to their deaths. By contrast, Xiaoqian is, in a sense, made more innocent in the remake, as we see in the opening scenes where she is distracted from killing Yan by his bag of lollies. However, this approach also serves to create a more extreme binary between her characterisation and the female characters around her, who are much more overtly sexualised than any women featured in the source film. This shift in who possesses the active gaze is also consistent with the introduction of much more direct sexualisation of women in some genres of Chinese-language cinema, as identified by scholars such as Dai Jinhua and Louise Edwards (Dai, 2002; Edwards, 2010).

In the remake, this increased sexualisation is perhaps best demonstrated through the use of the gaze as it applies in the scene where Ning and his band of men first arrive in the temple. The men are lured away by women (demons/ ghosts) who resemble prostitutes, with heavy make-up, jewellery, and off-theshoulder brightly coloured dresses. The chains around the men's ankles are markers of their enslavement to their own desires. In the haze of smoke and silk, the men are consumed by the women, who appear and disappear at will. The viewer observes this action as if they were one of the men, and the women are framed in medium shots, seductively peeking out from behind silk curtains before pinning the men down to kiss and suck the life out of them. Through the use of the camera, the viewer is encouraged to experience first the desire and anticipation felt by the men, followed by the terrible outcome.

There is no scene that correlates with the one just described in the original film. The number of women in the remake has multiplied considerably along with their vulgarity, and a later scene featuring Xiaoqian and two female ghosts, one wearing a low-cut top which clearly draws attention to her breasts, further makes this point. This costuming creates a contrast between the lead female, who allegedly is more victim than perpetrator, and those "Other" women. That is, those others who find killing not a duty, but a pleasure. This element of 
pleasure is emphasised by the Tree Demon herself, who sits under the temple, laughing and making sounds similar to orgasm while the men are being killed and their energy absorbed.

If we consider the films from a feminist film theory perspective, reading 'woman' in either of the films is difficult, given that 'woman' in A Chinese Ghost Story literally does not exist. By very definition, as a ghost in limbo, she is neither living nor dead. She is instead a fantasy enacted by different groups of men; the criminal, the warrior, the scholar. Her image is constructed out of the desires of men, whether that is to see a lover, an innocent girl in need of rescue, or a killer. The pursuit of Xiaoqian might be the subject of the film, but she is the object to be captured or killed. In the original film, the disappearing painting of Xiaoqian early in the narrative points to the impermanence of the image of woman. The opening scene of the remake, where Yan chases Xiaoqian through the forest and accidentally tears off her dress, echoes the symbolic representation of woman which Teresa De Lauretis describes in her feminist work Alice Doesn't (1984). De Lauretis uses Italo Calvino's book Invisible Cities, in particular, its reference to the city of Zobeide, where a group of men see a woman running naked through the streets of the town, to describe the absence of woman. The men build walls and alleyways, wishing to trap this womanhowever, the dream of each individual man differs, and so they are never able to contain her within the walls they build. The city, and the story, comes to be about her, not for or by her. Similarly, Xiaoqian is built on an image of woman, and her ghostly nature doubly articulates her non-existence.

\section{Forgetting History}

Further adding to the notion of Xiaoqian's non-existence or incompleteness is the introduction of the idea of Xiaoqian's memory loss, which does not feature in the original film. Hidden in the subtext of the relationship between Yan and Xiaoqian, there is also a key to understanding the broader implications for the changes between the two versions of $A$ Chinese Ghost Story. As the remake significantly re-orients the narrative through the writing in of their past relationship, it also re-writes time, memory and history.

Of course, this amnesia serves the function of heightening the film's tension and melodrama, as at one stage or another, it is the source of much pain and suffering for all three lead characters. It also means that in A Chinese Ghost Story (2011), the audience relies on the memories of Yan in particular to fill in vital information at the start of the film, and thus his act of remembering directs us through "something that would otherwise be un-representable; the elusive 
issues of guilt and motivation" (Fluck, 2003, p. 220). However, the significance of memory in the remake goes beyond a simple plot device. Xiaoqian's memory loss draws attention to the subjectivity of memory; while the audience has access to all of the information; the characters within the diegesis do not.

Crucial to Xiaoqian's character in the remake is the fact that Yan has robbed her of some of her memories; in particular, memories of their relationship. Xiaoqian in fact asked to be killed by him, since they cannot be together; but he is unable to do this, so instead, he wipes Xiaoqian's memories of them. There is a connection thus created between memory of the past, and suffering. As Yan articulates, “You won't suffer anymore, because you won't remember me". Xiaoqian therefore operates in the film with an incomplete understanding of her past, which in turn influences how her present and future can unfold. She is also unaware that she is missing these pieces of her history.

Thus the endings of the film are also quite markedly different, and heavily laden with symbolism. In the original film, Xiaoqian is freed from her servitude by Caichen and Yan, both men survive, and ride off together under a rainbow. The remake alters this ending, incorporating two secondary characters to assist, and re-ordering the narrative such that Yan, in order to free Xiaoqian, must sacrifice himself. In a battle to the death inside the temple, Xiaoqian's spirit is absorbed by the Tree Demon. In order to obtain her freedom, Yan and his warrior companion Feng Xue use Daoist magic to push Xiaoqian out of the Tree Demon's body. Yan then substitutes himself for her and fights the Tree Demon from the inside. We see the image of Yan interchange with that of the demon as he struggles to overpower her. With great difficulty, Yan pulls the magical dagger out of Xiaoqian's head. Only then is Xiaoqian restored to her whole self, as Yan removes the dagger from her head and unblocks the flow of memory. As Xiaoqian is distracted by the pain of her memories being restored, Yan uses this dagger to stab himself, also killing the Tree Demon.

What is the significance of this different ending to the remake? More specifically, why does Yan actually have to die? If he, as the Daoist warrior, serves as a medium between the realm of what should be "dead and buried" and what lives today (Teo, 1997), he could be symbolic of the fallen, transgressive, impure masculine ideal redeemed through taking out the monstrous-feminine in death. This is one potential interpretation, but his actions may also be symbolic of China's difficult relationship with its past. While in the original film he personifies Hong Kong's particular concerns about the impending take-over, as he is threatened by an omnipresent force, in the remake he is transformed into a martyr who, through the merging of his identity with another, is able to defeat the "evil" forces. If we read this ending as allegory for the negotiation and re-negotiation of the Chinese identity, the multiple subject positions 
from which the audience views the events (Xiaoqian, Ning Caichen, the Tree Demon, Yan and the two secondary characters) only serves to strengthen the idea that the Chinese and Hong Kong identities are no longer distinct entities but are instead one united front against a common "enemy". That everyone has to work together to kill off the Tree Demon, in particular, Ning Caichen and Yan, could be read as allegory for "one country, two systems" working together.

\section{Reflections: The 'State' of Hong Kong and Chinese Cinemas}

In a cinematic context, joining with a mainland Chinese company to create this remake, Hong Kong film-makers gain access the mainland Chinese market, but not without the plot becoming subject to the rules of censorship in China. Making a remake for the mainstream Chinese audience to enjoy has resulted in the expression of different forms of gender and sexuality than what was seen in the original movie. Interestingly, the remade film features a dedication to Leslie Cheung in the final credits, even though the remake as discussed is very far from the "queer" original, in its stricter interpretation of gender archetypes found in the wuxia genre. Outside the cinematic sphere, LG BTIQ rights in Hong Kong have not progressed significantly since it was returned to China: according to Yau Ching, the union that has emerged between "faith-based organisations, mega-churches and government bureaucracies, who have taken an activist approach to re-instating Chinese moralism post-1997 ... has resulted in non-normative sexual subjects being brought centre stage and often stigmatised together due to their 'abnormal/shameful' gender identities, object choices and/or sexual practices" (C. Yau, 2010, p. 1). The differences between the original and remade versions of $A$ Chinese Ghost Story reflect an emphasis on a more conservative interpretation of gender and sexuality.

While the original Hong Kong film allegedly existed in a space that resisted the colonialist and cultural boundaries placed upon it by the British and the Chinese, in the process of "straightening out" the original film, the remake undoes some of the subversive work of the source film, re-introducing a form of cultural authenticity to the conversation. Gender, as already discussed, as well as genre, play a crucial role in this, and Bliss Cua Lim's temporal critique of the fantasy genre in Asian cinema and literature in her work "Translating Time" (2009) gives some further insight into how this might have occurred. Lim discusses how the fantasy genre, through its themes, editing and style, has a propensity to undermine the hegemonic concept of time which historically has been used to exercise social, political and economic control through 
its emphasis on a "linear, developmental notion of progress" (B. C. Lim, 2009, p. 12). This notion of progress is fundamental to imperialist-colonist discourse, whereby colonised peoples were displaced to a time-space which rendered them primitive and outside of history, in contrast to the modern present coloniser. In this discourse, "heterogeneity is translated into homogeneity in order to govern unsettling, radical differences" (B. C. Lim, 2009, pp. 18-19).The fantasy genre, by contrast, often presents the past and present in co-existence, particularly through the resurrection of spirits and supernatural practices, and thus as a genre it can be seen to perform an important function in disrupting the natural, universal and stable nature of time and history. We can see evidence of this in the schizophrenic genre, narrative and camerawork of the 1987 Chinese Ghost Story film. This is less evident in the remake's comparatively linear interpretation of the narrative.

However, while Lim argues that the supernatural elements in fantasy films "insinuate the limits of disenchantment" (B. C. Lim, 2009, p. 26), in the case of A Chinese Ghost Story, the potentially disruptive nature of the fantasy has also been muted by the re-release of the original film in the same year as the premiere of the remake. Linking the two films in this way draws attention to the "progress" made in the last thirty years in Chinese cinema, particularly economically, in terms of budgets, and technologically, in terms of the use of CGI. With its sophisticated and elegant aesthetics, the remake makes the original film resemble "low art". By drawing attention to their common origins in traditional Chinese stories, it could be argued that the remake positions itself as the authoritative and faithful version, and subsequently also positions the 1987 film as a kind of perverted interpretation. The remake could be thus read as presenting a kind of a return to "authentic" Chinese culture, while the original film was a kind of aberration which was produced by a cinema under the influence of colonial rule and ideology.

The contrast between the at times incomprehensible visuals of the original film and the streamlined aesthetics of the remake in some ways mirror the process of disenchantment described by Lim, whereby "modern China" has moved beyond the belief in the superstitious, towards a form of economic rationalism which delivers symbols of ghosts and monsters to "culturally disparaged audiences" for financial gain (B. C. Lim, 2009, p. 24). Ironically, by re-releasing the original film prior to the remake's premiere, the remake appears to position the original Hong Kong creation as the production of a "pre-modern" society in a linear historiography of the story of China's progress, effectively re-imposing a colonised/coloniser relationship between these two regions. 
The remake thus also reflects upon some of the broader changes which have occurred in the cinematic industries in China and Hong Kong since the handover in 1997. The signing of the Mainland and Hong Kong Closer Economic Partnership Arrangement in 2004, which gives incentives to Hong Kong directors and talent to work with mainland Chinese companies, has resulted in a strong increase in the number of these productions. In the race to produce blockbuster movies and ride the wave of the commercialisation of cinema, which creates increasingly murky waters as to what constitutes 'an authentic Hong Kong film', locating the 'Hong Kong identity' has become an increasingly challenging task (H. Li, 2015).

In A Chinese Ghost Story (2011), Xiaoqian's diminished memory, and the impact this has on her identity and history, is perhaps as close as the remake comes to acknowledging the specific history of the trauma in Hong Kong's past, in the way it draws parallels with Freud's work. In diagnosing psychic trauma, Freud identified internal (conflict in sexuality) or external factors (war) that could cause the psyche to become overwhelmed. These traumas often manifest in neuroses, including the compulsive repetition of the traumatic experience in dreams and fantasies (De Lauretis, 2008). These repetitive patterns both speak to the original film's generic mixing, as well as mirroring the processes of remaking a film, but what is different between the two approaches is that while the source film revels in its disorientating style, the remake must reconcile these discrepancies. The trauma inflicted on Xiaoqian is "cured" by the actions of Yan Zhixia, almost as if the wounds of Hong Kong's past can similarly somehow be healed.

This neat conclusion only seems to serve the purpose of reinforcing the theme of unification/reunification already present in the remake of $A$ Chinese Ghost Story and further precludes any emphasis on regional identity, seamlessly streamlining the Hong Kong and Chinese identities into one. This remake thus seems be of the same category as some other mainland/Hong Kong cinematic collaborations such as The Founding of a Republic (2009) and Beginning of the Great Revival (2011), where scholars have identified a form of cinematic hegemony at work, with the cinematic style emphasising a grand, unifying narrative $(\mathrm{H} . \mathrm{Li}, 2015)$ that connects with a nation-building agenda rooted in the conservative approaches of "denying difference and blocking change" (Berry, 1994, p. 49). This issue has not previously been addressed in remakes studies due to the greater attention given to Hollywood remaking practices and associated arguments of Western cultural imperialism.

Through the comparative analysis of gender representations and expressions of sexuality between A Chinese Ghost Story and its remake, the chapter 
demonstrates how a remake might stand as a form of political allegory for the symbiotic yet competitive relationship between the two cinemas and regions of Hong Kong and mainland China. The following chapter will discuss political allegory in an alternative form, through the analysis of another pair of intracultural remakes, Spring in a Small Town (1948) and its 2002 remake Springtime in a Small Town. 


\section{History Repeating in Spring in a Small Town}

The preceding three chapters have presented a variety of potential factors that can influence remaking processes in a Chinese-language cinematic context, through the mapping of changes in representations of gender and the family between source films and remakes. In the final chapter, the role of temporality in shaping Chinese-language remakes will be investigated, through the analysis of two films produced nearly sixty years apart-Fei Mu's (费穆) Spring in a Small Town (1948) and Tian Zhuangzhuang's (田壯壯) remake Springtime in a Small Town (2002) (both called Xiao cheng zhi chun 小城之春 in Chinese).

The film is set in 1946, just after the Sino-Japanese War. Dai Liyan (戴禮言), his wife Zhou Yuwen (周玉紋), his younger sister Dai Xiu (戴秀), and their housekeeper Lao Huang (老黄) live in their crumbling family compound in a small village. The film centres on the difficulties suffered by husband and wife, two parties to an arranged marriage, and the conflict that ensues when Liyan's former classmate, and coincidentally Yuwen's former lover, Zhang Zhichen (章志忱), arrives at the house for an unscheduled visit. Yuwen faces a choiceleave her ailing husband for a better life, or fulfil her duty as a wife and resist temptation. Zhichen, loyal and concerned for the health of his friend Liyan, is also caught between his morality and his desire to rekindle his relationship with Yuwen. Liyan, who is unaware of the former love affair between his wife and his friend, slowly realises that his wife perhaps never loved him at all, and he must face the ugly reality that it is social convention and obligation, not true feelings, that keeps Yuwen by his side. The situation is further complicated by Dai Xiu showing an interest in Zhichen as well, leading to an awkward suggestion from Liyan that she and Zhichen should become betrothed. Once Liyan becomes aware of the true relationship between his wife and his friend, he attempts suicide, is saved, and Zhichen leaves shortly after.

The prior chapters of this book have focused upon the influence of variations in cultural and cinematic traditions upon the remake, whether in reference to the intercultural remake across traditional national boundaries or the intracultural remake moving from a pre-handover Hong Kong to contemporary China. The kind of cultural difference under consideration in this chapter is of a very different order. In this chapter, it is the particular historical legacy of Communist Party cultural policy towards the arts, and the political difficulties 
faced by both directors Fei Mu and Tian Zhuangzhuang, that are significant in understanding the changes between the two films. As such, this chapter will investigate the remake with a view to understanding how it might function as a commentary on both the key changing political policies on cultural and literary production as well as the broader political milieu within China over the course of the last sixty years.

\section{Cultural Politics in Spring in a Small Town (1948)}

From the outset, Spring in a Small Town (1948), and its director Fei Mu, were on the wrong side of the politics of culture in China. While his earlier films were commercially successful, Fei's works in the 1930 s were highly political, particularly the film Song of China (1935), which was strongly associated with the 1934 Nationalist New Life Movement. This movement, founded by Chiang Kai-shek, directly opposed the Communist Party, instead advocating a hybrid system of values incorporating elements of Confucianism, Western Christianity, nationalism and authoritarianism (Schoppa, 2000, p. 160). Fei's position as a Nationalist sympathiser had obvious implications for him once the Communist Party consolidated their control of China in 1949.

\section{Social versus Critical Realism}

Criticism of Spring in a Small Town was connected to the cultural policy which was introduced into China from the Soviet Union in the 1930s; the concept of socialist realism. Applied to all forms of art, including literature, film and paintings, social realism was the "fundamental principle of the aesthetic conception of revolutionary politics" that emerged in the Soviet Union in the 193os. It was consolidated as literary orthodoxy by Mao in his famous Yan'an Talks in 1942 and dominated all literary and art production during the Maoist era and up until a few years after the Cultural Revolution (B. Wang, 2010, p. 101), though its influence continued for many years after that. Socialist realism was promoted to combat imperialist, feudal and bourgeois/capitalist ideologies through the deployment of an active "transformative style, or a realism of social change" designed to "mobilise the broadest cross-sections of the population to forge a united front, which would involve all classes in mass politics" (B. Wang, 2010, p. 104). Mao's conceptualisation of the purpose of art was heavily concerned with the unification of the nation's people under a socialist banner "against exploitation, autocracy and foreign rule", but at the same time, Mao did not entirely reject the foreign, instead encouraging artists to "learn from the 
legacies of the ancients and the foreigners, even though they are the works of the feudal or bourgeois classes"1 (B. Wang, 2010, p. 105).

Mao's cultural policy thus involved a two-pronged approach, emphasising the transformational and transcendental potential of art, and positioning the arts as being essential to the "education and enlightenment of the people about a nascent reality and socialist hopes" (B. Wang, 2010, p. 105). According to Wang, Mao believed that "art and literature originate from social reality in its richness and immediacy, and the current reality is the authentic source from which artists can draw inspiration"; it is therefore rooted in the "plain language of the people" and is intimately connected with their struggles (B. Wang, 2010, p. 107). This interpretation later shifted to include romanticised revolutionary ideals, tapping into the transcendental potential of art, and enabling artists to inspire the masses in their achievement of revolutionary aims through more creative representations of these socialist political ideals (B. Wang, 2010, p. 109).

Spring in a Small Town thus did not resonate with the new leadership, who had an interventionalist approach to writers/artist filmmakers, demanding that all literature and art works centred on the lives of the proletariat and expressed an optimistic view of the progress towards a socialist society. Aesthetically, narratively and ideologically speaking, Fei's film did not fit with this agenda. The film was released at the same time as a string of resistance war films that appeared in 1947, some of which were considered to be, in fact, indictments of the Nationalist regime in the way they "explained to audiences why victory in the war felt like defeat" (Daruvala, 2007, p. 179), a phenomena that Carolyn FitzGerald described as 'yuan aesthetics' (FitzGerald, 2013). Spring in a Small Town nevertheless stood in contrast to socialist realist cinema in its post-war melancholy aesthetics, "sharing in a general post-war exhaustion and fear of the future" (Daruvala, 2007, p. 179). The film instead "refused to settle for a clear-cut socio-political solution, it did not offer a rally call or fake a solution" (Y. Wang, 2008, p. 115).

With its poetic style and melancholy disillusionment with politics, Fei's work was introspective, and as such, did not fit with Mao Zedong's socialist realist or revolutionary romanticism models (Daruvala, 2007; B. Wang, 2010). The film, despite being less politically charged than Fei's previous pictures, drew criticism for its "political indifference"; left-leaning reviewers labelled it as being

1 A re-interpretation of this notion of "using the foreign to serve the Chinese" has already been mentioned in relation to the film What Women Want; in that context, being utilised to advocate for consumerism as a tool to advance the cause of "socialism with Chinese characteristics" for modern families (see Chapter Two). 
"representative of a form of conservative petit-bourgeois sentiment" (Y. Wang, 2008, p. 107) in direct opposition to the government's socialist agenda, and as a result the film was branded as 'rightist', and disappeared for nearly thirty years (A.-l. Wong, 1998). Fei himself fled to Hong Kong where he lived in exile until his death just three years after Spring in a Small Town was produced.

\section{From Outlaw to Auteur-Fei's Post-198os Transformation}

As the sidelining of his work originally signalled the power of the Communist Party's national agenda for the arts, the change in attitudes towards Fei's work is equally indicative of the power of national cultural policy in China. Only in the more liberal cultural environment of the 1980s, at the beginning of what Yiman Wang describes as the "post-socialist era, which was characterised by political apathy, escalating globalisation, commercialisation, and the aestheticization of sentimentality", did the film re-emerge at the forefront of cinema (Y. Wang, 2008, p. 108). As the parameters of acceptable art forms have changed, and the cinema of China has been viewed by different audiences in the process of China's increasing participation on the global stage, critical and governmental attitudes towards Fei's work have likewise shifted. In 2005, the centennial celebration year of Chinese cinema, the film received public recognition when it was voted best Chinese film ever made by the Hong Kong Critics Association (Udden, 2012).

Most of the contemporary research which discusses Spring in a Small Town is rooted in auteur theory, with discussion of Fei Mu's work often included in anthologies of Chinese cinema, such as Yingjin Zhang's A Companion to Chinese Cinema (Zhang, 2012) or Chris Berry and Mary Farquhar's China on Screen (C. Berry \& M. Farquhar, 2006). Fei is now regarded as a pioneer of Chinese cinema, and recent research reflects this attitude towards his work. Gary Xu discusses Fei as a pioneer of the innovative use of technology $(\mathrm{Xu}$, 2012). James Udden (2012) looks at Fei Mu as a director whose style differentiated his films from other works created around the same period in Chinese and world cinema. According to Udden, Fei's employment of techniques involving camera shots, tracking, shot length and chiaroscuro/lighting, support the narrative's subtle and restrained approach to depicting the emotions of its characters. Udden emphasises that "no other Chinese film of this time that we know of has quite these qualities, nor do most films outside of China" (Udden, 2012, p. 21).

Victor Fan's work Approaching Reality (2015) considers the cinematic "theoretical notions" that can be read within Fei's films (Fan, 2015, p. 111). Fan posits 
that Fei's style used the gap or absence between the image on screen and the audience's understanding of "reality" to highlight that which cannot be seen; that is, the "potentiality of time, desire and life" (Fan, 2015, p. 112). Fan refers to the techniques of xuanxiang and kongqi, translated as "suspension-imagination" and "air/atmosphere" that Fei used to describe his construction of "cinematographic reality". In this realm, reality is represented by that which is not conveyed, either linguistically or visually; a sense of the realities of life is thus constructed by the viewer through a "process of contemplation" of that which is distinctly not real (Fan, 2015, p.136). Fan uses the example of a scene in Spring in a Small Town between the four main protagonists to demonstrate the multi-layered process of reading these interactions between constructed reality and what the viewer is invited to discern from the scenario. In his own way, remake director Tian Zhuangzhuang has taken up Fei's techniques of xuanxiang and kongqi. But as will be shown later in this chapter, the effect of creating a pocket in time where unfulfilled desires can promulgate has evolved, becoming distinctly less personal and decidedly more political in the current cinematic and cultural climate in China.

\section{Reading Gender in Spring in a Small Town}

Fei's political values and his directorial innovation impacted both the broad themes of the film, as well as more specific features such as the way gender was depicted. Spring in a Small Town's generic status as a melodrama, or wenyi film, placed gender issues as a central concern of the narrative. As explained by Stephen Teo, "the term wenyi is an amalgam of (the Chinese characters) literature' and 'art', emphasising the more feminine tendency of the genre as well as the more civil virtues of literature and art that somehow graced the genre as the Chinese saw it" (Teo, 2012). Wenyi films generally concern themselves with family relationships and ethics, and frequently depict romances, but the genre itself is "imprecise, ranging from highly sentimental and exaggerated love stories with songs thrown in, to love stories and 'women's pictures', with their female protagonists as long-suffering heroines" (Teo, 2006, p. 203).

Fei's gender representations in Spring in a Small Town are reflective of a relatively restrained approach to the wenyi genre. Fei's emphasis on emotion, beauty and naturalness, brought together by a loose script and incorporating the actor's real life gestures and mannerisms, attempted to bring a sense of honesty to the relationships depicted (Daruvala, 2007). Susan Daruvala argues that the gender representations created by Fei are the product of a number of influences; Fei's close relationship with the women who raised him, his 
attitudes towards other forms of Chinese art such as classical poetry and Peking Opera, and his political, moral and directorial inclinations. With its narrative focussed on a love triangle, the film could easily have "fallen into the pattern of re-affirming socially prescribed rules around marriage, regardless of the unhappiness these rules cause" (2007, p. 174), but Fei's modernist approach treated the difficult subject with a sensitivity that avoided judging the characters for their flaws by strict Confucian standards, nor did it compel them to engage in revolutionary behaviour, as was common in Communist cinema at that time (Daruvala, 2007). Daruvala reads the film as being representative of a less rigid interpretation of Confucian moral ethics, whereby humanism is paramount over the more "outmoded ideals such as hierarchy, or obeying one's husband" (2007, p. 174). Confucian concepts of qing (情), passion, and li (礼), propriety, are key to understanding the boundaries and restraints within which the characters operate (Daruvala, 2007).

As already stated, Fei directed his actors to be as natural as possible, however, he also drew inspiration for the gestures and movements of his characters not from socialist realism, but from Chinese opera, creating a connection between his film's cinematic expressions of gender and the types of masculinity and femininity that populated Chinese traditional theatre, along with the feudal system associated with this traditional art form (Goldstein, 2007). According to Goldstein, "the aestheticization of costumes and gestures were crucial elements in the emergence of female roles that combined the purity ascribed to women from elite families with visions of opulence and graceful sexuality, capturing a new feminine ideal and a new fantasy" (2007, p. 128).

From Daruvala's perspective, Spring in a Small Town could be read as a feminist film, with its prioritisation of the female perspective, and its concern with the suffering of the lead female character Yuwen. She states that "the most startling thing about the film is the way it is dominated by the voice-over of the female protagonist, Yuwen, with the result that we hear what is happening from her viewpoint and enter very deeply into her subjective world (2007, p. 176). Yuwen's voice-over is unapologetic and frank in her description of her relationship with her husband - there is no sense of guilt for these emotions" (2007, p. 177). Daruvala states that "Fei's modernist cinematography privileges the main female protagonist's subjectivity" in a way which is inconsistent with other films produced during that time (2007, p. 171), an argument supported by Udden, who also sees the role of the voice-over as being particularly important, arguing that Fei was the first Chinese director to actively employ this style, and that the primary function of this voice-over is "psychological, which does not fit with traditional or modernist norms at that time"(2012, p. 321). 
Gender representation in Spring in a Small Town was also deeply connected to the political context described earlier in this chapter. Paul Pickowitz describes the representation of the family as a central allegory for to the representation of the impact of the civil war on society in general post-war Chinese films, with Spring in a Small Town providing one such example of this phenomena (Pickowicz, 200o). In this film, Daruvala argues that the damaged house represented the fragile state of the country and the two male leads, the sickly, traditional Liyan contrasted against the Western educated doctor Zhichen set up a confrontation between the feudal past and modern (read, Western-oriented) future (Daruvala, 2007). The film's ending, where Yuwen and Liyan look out into the distance from the city wall, symbolically oriented them towards a new future; however, their direction is not clear, and this ambiguity contradicted the revolutionary film agenda. As will be discussed later in this chapter, the changes made by Tian Zhuangzhuang in his remake, including the complete removal of this final scene, strongly underline the symbolic importance of gender representation as a form of allegory for China's political systems in this pair of films.

\section{The Changing Politics of Cultural Policy: Springtime in a Small Town (2002)}

Carrying with it the legacies of the original film, as well as the marks of some of the most turbulent of the social, economic, cultural and political changes which have occurred in China over the past sixty years, Fifth Generation Chinese director Tian Zhuangzhuang's remake, entitled Springtime in a Small Town, entered the cinematic landscape in 2002. Over the period between the two films productions, Chinese-language cinema moved through the initial Communist Party propaganda phase, the relatively closed period of the Cultural Revolution, and into a more recent period of rapid expansion and internationalisation. Tian himself, not unlike Fei $\mathrm{Mu}$, has had a controversial relationship with the Chinese authorities, at one time finding himself the recipient of a ten-year ban from film-making after he exhibited his film The Blue Kite (1993) at Cannes International Film Festival without official permission (Marchetti, 2000, p. 993). His remake thus provides a particularly valuable opportunity to gain a better understanding of how a remake might express the complexities of China's shifting cultural policies towards cinema.

Tian was born in April 1952, in Beijing, to parents who were both highly recognised for their acting talents (Ni, 2002). In 1978, he joined the Beijing Film 
Academy, and graduated in 1982 with fellow filmmakers Zhang Yimou (张艺谋) and Chen Kaige (陈凯歌). Tian began his career making documentaries, with a particular focus on ethnic minorities, employing a rather obscure style which was not popular with mainstream audiences (Tam \& Dissanayake, 1998). His 1993 film The Blue Kite, which directly addressed the events of the Hundred Flowers Movement, the Great Leap Forward and the Cultural Revolution, while well received in foreign film critical circles, winning the Grand Prix award at the Tokyo International Film Festival along with the Critic's Award, New York Film Festival, 1994 (Zhang, 2003, p. 630), was too politically sensitive to be screened in China (as will be discussed later in this chapter). Like the films of Chen and Zhang, The Blue Kite represented a move towards a more contemporary style of film-making, with a stronger focus on "narrative, spectacularity and melodrama" (Tam \& Dissanayake, 1998, p. 43), all prominent features of later Fifth Generation films.

\section{The Fifth Generation Directors}

The Fifth Generation of Chinese directors refers to a group of filmmakers who were the first to graduate from the Beijing Film Academy after China's Cultural Revolution. They are well-known within cinematic and scholarly circles for creating films that have been heavily influenced by the trauma they, their families, and society experienced during China's most tumultuous years (C. Berry \& M. Farquhar, 2006; Ni, 2002). Zhang Yimou, Tian Zhuangzhuang and Chen Kaige all spent time with the working class and peasantry as a result of government policies, and their experiences put them in direct contact with the reality of living under Mao's vision during this period (Zhu \& Robinson, 2010). Their films have thus been read as "transitional"; a response to the politics of their times, with themes which were often heavily critical of the Communist Party, and often disguised from censors by allegory (Larson, 2011). The themes of their films have thus brought them to the attention of the authorities, as sensitivities around many of these subjects are still extant.

While the Fifth Generation films were known for their critical exposure of problems with Communist Party policies and practices, they were nevertheless influenced by the literary method of socialist realism that was so restrictive for artists during the Maoist era. As Wendy Larson states, the Fifth Generation inherited its moral social framework and focus on the countryside from the socialist period, with narratives which often "pit individuals against the implacable forces of tradition", while visually they evoked social realist traditions with their strong use of colour and powerful images. At the same time, films like Red Sorghum (红高粱) (1987) and Ju Dou (菊豆) (1990) subverted social 
realist standards by focusing on "the directors' abstract concerns with representation, history, language and truth" rather than any kind of socialist, collectivist vision of the future (Larson, 2011).

While the strong relationship between Fifth Generation films and Chinese history and politics creates the impression that these stories resonate with experiences of being Chinese, simultaneously, the works of the Fifth Generation are also championed as examples of "global Chinese cinema" in how they utilise these same images and stories of China to captivate international audiences (Larson, 2011). This success has been contingent upon the evolution of the cultural policy of the Chinese Communist Party, with cinema shifting from being primarily concerned with addressing domestic audiences, to also playing a very important role in managing China's international image (Rawnsley \& Rawnsley, 2010; Su, 2010; Zhang, 2010). In the context of cinematic production and reception, contemporary film festivals are now acknowledged to be not only "particularly important for the survival of world cinema, art cinema, and independent cinema", but they are also increasingly significant to the success of more mainstream cultural productions as well. "Hollywood premières are also increasingly reliant on the media-sensitive glamour and glitter of the festival atmosphere to launch their blockbusters. The leading film festivals—such as Cannes, Berlin, Venice, Toronto, and Sundance-are particular bustling nodes of activity where people, prestige, and power tend to concentrate" (Valck, 2007, p. 35). A number of highly-acclaimed Chinese directors, including Tian Zhuangzhuang, Zhang Yimou and Chen Kaige, have enhanced their global and domestic profiles, and subsequently, the status of Chinese-language cinema, through the international film festival circuit (Tam \& Dissanayake, 1998).

At the time of Springtime in a Small Town's release, Chinese cinema was still riding a wave of film festival success which started in the 1980s, with particular acclaim at the festivals of Cannes, Venice and Berlin. From the late 1980 s to as recently as 2011, consistent with the rise of the Fifth and Sixth Generations of directors, Chinese films came to the fore in these arenas, with awards such as the 1988 Golden Bear for Red Sorghum, the 1992 Golden Lion for The Story of Qiu Ju (秋菊打官司), and the 1993 Palme d'Or for Farewell My Concubine (霸王别姬) ( $\mathrm{Ni}, 2002)$. More recently Jia Zhangke received the Cannes Golden Lion for Still Life (三峡好人) in 2006, and Ang Lee also received the Golden Lion for Lust, Caution in 2007. Springtime in a Small Town, as a San Marco Prize winner at the Venice Film Festival in 2002, thus found itself in the middle of what was considered to be a 'golden age' of Chinese cinema in this international festival circuit. 
Prima facie, Springtime in a Small Town seems to fit well with the model of an archetypal international festival film described by scholar Bill Nichols:

Films from nations not previously regarded as prominent film-producing countries receive praise for their ability to transcend local issues and provincial tastes while simultaneously providing a window onto a different culture. We are invited to receive such films as evidence of artistic maturity - the work of directors ready to take their place within an international fraternity of auteur-and of a distinctive national culturework that remains distinct from Hollywood-based norms both in style and theme [...] Most forms of cinematic expressivity are minimally present. We find no magical realism, no expressionism, surrealism, collage, or bold figures of montage. Melodramatic intensities, or excess, are extremely rare. Point-of-view dynamics are usually weak to non-existent. The great majority of scenes unfold in a third-person, long-take, longshot, minimally edited style. There is only limited use of music and even dialogue.

NICHOLS, 1994, P. 21

Tian's remake thus seems to respond to the complexities of Chinese politics by avoiding the topic altogether, which appears to be consistent with Yingjin Zhang's argument regarding censorship in the international film festival space. Zhang highlights that despite the successes of Chinese directors in this international arena, access to these festivals and to international markets more broadly for Chinese directors is still strictly controlled, and directors who wish to enter films are subject to the censorship process. As Zhang states, this appears to have influenced the content and themes of films released in this space, and "while politics has readjusted its strategic relations with art from all-out domination to sugarcoated co-optation, art appears to have willingly accommodated politics to such an extent that at times it is entirely complicit with official ideology" (Zhang, 2010, p. 45). Some Fifth Generation directors, Zhang Yimou in particular, have been accused of 'selling out' later in their careers, avoiding the difficult or politically sensitive subjects of their early films in order to distribute their films to a wider audience (Larson, 2011).

While some topics may be censored outright, the wider issue of how China is represented on the global stage is also a sensitive one, and the Fifth Generations' successes have also provoked debate on this subject. The films created by Tian's compatriot Zhang Yimou in particular received criticism from some prominent film scholars as being examples of directors pandering to 
Western notions of China as the 'exotic Other'. His films have been extensively analysed by film scholars and intellectuals, who debate the extent to which Orientalist themes and motifs in his films exaggerate the exoticism and mystery of China (Cui, 2003; Lu, 1997; Qin, 2010). It has been argued that Zhang's approach to filmmaking resulted in the reduction of characters, settings and Chinese cultural traits to crude stereotypes which were easier to understand for non-Chinese viewers, exaggerating certain myths or stereotypes about China (Chang, 2009; Lu, 1997).

These representations of a mythical China were often closely connected to representations of gender. Tonglin Lu developed a model of the features of this kind of 'Orientalist cinema', particularly focussing on Zhang Yimou, in her work Confronting Modernity in the Cinemas of Taiwan and Mainland China (2002), which is summarised in the following terms by Pi-chun Chang (2009):

Zhang Yimou developed three strategies to appeal to Western audiences. The first characteristic is women's oppression. The protagonist must be a young woman, who is always 'sexually deprived, physically abused, and spatially confined'. She is terribly oppressed by some strange tradition of feudal China. The second trademark is that Zhang's works are full of (re)invented pseudo-traditional Chinese rituals. For example, the carriers' merry jolting of the wedding sedan in the opening scenes of Red Sorghum, and the rituals of lighting red lanterns and foot massage before sexual intercourse in Raise the Red Lantern, among others, were inventions rather than being based on actual ethnic customs. Liu writes that all these rituals serve as "signifiers of Chineseness for an international audience. Precisely because they have no reference point whatsoever in Chinese culture, the rituals function even more effectively as visual signs of pure difference" (Lu, 2002, p. 160). The third strategy is to imply that China is an iron cage with no exit. This cage represented by a traditional courtyard in Zhang's works, traps and confines the female protagonist, suffocating her dream of liberty and individuality.

CHANG, 2009, P. 14

Springtime in a Small Town seems to fit this model of exhibitionist, Orientalist Chinese cinema remarkably well. Critical reviews of the film describe it as an intimate chamber melodrama, a period piece, and a visually rich love story, focusing on the love triangle, the film's aesthetics and its historical setting as core elements of the film (Bradshaw, 2003; Holden, 2002; Stratton, 2002). It deploys a number of the stereotypes Lu describes, with a plot focused on a 
young woman, trapped in an arranged marriage, suffocating under the weight of obligation and duty. We know that sexual relations between the married couple have broken down, which adds to the pair's suffering. The house is a constrained, oppressive environment, with many windows and doors to enclose the woman. Tian even employs a courtyard, as Zhang does, which may serve the same function as in Zhang's films.

However, Yiman Wang argues that Tian is different to other Fifth Generation directors, as "among the many possible strategies for hitching a ride with the global cultural economy (including producing Chinese versions of blockbusters and using transnational all-star casts, as his former classmates Zhang Yimou and Chen Kaige have done), Tian chose the road less travelled, as Fei did over half a century earlier. He clings to the "intellectual moral high ground" and insists on making "films for the next century" (2008, p. 120). Tian Zhuangzhuang has enjoyed international acclaim for his films, but not necessarily commercial success, and his remake of Springtime in a Small Town exemplifies this. In her article "Remembering a Film and 'Ruining' a Film History: On Tian Zhuangzhuang's Spring in a Small Town", Wang seeks to understand why Tian remade the film, and why he repeatedly uses the rhetoric of failure to describe his production (Y. Wang, 2008).

The most striking aspect of the remake is that it seems to be a near carboncopy of the original, which is interesting given that more than sixty years have passed between the productions of the two films. The plots of the two films are nearly identical, which Tian himself attributes to a heavy reliance on the original for guidance, a process he described as "tracing the original" (Y. Wang, 2008). Tian, in his interviews on the film, describes his admiration of Spring in a Small Town, which is also reflected in the opening credits of the film: "With this film, the producers wish to pay their respects to China's pioneering filmmakers". It would be thus natural to assume that Tian's remake is a form of homage, an argument which finds support in Tian's own interviews in relation to the film.

Wang argues that the director deliberately chose to make this remake using a style which was not commercially successful because his motivation was instead more personal, showing a nostalgic "retrospective fascination" with the past, aestheticizing the decadent ruins for a new (Chinese) audience who have accumulated sufficient cultural capital to appreciate the loss of splendour portrayed in the film (Y. Wang, 2008). The director's remaking strategy thus used memory to re-write film history on various levels by invoking nostalgia for Fei's original film and the remembrance of a glorious but "ruined" past. In his remake, Tian thus revises China's cultural and filmic history "through the act of retracing the past" (Lee, 2008, p. 8). Springtime in a Small Town's purpose 
as a remake thus became associated with a wider project focused on reliving, restoring, and archiving the past (Y. Wang, 2008, p. 105).

While the remake generated intense domestic media attention, Springtime in a Small Town failed to produce results at the domestic box office (Y. Wang, 2008). Instead, “Tian's unhurried, detached camerawork resisted melodrama and the audience's desire for character identification, and thus knowingly jeopardised his box office potential" (Y. Wang, 2008, p. 118). Furthermore, "his slow camerawork and lack of close-ups continued his trademark style and deliberately decreased the entertainment value of the film" (Y. Wang, 2008, p. 120). Springtime in a Small Town received critical acclaim at the Venice Film Festival in 2002, winning the San Marco Prize, and it toured many other international film festivals including those in Toronto, Melbourne, Vancouver, New York and Brisbane. That the remake was not a domestic commercial success, and instead received international acclaim, seems to support Wang's assertion that Tian's directorial approach "exchanged immediate box office payback for cultural capital" in the global film festival scene (Y. Wang, 2008, p. 120).

However, Springtime in a Small Town could also be read with reference not only to the past, but as an allegory for the present and perhaps even the future state of the Chinese nation. The term 'failure' that Tian uses to describe his film could refer to far more than just an economic situation; the remake also potentially acts as an allegory for failure on a broader scale, in keeping with Tian's previous politically motivated directorial style. The remake can therefore also be read as subverting both the commercial imperative to create films for financial gain and the censorship agenda in the way it alludes to these political issues.

\section{Re-reading the Remake-Gender and Politics in Springtime in a Small Town}

Wang argues that Tian's film is a product of the 21st century, an age when increasing economic prosperity means Chinese citizens now have the time and money for cinematic reflections on their past (Y. Wang, 2008, p. 116). By aetheticising the ruins of the past in a "post-socialist way which privileges consumption and disavows politics" (Y. Wang, 2008, p. 117), the remake is thus positioned to be more concerned with homage and nostalgia than with making a political statement. However, given the political themes of Tian's earlier works and his penchant for allegory with a strong gender focus, a de-politicised reading of his remake seems highly unusual. What could be missing is a point of reference, a filter through which Tian's remake can be analysed with 
consideration for its potential political implications. The following section of this chapter will frame discussion of Springtime in a Small Town with reference to Tian himself and his most politically controversial work, The Blue Kite (蓝风筝) (1993), using gender and the family as a means of analysing how this remake might represent the complexities of creating film under the continued influence of past and current national cultural policies in China.

The Blue Kite, as a result of its clear political setting and symbology, has been acknowledged as one of the most significant works created by Fifth Generation directors (Neilsen, 1999). Tian tells this story through the use of a family narrative, with the film focusing on the lives of the young boy Tietou (铁头) and his family, and the trials they endure during the 1950s and 1960s in China. Set in a compound in Beijing, we follow this family's story, from the marriage of his parents Lin Shaolong (林少龙) and Chen Shujuan (陈树娟) in the early 1950s, to the birth of Tietou, and through his childhood. The film is structured by divisions entitled "Father", "Uncle" and "Stepfather", and depicts "the forceful usurpation of the father's role by the Communist Party, and its effects on family and society" (Neilsen, 1999), showing the breakdown of the family unit under the pressure of policies which divide members of society into Left and Right, with severe consequences for those on the wrong side of this divide. Family members, friends and colleagues who once enjoyed relationships of reciprocity are pitted against each other, some motivated by ideology, others by a competitive need to survive in such an unstable environment, and some are just caught in between (X. Zhang, 2008). The result for Tietou's family is the loss of three father figures: Shaolong, after being "sent down" to a village to perform hard labour after being labelled a "Rightist", who is killed by a falling tree branch; Uncle Li Guodong (李国栋), who due to malnutrition and overwork dies of liver failure, and Wu Laisheng (吴需生), who dies of heart failure. His mother Shujuan is finally sent to a labour camp, leaving Tietou on his own.

These deaths and misfortunes are not merely a case of bad luck. In the film, we see a number of figures both literally and metaphorically fall victim to events-like Shujuan's brother Shuyan (陈树岩), who enthusiastically engaged with the Party's cause. He slowly loses his eyesight over the course of the story, a symbol of his inability to foresee and avoid the events which unfold (X. Zhang, 2008).The Blue Kite thus utilizes many symbols which link the family's experiences to the broader political context, in what Xudong Zhang describes as "a textbook example of national allegory, which swings regularly between traumatic personal experience and memories of national disasters" (X. Zhang, 2008, p. 283). The combination of this thinly veiled allegory and the potential for the embarrassment of the release of the film to an international 
film audience without official sanction were significant contributing factors to Tian's earlier mentioned ban from filmmaking (Marchetti, 2000, p. 993).

Springtime in a Small Town was Tian's first film since his return from this cinematic exile. The two films seem initially to be in a completely different vein, with Springtime in a Small Town's cast of just five characters, limited locations and almost non-existent references to politics in direct contrast to The Blue Kite's politically charged and dynamic settings and themes. However, it could be argued that Tian's remake is as much a continuation of the exploration of the themes which were a feature of The Blue Kite as it is a remake of the original film. While chronologically, Springtime in a Small Town is set in 1946 and The Blue Kite in the 1950s and 196os, it is Springtime in a Small Town, in many respects, which represents the next development in a longstanding pattern of works from this director; works that have used the family as a means of making social commentary and delivering criticism.

Both The Blue Kite and Springtime in a Small Town are framed through the experiences of a family. The Blue Kite documents the family from its beginning through to crisis point, with the deaths of all three of the female protagonist's partners. It records the anger, violence, tension, and conflict of those turbulent times. The remake covers the story of the family once it has passed this breaking point - the period post-crisis, when futility and resignation are the dominant emotions. It is as if Springtime in a Small Town is taking us forward one generation, to see the aftermath of the crises that were the Great Leap Forward and the Cultural Revolution, through the eyes of the family. The semiotic significance of the term 'Spring' in modern society lends further weight to the argument that Tian's remake could be read not just as a nostalgic reflection on the past, but also as a response to cultural policy and a form of subversion of the various forms of restrictions placed on artists in China, with gender representation forming a central part of this resistance.

\section{Springtime in a Small Town-The Changing Nature of Gender, the Family and Allegory}

The first scene of Springtime in a Small Town opens with a shot of an old city wall, crumbling. Zhou Yuwen appears, in a long shot, walking with an empty basket on top of the wall. We hear melancholic music, the birds, and her footsteps. We then switch locations, and pan down at an angle from the sky opening onto a courtyard, to get our first view of Dai Liyan. It is not evident at this point that Yuwen and Liyan are married, and Liyan, obscured by tree foliage, is rescuing old menlian (door frames adorned with good luck phrases) from a pile of debris. The lonely whistle of the train signals the arrival of a threat to 
Liyan; as he hears it, he sighs, almost as if he knows what is around the corner. Old Huang, their housekeeper, brings him a scarf, and they talk about Liyan's health. Old Huang believes the spring coming will help Liyan's recovery from his illness, but Liyan has a different perspective. "My health, like this house, is beyond repair". Huang counters, "It is peacetime now, the house can be fixed gradually". We thus become aware that the state of the house is due to the ravages of war.

We return to Yuwen, who is finalising her errands, and we see her in medium shot walking home through the ruined city. She is enclosed by the walls, as if she is trapped in a very particular, narrowly defined version of the world. Neither she nor the viewers are able to construct a complete picture of the environment in which she lives from these fragmented and incomplete images of walls and laneways. The two main protagonists then meet in their courtyard, and the state of their relationship is immediately established. The camera circles around the two, linking them together, but they stand far from each other, giving the impression of both physical and emotional alienation. Yuwen only stops to talk to Liyan after he calls out to her. The verbal dialogue, combined with the rigid body language of the two characters, speaks to the distance between them. Yuwen and Liyan very rarely stand close together or look at each other directly in this scene, and there is no physical intimacy. They alternate in turning their backs on each other, and Yuwen in particular stands at an angle which closes her off to her husband, with one shoulder pointed towards him, but her body opened away from him.

Liyan's plea for sympathy when he throws his medicine on the ground in despair receives a cold, factual response from his wife- "the medicine must be working, otherwise you would not still be taking it". His attempt to communicate, "Yuwen, we should talk", is similarly rejected. While this conversation is occurring, the character of Zhichen has stepped off the train, making his way energetically towards the house. Our view of Zhichen is completely different from that of Liyan and Yuwen; he is framed in long or extremely long shots, and sometimes in wide open space. When he walks through the village, the viewer can fully appreciate his surroundings - the collapsed buildings, deserted streets, and scorched walls give a much more comprehensive indication of the environment in which the characters live. Zhichen thus provides a more broad-minded, modern view of the world than the narrow vision through the eyes of Liyan.

This introductory scene sets the stage for the rest of the remake's introspective style; a style which, when used in Fei's film, drew criticism for its associations with the lifestyles of the bourgeoisie. During Mao's era, the bourgeoisie 
were considered to be one of the exploitative classes whose power needed to be limited (W. Chi, 1986). The socialist realist artistic policy was one means of directing the focus towards the working and lower classes instead of the bourgeoisie, who owned the means of production and were primarily concerned with the value of property and the preservation of capital to ensure the persistence of their economic supremacy in society (Edgar \& Sedgwick, 1999). Yuwen appears more manipulative in the remake, provoking Liyan to distress with her cold behaviour towards him, and testing Zhichen's moral fortitude. She is more vocal in her unhappiness. Liyan is positioned as a hypochondriac, as opposed to his weak but harmless and likeable character in the original.

While the protagonists still live in a dilapidated house that may be collapsing on the outside, the inside is filled with decadent furniture. There are a number of occasions where Yuwen in particular shows a sense of vanity, a taste for the luxuries of life, and she often wears beautiful silk dresses, and adorns herself with perfume and jewellery. On at least two occasions, we watch the ritual application of these adornments - before she sees Zhichen, and before the birthday party, Yuwen slowly and artfully applies her makeup and perfume, and adorns herself with bracelets. Liyan also is always immaculately groomed and beautifully dressed.

The class and gender identities of the characters in Tian's remake can thus be seen to conform to the class stereotypes established in the Mao era. Fei, of course, was never subjected to training in or inculcated with socialist realist literary methods, and his characters were too subtle and complex to fit with that rigid interpretation of class. In contrast, the protagonists in Tian's remake are much more closely connected with class stereotypes of the bourgeoisie seen in earlier socialist literature. Tian's characters have a tendency towards excess; their emotions, their gestures, and the class based versions of masculinity and femininity they embody have become more exaggerated than those depicted in the original. This demonstrates the lingering influence that cultural and political policies and interventions have had in the Chinese cinematic cultural context.

\section{The Metaphor of the Family Home}

The changes that have occurred to the gender representations within Springtime in a Small Town can be read as a reflection on present political concerns, a notion that appears to be supported by Tian's modification of the symbolic use of the family home to stand not as a metaphor for war, but for another form of decline. The introductory scene of Tian's remake returns us to the site of the family home, a place which Susan Daruvala identified earlier as representative 
of post-war misery and an allegory for both the broken marriage and China's choice between feudal and modern ways of living and thinking (Daruvala, 2007). However, the differences between source film and remake in how the home is depicted could be read as a form of commentary on the changes that have occurred in interventionist national cultural policy and the current political climate in China.

As Tian describes in his interview with The Movie Show in 2003, Springtime in a Small Town was set in an old Ming Dynasty chancellor's house, near Tai Lake in Suzhou. Though he was a high ranking Imperial Court member, his house, when chosen by the filmmaker, was just a shadow of its former glory, with Tian stating, "when we saw it (the house), it was just some pillars and a yard. We fixed about 200 doors and windows. The house seen in the film was based on the original structure. But all the details were added on by us" (Tian, 2003). The implications of such an elaborate reconstruction are fascinating. While initially Tian's actions could appear to fit with the Orientalisation model, whereby details which emphasise Chineseness to non-Chinese viewers are artificially inserted, the situation is perhaps not so straightforward.

The house in the original film was a kind of testament to the (bourgeois) grandeur of the lives led by the characters before the war; its breakdown, a symbol of both the damage caused by consecutive wars and the internal breakdown of the marriage (Daruvala, 2007). Wang's reading of the remake's reconstruction of the house and surrounding ruins positions the home as being representative of a form of "post-socialist spectacle of decadence" which has only become possible through the increasing economic prosperity of China and the people's subsequent desire to "consume decadence" (Y. Wang, 2008, p. 113). However, there is also an alternative reading of this reconstruction process. If the reconstruction of a Ming Dynasty elite's house is read as a political rather than aesthetic or economic statement, this act becomes a very pointed commentary on the foundations of modern Chinese society and politics. Aside from the overt connections with Communist China already discussed earlier in this chapter, the reconstruction of the family home in the remake creates a sense of history repeating itself, and it shares connections with other key moments in China's history through its association with the themes of decline, decadence, and ultimately, failure.

Springtime in a Small Town creates a link between itself and the Ming Dynasty primarily through the strong presence of the earlier mentioned chancellor's home-virtually the entire film is set in this one location. The Ming Dynasty (1368-1664AD), established by Zhu Yuanzhang (朱元璋), was built on the foundations of the Mongol Yuan Dynasty (126o-1368AD). This was a period of re-orientation towards "traditional Chinese ways", and the Mongols, who 
were considered invaders, were stripped of Mongol markers in society such as dress, personal names and other cultural practices. These were replaced with more "traditional" practices from the Tang and other earlier Chinese dynasties. The Ming Dynasty also brought about a strengthening of the application of Confucian principles, and the most powerful advisors to the emperor were well-versed in this philosophy (A. Chan, 1982). The emperor also valued strict obedience, using himself as a model example for the people to follow, severely punishing those who did not follow orders (A. Chan, 1982). The emperor's power was absolute, his control "even extending to the checking of dangerous thoughts ... independent ideas did not please the monarch" (A. Chan, 1982, p. 15).

The Ming Dynasty collapsed after two hundred and seventy-six years. Power struggles, incompetent leadership, and corruption made the Dynasty susceptible to rebellion and invasion (A. Chan, 1982). The Imperial Court was the site of much of this corruption, as the eunuchs usurped power from traditional leaders. Natural disasters and exploitation of the poor by the rich hastened the once powerful dynasty's decline (A. Chan, 1982). The remade film is not focussing its criticism on the Ming Dynasty particularly, but instead uses this Ming Dynasty house as a symbol which represents all of the negative aspects of traditional Chinese culture and history, including the oppressiveness of arranged marriage, class inequality and a broad criticism of that which is archaic.

During the Republican/Nationalist era in Chinese history, there is a repetition of many of the same criticisms of the leadership group as those described in the Ming Dynasty. The Communist Party attacked the Nationalists, led by Jiang Jieshi (蔣介石, Chiang Kai-shek), on the basis that the Nationalist leadership was corrupt and had created poor conditions for Chinese people. Indeed, the Republican era, from 1912-1949, has been described as a period of great difficulties, with the country repeatedly beset by both domestic and foreign troubles (Mitter, 2008; Spence, 2013; Zarrow, 2005). As James E. Sheridan writes, "during the Republican period, disintegration and disorder were at their maximum. It was a period of transition ... which saw the death of one socio-political system and the birth of another" (Sheridan, 1975, p. 4).

While "pre-modern China often disintegrated territorially; because of Confucianism, the social cohesion of the Chinese people was never significantly damaged. Only in the twentieth century did China disintegrate both socially and territorially" (Sheridan, 1975, pp. 17, 18). Furthermore, there were divisions created by the perceived incompatibility between Confucian philosophy and Western industrialisation. The desire to develop and strengthen China against military powers forced China's leaders to adopt Western weapons and technology, which led to a social division between reformists and 
traditionalists, with both groups attempting to re-negotiate the boundaries of both philosophies in order to promote development without accepting the associated Western value system (Taylor, 2013).

This historical trend of disintegration/re-integration, wax and wane, bleeds through into Fei Mu's original film, which shows the aftermath of war in China. Fei's film however does not, as Daruvala states, "take sides" (Daruvala, 2007). In other words, it does not pass judgement on those who were involved in these events. However, it could be argued that the same cannot be said for Tian's remake. By reconstructing a house which is strongly associated with moribund traditional culture, the viewer is encouraged to draw parallels between this particular past, the present, and the future. The house is no longer the site of marital or post-war misery, but instead, it is a house which has been re-built on corrupt foundations. That it has collapsed again speaks to an underlying notion of inevitability and futility, such that when we see Liyan digging through the remnants of the house, dusting off old relics, the viewer is strongly positioned to feel that his actions are largely in vain. As long as Liyan is building on those foundations, he will live only to see the same events repeat themselves.

The difficulties experienced by the couple in Springtime in a Small Town can therefore be read much more deeply than just being a reflection on the harshness of China's archaic marriage practices. The metaphor of the collapsing house and the broken marriage can be extended beyond concerns of historical gender roles, to instead represent the decline of contemporary Chinese society. While What Women Want portrayed gender, the family and contemporary society from an idealistic point of view, Tian's remake instead gives us a sense of the other side of the story; how little real progress has been made, and even forecasts of the decline of the current 'empire'. Through its analysis of gender and the family home, this chapter shows how Tian's remake functions as a form of historical political allegory.

Simultaneously, the allegorical function of the remake also extends to function as a commentary on the artist and director in contemporary China. In Springtime in a Small Town, there is the same filmic style which characterised The Blue Kite - "a stirring narrative, plain and strong ... a portrayal that speaks clearly through its silence, and is gentle but deeply meaningful" (Ni, 2002, p. 4). This silence found in Springtime in a Small Town is more than just a reference to the blank space of the traditional Chinese painting that the original film evokes. This relationship between film and art is not new, and is in fact discussed by Fei Mu himself in reference to his own films (Fan, 2015). But while Fei Mu used silence to emphasise humanist or Confucian ethical undertones, or to delve into the relationship between cinema and reality itself (Fan, 2015), Tian's remake could be read with reference to a more current issue experienced by himself and his compatriots. More recently, Fifth Generation directors have 
spoken at length, in a number of academic and non-academic forums, about the role of censorship on their art. Since the Cultural Revolution, freedom of speech has become an increasingly difficult topic, and a generation found that "freedom" of speech was tentative and conditional, and could be appropriated by a dictatorship for its own purposes.

While in the past Tian attempted to subvert the linguistic violence that denied the differences in the Chinese nation by, for example, dubbing his film The Horse Thief in Tibetan instead of Mandarin or otherwise silencing Han voices (Berry, 1994), this time it could be argued that he mobilises the silence, or absence of sound, within Springtime in a Small Town to make a broader point about this censorship. Now, the suffering of Tian's lead characters is conducted in silence-from the very beginning of the film, Liyan's attempts to talk with his wife fail. Throughout the film, Liyan and Yuwen at times try, but are unable to speak honestly about their feelings and their situation. Duty, obedience, fidelity, and perhaps, fear; these principles silence them, prevent them from expressing themselves. This is reinforced by the remake's removal of one of the most significant voices heard in the original film-Yuwen's voice-over narration. Only with the arrival of Zhichen is the married couple forced to confront their feelings, however they still only ever allude to the problems at hand rather than openly discussing them. When Liyan tells Zhichen that it would have been better for him to have married Yuwen, his comments are met with silence - there is no denial of the statement, but there is no acceptance of it either. While Yuwen cares for Liyan, at the end of the film she does not seem to have found any love for him-her relationship with him is still one motivated by guilt and obligation. This interpretation differs from the reading given by Daravula of the original film, where after Liyan attempts suicide, Yuwen re-commits herself to him, showing deep attachment to her husband by the end of the film (Daruvala, 2007). In contrast, in the remake, while Yuwen is visibly upset by Liyan's actions, the dominant emotions in the room while Liyan is being treated are fear and guilt, not renewed love. Every attempt to understand Liyan's behaviour, particularly by the younger sister, is met with a visible grimace from Zhichen in particular. These characters know that to speak out brings consequences and condemnation, and as the story of Tian's life shows, this applies not only to the marriage of his characters, but to contemporary Chinese artists and citizens in general.

Despite its bleak outlook for its characters, Fei's original film does in fact present a glimmer of hope for the future in its final scene, which sees Yuwen looking out over the crumbling city wall, pointing towards the future, with Liyan now by her side. Significantly, in the remake this is replaced with the image of Yuwen embroidering, and a final shot of the wall, empty. This is the second time we see this image of Yuwen; the first is when Zhichen arrives. In this first depiction, the 
camera pans from left to right, and zooms in on Yuwen as Lao Huang tells her that they have a guest. That Yuwen returns to her embroidery for the second time, after all of the turmoil which has occurred, emphasises that nothing really has changed for her in the household. However, the sequence unfolds differently when it is repeated at the end of the film. Yuwen is again seen in a medium shot, with the camera circling her, but this time we hear the whistle of Zhichen's train as it departs. Yuwen starts and turns herself gently towards the window, as if to open herself to be closer to him. The sequence is interwoven with a shot of Liyan downstairs gardening, cutting back dead branches in preparation for Spring. Again, as at the start of the film, he hears the train whistle and sighsthis time, perhaps with relief. We return to Yuwen, who is now even more distant and isolated, being framed in a long shot. She is still alone, and there is just the sound of the train which fills the room. The idea of the hopeful future presented in the original film is thus replaced with both repetition and stagnation in the remake through the repeated actions of the characters at the beginning and end of the film.

The repetitive nature of the remake is therefore reflective of the repetitive course of history-first the failures of the imperial system, then the ravages of the civil war, then the Great Leap Forward and the Cultural Revolution. By going back in time, even as far as the Ming Dynasty, connections are created between the corruption of that period, the Nationalist Government, the communist past and the potential future of the Communist Party. Perhaps it is in the character of Dai Liyan's younger sister Dai Xiu that we see the embodiment of this vision of the future. As a teenager in the film, Dai Xiu negotiates the loss of her innocence, as she develops feelings for Zhichen only to have her hopes dashed, while she watches the disintegration of the marriage of her brother and sister-in-law. Dai Xiu is the only character in this small band of people who has the courage and naivety to ask the hard questionsdoes Yuwen love Zhichen? Why would her brother try to kill himself? As the audience, we watch her naïve, childlike optimism as she plays, dances and sings turn to something more bitter and sombre-a reflection on the long, hard process of modernisation in China, and a warning as to the potential future consequences of the current path.

\section{Springtime in a Small Town and Political Revolution}

While warning of the potential for repeated mistakes by deploying the tropes of feudalism and the bourgeoisie, the semiotic connections of the term 'Spring' also open up the potential of the remake to be read as a political call to action. 
Though Tian gave his remake film a slightly more 'contemporary' feel, updating it to colour for example, (Y. Wang, 2008), he chose to keep the same Chinese title for the film一Xiao cheng zhi chun (小城之春). In Chinese, the word 'Spring' has specific connotations-re-birth, change, life, a time when flowers bloom, but at the time of the release of Fei's original film, this term did not have the same political connotation as it has today. Since the 1950s, the term 'Spring' has increasingly been appropriated for political purposes, such that now the word also stands as a signifier of the desire for political change. With this in mind, Tian's choice to remake Fei's film utilising this story and symbol is highly significant in how the film constructs its subtle political commentary.

In the context of contemporary Chinese politics, the term 'Spring' and its associated elements appear repeatedly in connection with political movements. It is apparent in the name given to one of the most significant campaigns undertaken during Mao's era, the One Hundred Flowers Campaign, which occurred from late 1956 to July 1957. During this period, citizens were encouraged, and then later coerced, into openly expressing their criticisms of the regime to the leadership. "Let a hundred flowers bloom, and a hundred schools of thought contend", was Mao's invitation to intellectuals. The goal of this activity was to encourage innovation and fresh thinking in science and the arts, but the topic of many participants' criticisms quickly turned towards leadership. (Scott, 2016, p. 163). The Communist Party was thus forced to abandon the experiment after a short period of time, and the subsequent period was one of retribution against those who had questioned the leaderships competency, known as the Anti-Rightist campaign, which saw many prominent intellectuals sent to labour camps for their criticisms (Pye, 1999). Shortly after this, the Great Leap Forward began, heralding the beginning of a nearly twenty-year period of catastrophic social and economic upheaval, broken only by a short period of recovery between 1962 and 1966, before the Cultural Revolution commenced.

While China was in the grips of the Cultural Revolution, on the European continent, years of malcontent among citizens came to the surface in 1968, which saw a number of protests against Communist leadership in Eastern Europe, including in Yugoslavia and Poland, but particularly in Prague (Klimke, Pekelder, \& Scharloth, 2011). The movement there became known as the Prague Spring, and this was a dangerous time for Communist leadership. The Communists had ruled in Czechoslovakia since 1948, shortly before the Chinese Communists also came to power, but in May 1968, dissatisfaction with the government's approach to the economy and the treatment of workers, as well as perceived interference in local issues, resulted in the election of a leader who attempted to democratise Czechoslovakia, introducing reforms 
granting greater freedom of speech, media and movement and dividing the country into two regions, the Czech Republic and the Slovak Republic. In response to this, the Soviets invaded Czechoslovakia on the 21st August 1968, reversing many of his reforms, and they remained in power until being overthrown in 1989 with the collapse of the Soviet Union (Townson, 1999).

The connection between spring and political reform in China became even more prominent after this Prague Spring, when the name was co-opted for the 1978/1979 campaign known as the 'Beijing Spring' (北京之春), and a later magazine, still published online today, which similarly focuses on issues of democratic, human rights and social justice reforms. The title was also re-used for a second time in 1997/1998, during the period immediately after Hong Kong's handover to China, when the CCP initially relaxed some controls over political organisation and expression. Common across these events and the earlier mentioned One Hundred Flowers Movement is the call for, or instigation of, a period of liberalisation, followed by a crackdown, and thus over time, the term Spring has become heavily associated with this particular call for political revolution. That the title 'Beijing Spring' mirrors almost exactly the title of Fei and Tian's film in Chinese creates a strong semiotic connection between these political movements and Tian's remake in particular.

These associations between Spring and political revolution persist even today, with the most recent usage being in Arab states. The Arab Spring, which began in 2010 and also took its name from the 1968 Prague Spring, has involved a series of uprisings in Egypt, Tunisia, Lebanon, Bahrain, Syria, and many other Arab nations (Kte'pi, 2012). The reasons for these disputes are complex and are not the subject of this book, however, a key aspect of these rebellions was the rejection of authoritarian rule (Kte'pi, 2012). China has not been isolated from the impact of these revolutions, and world leaders, international news organisations and later, scholars, speculated at the time about the possibility of a similar form of uprising occurring in China (Clem, 2011; Hille, 2011; Olimat, 2013; Ramzy, 2011). In China there were calls for a 'Jasmine Revolution', and prodemocracy protests in February 2011 heightened fears, resulting in arrests, and a crackdown on sensitive websites and public gatherings (Clem, 2011; Hille, 2011; Olimat, 2013; Ramzy, 2011).

In retaining the same Chinese title as the original film, the viewer can place Tian Zhuangzhuang's remake within the context of these past political revolutions and uprisings in Communist history and draw parallels with the current political situation in China. The plot of Springtime in a Small Town also, in some respects, follows the pattern of these political movements, with the initial hope that comes with Zhichen's arrival being eventually extinguished by Liyan's attempted suicide. The eventual failure of Yuwen and Zhichen to 
change their circumstances in fact mirrors the outcome of these 'Spring' protests on a number of occasions across Chinese history. The collapsing house and marriage in the remake thus come to be reflections upon these political events, while at the same time, they symbolically represent the unsustainability of the current system, and the continued necessity for political reform through their connection with the word 'Spring'.

\section{Reflections}

Despite the passage of more than fifty years, Tian's remake Springtime in a Small Town is remarkably similar to the original film in the way its director uses gender representation and the family home as central allegories for the political and social conditions within China. While Fei's film was entrenched within the post-war politics of its time, the similarities between his film and Tian's remake also disguise a myriad of subtle changes which reflect the influence of the Chinese government's cultural policies on cinema since Fei Mu's original film was produced. This chapter has shown how the changes which director Tian Zhuangzhuang has made bear the mark of both his political inclinations and the influence of socialist realist traditions, particularly in the way class and gender identities have been constructed around the notions of the spoilt wife and the weak intellectual. The remake's representations of gender and the family home exaggerate the bourgeois element which was already present in the original film, and these take on new meaning given the issues of corruption and wealth that have brought the Communist Party's credibility into question.

What is also evident in the remake of Spring in a Small Town is a change in how the cinematic techniques used by Fei in his original work, xuanxiang suspension-imagination and kongqi atmosphere, can be read in light of the changing use of metaphors in contemporary Chinese-language cinema. While Fan outlines that Fei's approach to cinematic reality was which gave broad "brushstrokes" to a viewer who can discern reality from the gaps in between, whether these be Confucian ethical musings or humanist views on desire, love, and obligation, Tian's approach to reality needs to be constructed through consideration of additional layers of political "blank space". This is the space in which politically allegory is most effective at drawing attention to that which is absent in the lives of today's Chinese citizens (Fan, 2015).

This chapter has demonstrated the tangible impact of the historical intervention of the Communist Party's coercive literary and cultural policy on the creation of this remake. Furthermore, the remake also reflects very recent shifts 
in cultural policy, namely the recognition of cinema as an important form of global soft power, and the subsequent increasing number of Chinese films being released to international audiences (albeit only after being approved by censors). This combination of historical legacy and current political factors is quite unique to the Chinese cinematic and cultural context, and has been under-researched in Chinese-language remake studies to date. By appearing entirely apolitical, Springtime in a Small Town is able to exist within this international space while also subverting this current political cultural policy through political allegory. 


\section{Remaking “China”}

While past remake studies have provided valuable insights into both the role of cultural difference and the importance of gender representation as a marker of this difference in remakes, the analyses conducted in previous chapters show that remake studies is able to move beyond the focus on cultural imperialism which was a feature of earlier Franco-American research in the field. Chinese-language remake studies have moved towards a less rigid, more transnational approach in keeping with the theoretical disposition of Chinese-language film studies more broadly, but they have similarly been inclined to discuss the Chinese-language remake with reference to the hegemonic visions of Hollywood. This monograph builds upon this work while simultaneously taking the study of Chinese-language remakes to a more neutral space, through focusing on reformulations of gender and the family in Chinese-language remakes of films from the U.s., Hong Kong and pre-communist China from a variety of genres and time periods. Rather than addressing remakes as purely a cynical commercial exercise, or as an example of one culture misappropriating another, it has instead investigated the broader myriad of potential reasons behind changes which can be observed between source films and remakes, and the significance of these differences in a Chinese-language cinematic and cultural context.

The films in this work were first chosen because they adhered to the strictest definition of a remake - the acknowledged, direct remake - which meant that arguments regarding what constitutes a remake could be set aside. However, the choice of films also takes remake studies in a new direction through the inclusion of both inter- and intracultural pairs of films, providing an opportunity for the discovery of new perspectives on remakes through their differing places of origin, generic categorisations and times of production. At the same time, all of the films shared a common thematic thread where gender representation emerged as a key juncture at which many of the variables involved in remaking the source film met. Each of the analyses conducted highlighted a different aspect of remakes studies to show the increasing complexity of issues related to the field.

\section{Remakes and Perspectives on Being Chinese}

While all four films approached the issue from different perspectives, with varying degrees of emphasis on the role of the director, genre and gender, at 
the heart of the changes which have been made between each of the source films and their remakes are ideas surrounding what it means to be Chinese today. All four pair of films highlighted the contested nature of Chinese identity, raising different perspectives on contemporary life in China. Regardless of whether their source films were set in another time or place, these remakes speak to contemporary interpretations of Chinese history, society, politics, values and identity.

The analysis of What Women Want (2000 and 2011), supported the findings of early French-American remake studies, in that the film marked 'cultural difference' through the adaptation of gender roles between the source film and its remake. A comparative narrative analysis demonstrated that at the heart of the remake were crucial differences in gender construction and representation which reflected the different needs and expectations of the films' target audiences. Both films essentially put forward the same story of failed masculinity, redemption and transformation, but they relied upon different conceptualisations of gender and sexuality, and projected different ideal models of the family according to what is perceived to be their respective traditional and 'modern' cultural norms.

Psychoanalytic analysis conducted on both films found that while the original Hollywood production laid the blame for Nick's behaviour at his mother's feet for not providing him with a strong male role model or father figure, the Chinese-language remake introduces the concept of the multi-generational family via the character of Sun Meisheng, Zigang's father, to explain his son's attitudes. Zigang's masculinity is compared and contrasted to his father's in a way which connects with broader social discourses on the tensions between traditional and more contemporary values in Chinese society. While the original film was quite nostalgic, the remake adopts a more critical view towards history. Sun Meisheng's inclusion in the film, and his vocalisation of certain truths about his own treatment of his wife and family, both repudiate the negative aspects of traditional Confucian gender relations that were based in hierarchies, and at the same time, selectively reinforce values from the same tradition such as filial piety and the role of the parent as teacher.

As the protagonists of films which associate themselves so closely with the question of "what women want", the female characters in these narratives provide some interesting insights into how women might be represented in this kind of discourse on gender. While both versions featured women in the workforce, their agency was in most cases, low, and their characterisations were heavily bound to ideas regarding self-image, sex, domesticity, and materialism. These notions were conveyed to the audience powerfully and with a sense of authenticity, in women's own words and thoughts, through the 
narrative vehicle of Nick's/Zigang's mind-reading ability. However, as in the case of masculinity, there were differences between the source film and remake in how femininity was projected. Woman in the case of the American film was neurotic, either sexually repressed or hypersexual, and indecisive. In the Chinese-language remake, Sun Zigang's early assessment, that "women want men with money" seems for the most part, correct in the context of the remake's narrative. Women in the Chinese-language film are self-obsessed, concerned mostly with self-image and material possessions. While the lead female protagonist has more substance, her financial independence and work ethic turn out to be fronts for her lack of success in relationships, and her life is only made complete through her integration into Zigang's family unit. The remake is thus deeply conservative in its depiction of femininity despite the occasional humorous attack on male characters.

The remake also relates itself to the perceived difficulties facing modern Chinese citizens, where some aspects of this traditional family model come into conflict with the demands of contemporary life. While the original American film is happy to accept the male protagonist's daughter being cared for by another man, the Chinese remake emphasises that the model of single, divorced parent is not ideal, and as such, Zigang finishes the film with a "complete" family — his new love, his daughter and his father. By adding the father figure in Sun Meisheng's character, the narrative of the remake thus shifted from being primarily concerned with the couple, to being about the wellbeing of the family. The remake is also aspirational in the way in which it presents a vision of the modern Chinese family, who is wealthy and successful and show their love for each other through the purchase of material goods. More broadly, the remake provides an expression of how China's increasing participation in the world economy, and its subsequent interactions with other expressions of gender, have in turn influenced gender roles within Chinese society.

While the chapter built upon the methodological approaches of early works, this pair of films also demonstrated how discussion regarding these differences is not necessarily inevitably tied to notions of cultural imperialism. While the remake certainly makes changes to the source material to reflect its audience's background, it does not set up an artificial dichotomy that pits American culture against Chinese culture. The remake instead functions as a commentary on Chinese culture made for a domestic audience, and it presents one particularly idealistic, aspirational vision of what it means to be Chinese today. In this way, this particular remake is indistinguishable from other forms of modern day propaganda that perpetuate notions of social stability through keeping families together and functioning as strong economic units. 
Chapter Three approached issues involved in cross-cultural remakes from another angle, considering the mediating factors of auteur and genre in the analysis of Blood Simple (1984) and A Woman, a Gun and a Noodle Shop (2009). The generic shift which is evident between Blood Simple and $A$ Woman, a Gun and a Noodle Shop and the fact the films were both made by auteurs who have particular styles, complicated the analysis of gender and familial representation, bringing to light the impact of these influences in shaping remakes. It is not necessarily social or political culture that is the dominant force here, it is cinematic culture through which directors construct images on screen to convey their understanding of cinema on multiple levels, narratively, visually and symbolically.

Gender is almost a by-way through which this communication is achieved, with the directors, while both drawing upon the concept of failed masculinities, approaching this theme in different ways. The Coen brothers had their male protagonists failing to meet macho cowboy, detective and even mafia stereotypes, and they broke down masculine-coded institutions such as the state and the law both through the narrative's setting in an isolated area and through the eventual killing off of all three male protagonists. Zhang achieved a similar effect by corrupting Beijing Opera roles, showing how previously noble and powerful men might become twisted, weak and impotent. His representations of masculinity are thus not inconsistent with male characters in his earlier films where older men inflicted terrible trauma on their families. Laobanniang demonstrates the same kind of steely resolve in the face of adversity that we see in many of Zhang's other leading women. She endures the humiliation of her marriage to a decrepit old man and the sexual punishment which physically marks her as Mazi's property, reminiscent of how cattle are branded by their owner. However, unlike some of Zhang's earlier female leads, particularly roles played by Gong Li, Laobanniang's infidelity does not correlate with any sexualisation of her character. Zhang's portrayal of her character appears to be a turning point in his focus, with less attention given to the depiction of the erotic dimension of female sexuality.

The two intercultural remakes in this study demonstrate that in the case of Chinese-language remakes, cultural imperialism is not necessarily a significant factor, however, cultural difference is still an important aspect of the creation of these remakes. In the second pair of films, cultural difference manifests itself instead through the different cinematic and/or artistic traditions drawn upon by the source film and remake. Zhang uses the language of symbols that simultaneously mark 'Chineseness' which he has deployed through his career to reinforce his status as a director equal to his global counterparts, converting a Coen brothers cult classic film into another visual language for those who understand his work and its cultural complexities. 
While Chapter Three considered questions of genre when shifting from Hollywood to mainland China, Chapter Four took the discussion of genre to a new place with its analysis of the Hong Kong original film A Chinese Ghost Story (1987) and its remake (2011). This love story between the young scholar and a beautiful ghost draws upon a long tradition of romance stories in Chinese literature which have also made their way onto the screen. However, the original film adapted this story to reflect the themes of political anxiety regarding Hong Kong's handover to China and its casting of bisexual actor Leslie Cheung presented a chaotic mixed-genre film featuring an array of sexually ambiguous characters.

The 2011 remake transformed these roles to reflect more hetero-normative expressions of gender, abandoning the gender ambiguity of the original villain, and suppressing the homo-social relationship between the lead men in favour of a heterosexual love triangle narrative. The realignment of masculinities and femininities in the 2011 remake speak to a greater set of changes in the relationship between mainland Chinese cinema and its diasporic counterparts. Xiaoqian's memory loss at the hands of Yan points to the difficulty of dealing with the past and the tendency to forget-both issues which are of contemporary relevance when considered in relation to Hong Kong's colonial past and current political situation with mainland China. The suppression of deviant forms of sexuality present in the remake, as well as the repositioning of the original film as a relatively crude cinematic achievement in the face of the huge advances in CGI and cinematic techniques demonstrated in the remake also could be read as a re-defining of the relationship between the Hong Kong and mainland Chinese cultural production industries, where mainland China now holds the balance of audience and financial clout and Hong Kong must adapt to these pressures.

This relationship could be understood as mirroring that which exists between coloniser and colonised, with the British replaced by mainland China, and Hong Kong engaging in a battle for the right to maintain its own diasporic position in Asian cinema. The remake could be read as denying the contested nature of the Chinese identity, with the changes made to gender representations encouraging viewers to see Hong Kong and mainland China as the same 'Chinese' culture. The pair of films expands our understanding of the remake phenomenon by revealing other dimensions of remaking practices that are relevant within the specific framework of Chinese-language cinema, and the analysis is heavily bound to the social, cultural, cinematic and political circumstances of these regions.

Finally, this book considered a pair of films which highlighted the influence of the passage of time in shaping the differences between a source film and its remake, with a particular focus on how the remake bears the marks of past and 
present interventionalist national cultural policies in China. Spring in a Small Town (1948) and its 2002 remake Springtime in a Small Town, initially appeared to be carbon copies of each other, despite almost sixty years having passed between their productions. The remake created by Tian Zhuangzhuang, approaches the original narrative under the pretense of being apolitical, creating a visual display which maximises the exotic and erotic pleasures of a love story set in the ruins of a grand Ming Dynasty home. The slow pace, ponderous camera shots and relationship-oriented narrative all appear to carefully distance the remake from any kind of political statement or sentiment.

But upon analysis, there was in fact a political edge to Tian's remake hidden beneath the layers of love, loss, obligation and infidelity. If the film is read with reference to how Tian has previously depicted political turmoil in his films, particularly The Blue Kite, Springtime in a Small Town also uses the family unit as a case study for the impact of political decisions on people's lives in China. The use of the failing marriage and family home in Springtime in a Small Town could be read as an extension of this political discussion, drawing parallels between this kind of familial deterioration and/or stagnation and the repeated failures of contemporary political leadership in China. The decadent lifestyle which Yuwen and Liyan perhaps used to live has faded, declined. Now the walls and corridors of the house block the communication between the married couple as well as the lovers, creating a labyrinth of secrets. Out in the garden, the surrounding walls are crumbling, opening the marriage up to interference from external powers and letting in light which illuminates painful truths.

While seeming to be apolitical, Tian's remake uses gender not to make a point about the pitfalls of arranged marriage, or the morality of infidelity, but for pointed political commentary. By choosing to almost exactly replicate the original film, the repeated imagery of the family home and failing marriage becomes an allegory that connects the feudal past and the Nationalist era in which the original film was made with the political environment of the remake. To emphasise the danger of a repeat of the same issues of corruption and nepotism that Chinese society has seen in the past, Tian mobilises the term 'Spring' in the film's title to draw attention to the political movements which have connected this word and its associations with new beginnings and change. This case study demonstrates how it is not just the time of production that influences a remake, but also the passage of time itself. Given the vast social and economic upheavals that have occurred over the past sixty years, this chapter expands the field of remake studies to consider the influence of these events in Chinese history, politics and society. The remake thus presents a particular vision of China's past in order to position these issues at the centre of the Chinese present. 


\section{Remakes and Transnational Chinese-language Cinema}

In the case of Chinese-language cinema, while flows of capital and cinematic styles are certainly no longer limited by national boundaries, these remakes nonetheless demonstrate that there are distinct narrative strategies employed to target specific audiences. There is no disputing that there are indeed strong transnational elements present in Chinese-language cinema, which have been discussed extensively already by a number of significant scholars in the field. ${ }^{1}$ However, there are differing degrees to which this theory might be applicable to individual films, and in the case of the Chinese-language remake, the imperative to make a commercially successful film, where present, strongly drives filmmakers to create locally tailored products. In the case of $A$ Woman, $A$ Gun and $A$ Noodle Shop and Springtime in a Small Town, these two remakes also highlight the complexity of the arthouse/commercial film 'divide', or lack thereof, in the context of Chinese-language cinema. The Chinese version of A Woman, A Gun and $A$ Noodle Shop in particular shows how a Chinese-language remake can be both high and low art at the same time; both arthouse cinema and commercial product. This is a significant departure from the notion that remakes are a just a form of inferior low art that was of such concern to Franco-American remake studies. In the case of each pair of remakes in this study, there are thus different combinations of factors which work to emphasise or de-emphasise the globalised nature of Chinese-language cinema.

The degree to which the Chinese-language remakes in this study engage with ideas of a "global Chinese cinema" is reflected in how they adjust the source film in order to reach their intended audience, and each remake demonstrates a slightly different approach. In Chapter Two, the analysis showed very clearly the importance of the spectator through its quite overt restructuring of the film's narrative to address the multi-generational family. A Chinese Ghost Story moves to consideration of how the remake addresses the Chinese audience as a homogenous entity, with the seamless interaction of Hong Kong and mainland Chinese actors and a traditional Chinese story and setting.

Chapters Three, Four and Five demonstrated a more complex approach to audiences, with Zhang Yimou's directorial approach to remaking Blood Simple as A Woman, A Gun and A Noodle Shop quite clearly identifying two audiences for his remake. While he had already substituted the Coen brothers style with his own, Zhang further emphasised the duality of his remake by releasing two versions of the film, one for the domestic New Year's audience, the other, the international film festival elite. The stylistic flourishes which he incorporated into the internationally released version align the remake much more

1 This is discussed in Chapter 1, where some significant works exploring this theory are cited. 
closely with the sensibilities of the original text; sensibilities which would be lost on the majority of the remake's domestic audience who would never have seen Blood Simple. Similarly, the local comedy of the domestic version would have been almost certainly lost in translation for an international viewer. The remake in this case cleverly connects both with exotic notions of "China" and broader cinematic culture for non-Chinese spectators, while at the same time, using indigenous generic markers that rely on local humour and cultural knowledge for the domestic audience, who have a different view of what it means to be Chinese.

Rather than creating two versions of the remake like Zhang did, Tian's remake in Chapter Five features a dual form of audience address within the same film. Unlike Zhang's remake, Tian's film doesn't appear to use this dual address for commercial reasons, but instead uses it as a way of disguising the potentially politically sensitive nature of his film from the censors. By concealing his political allegory behind the exotic images of past China which appeal to film festival audiences, Tian's film is at the same time exploiting the remake's inherently repetitive nature to make a political point regarding the repetition of past mistakes across history. These two remakes therefore show that remaking processes are highly contingent on audience understanding, and perhaps in the case of Tian's remake, changes made to a source film are not always designed to enhance audience comprehension in the Chinese-language cinematic context, with similarities instead creating new meaning for contemporary Chinese audiences through the connection they make with the past.

\section{The Future of Remake Studies}

Through observing the changes made to source films through the lens of gender and the family, a number of key elements which are crucial to understanding the complexities of the remaking process have been identified. The analyses conducted reached some significant conclusions regarding the similarities and differences in how gender and the family are represented, not just between source films and their remakes, but also between remakes included in this study.

Due to the need to limit the scope of the monograph, this study was not able to explore fully the potential alternative readings of the Chinese-language remakes within, for example, Chinese-speaking diasporic communities outside Hong Kong and mainland China, such as Singapore and Malaysia. It would be an interesting future project to consider how the different political and socio-cultural contexts of these regions may have influenced audience expectations and readings of these remakes. How, for example, would a Singaporean audience respond to a film such as What Women Want? How far do the values 
depicted in this film reach; what aspects would be considered archaic amongst those who are considered ethnically Chinese, but have been raised in environments which are not subject to strict censorship in cinema?

In a similar vein, as the study focused on narrative discourse analysis and associated theories and methodologies, it was not able to consider the role of industry structures in Chinese-language cinema and the influence these may have on the production of remakes. While gesturing towards the remake as an example of the breaking down of the silos of arthouse versus commercial cinema, future projects could more fully investigate the remake in an industry context. Co-productions and remakes with new collaborators outside the Hollywood-Japan traditional partners, such as Korea, are another future area of research in terms of how ideologies are negotiated in these spaces; complexity which is only compounded in the case of a 'remake'. While this book did not endeavor to define, or redefine what constitutes a remake, there certainly is room for consideration of how partnerships between Chinese and other film production companies and corporate partners might influence the boundaries of these definitions, as well as the narrative content of the remake. With such strict quotas and censorship guidelines, there is a need to consider more deeply in another study how these factors can alter a source text in ways which previous studies on French, Hollywood and Japanese remakes would have had little grounds to concern themselves with. Brian Yeclies and Kai Soh (2017) have begun this work with their investigation into the Korean-Chinese coproduction systems that have been evolving over the past fifteen years, including an analysis of the Chinese remake of Miss Granny (2014), which shows how Korean filmmakers utilise the co-production structure to bypass restrictions much in the same way Hollywood counterparts do, and Chinese companies likewise hire Korean staff to get around the need for purchasing expensive TV or film rights. There is more work to be done in terms of the implication of these burgeoning relationships for cinematic production, including remakes; a task for a different study into industry connections.

Following on from this, the potential for remakes to serve as tools of propaganda to disseminate ideas regarding Chinese values and society, which was identified as a possible factor influencing the narrative of What Women Want, could be further investigated in the context of Chinese films which are aimed at international audiences, as part of advancing understanding of how Chinese cinema functions as a tool of soft power in a variety of media-consuming spaces. Already, with television and film moving towards individual streaming platforms such as Netflix in the West, and sites such as Youku, Douban and Tudou in China, viewers are being engaged both as part of a viewing community and as individuals. Licensing agreements and co-productions in these 
spaces may lead to some very interesting cinematic experiments, opening the door for audiences who would not previously have been exposed to Chinese productions to have this content brought into their living rooms. Online platforms in particular provide a wonderful opportunity for researchers to gauge audience expectations and reactions to films in ways which would not have been possible ten years ago-Yecies and Soh demonstrate this through their analysis of content found on website Douban (Yecies \& Soh, 2017). No longer is a film's success with an audience measurable by its box office takings. Now, we can, and must, look beyond these dollar figures to consider other numbers; number of likes, number of views, number of shares, number of comments, and audience ratings online. A remake's success could therefore be mapped not by the figures released by the film company or its media, but by audiences themselves, providing new and exciting ways of measuring audience reception.

Also included under this theme of audience reception could be the consideration of counter-narratives or transformations of source texts in the form of unofficial remakes and fan productions created for online platforms. There is already an extremely prolific fan-based literary world online, and several films have recently been produced off the back of successful online novels (Qin, 2016), with fan feedback forming part of the writing process for some online content authors (Qin, 2016). The idea of remakes informed directly by audience inputs is a tantalizing one. Who's to say that in the future, Chineselanguage films may not be constructed from what is traditionally considered "the audience" up, rather than from the industry/top down?

The findings of each of the chapters demonstrate how each pair of remakes present a different view on what it means to be Chinese, and the remakes included in this study show the continued struggle in Chinese-language cinema and society over what can be considered 'cultural authenticity'. With the increased presence of the new media technologies outlined above, and the potential multiplicity and fragmented voices that comes with them, it is unlikely that this issue is going to be quickly resolved. Despite the success of films such as Crouching Tiger, Hidden Dragon and Hero, the remakes in this study show the continued relevance of the domestic, locally oriented narrative, in contrast with the alternative depictions of Chineseness that were seen as inauthentic and did not appeal to Chinese audiences (K. Chan, 2009). When the remakes in this study are considered together, they indicate that while Chinese-language cinema might be considered to be increasingly global, or transnational, there are nevertheless very clear indications that the transnational is still articulated with reference to the national (C. Berry \& M. Farquhar, 2006), and that this conceptualisation of the national is a very significant factor in how the narratives of remakes are created. 
The remake is a highly fruitful tool for the study of trends and concerns within Chinese-language cinema more broadly, through the way in which this kind of film exploits the concepts of similarity and difference to redefine its source text. As China continues to grow economically and cinematically, increasing its connections to the global cinematic community and defining and redefining its values and direction as a nation, the remake will continue to be an important cinematic phenomena which yields interesting and useful findings for Chinese-language cinema and culture scholars alike. 
Sarah Woodland - 978-90-04-36330-4 Downloaded from Brill. come4/26/2023 12:13:58AM via free access 


\section{Glossary}

\begin{tabular}{|c|c|c|}
\hline Chinese & Pinyin & Comment \\
\hline 孫子剛 & Sun Zigang & $\begin{array}{l}\text { Andy Lau's character and the main male } \\
\text { protogonist in the Chinese remake of } \\
\text { What Women Want }\end{array}$ \\
\hline 李仪龙 & Li Yilong & $\begin{array}{l}\text { Gong Li's character and the main female } \\
\text { protagonist in the Chinese remake of } \\
\text { What Women Want }\end{array}$ \\
\hline 孫美聲 & Sun Meisheng & Sun Zigang's father \\
\hline 豆豆 & Dou Dou & Sun Zigang's daughter \\
\hline 张艺谋 & Zhang Yimou & Director \\
\hline 赵本山 & Zhao Benshan & A Chinese comedian and actor \\
\hline 间妮 & Yan Ni & A Chinese comedian and actor \\
\hline 小沈阳 & Xiao Shenyang & A Chinese comedian and actor \\
\hline 猫猫 & Маo Мао & A Chinese comedian and actor \\
\hline \multirow[t]{2}{*}{ 王麻子 } & Wang Mazi & $\begin{array}{l}\text { Lead male protagonist and boss in } \\
\text { A Woman, a Gun and a Noodle Shop }\end{array}$ \\
\hline & Laobanniang & $\begin{array}{l}\text { Wife of Mazi in A Woman, A Woman, } \\
\text { a Gun and a Noodle Shop }\end{array}$ \\
\hline 李四 & $\mathrm{LiSi}$ & $\begin{array}{l}\text { Laobanniang's lover in A Woman, a Gun } \\
\text { and a Noodle Shop }\end{array}$ \\
\hline 赵六 & Zhao Liu & $\begin{array}{l}\text { Overweight cook in A Woman, a Gun } \\
\text { and a Noodle Shop }\end{array}$ \\
\hline 陈七 & Chen Qi & $\begin{array}{l}\text { Waitress/employee of Mazi in A Woman, } \\
\text { a Gun and a Noodle Shop }\end{array}$ \\
\hline 蒲松龄 & Pu Songling & $\begin{array}{l}\text { Author of Strange Tales from a Chinese } \\
\text { Studio, from which the story of } \\
\text { 'Nie Xiaoqian' originates }\end{array}$ \\
\hline 聊齋誌異 & Liaozhai zhiyi & Strange Tales from a Chinese Studio \\
\hline 聂小倩 & Nie Xiaoqian & $\begin{array}{l}\text { Lead female protagonist in A Chinese } \\
\text { Ghost Story }\end{array}$ \\
\hline 寧采臣 & Ning Caichen & $\begin{array}{l}\text { Male protagonist in A Chinese } \\
\text { Ghost Story }\end{array}$ \\
\hline 燕赤霞 & Yan Zhixia & $\begin{array}{l}\text { Male protagonist in A Chinese } \\
\text { Ghost Story }\end{array}$ \\
\hline 姥姥 & Laolao & $\begin{array}{l}\text { Tree Demon, villain of } A \text { Chinese } \\
\text { Ghost Story }\end{array}$ \\
\hline
\end{tabular}

(C) SARAH WOODLAND, 2018 | DOI:10.1163/9789004363304_008

This is an open access chapter distributed under the terms of the CC BY-NC 4.o license wood land - 978-90-04-36330-4 
cont.

\begin{tabular}{|c|c|c|}
\hline Chinese & Pinyin & Comment \\
\hline 夏雪风雷 & Xia Xue Feng Lei & A character in A Chinese Ghost Story \\
\hline 三藏 & Sanzang & $\begin{array}{l}\text { A Buddhist monk, famous character of } \\
\text { the novel Journey to the West }\end{array}$ \\
\hline 费穆 & Fei Mu & $\begin{array}{l}\text { Director of Spring in a Small } \\
\text { Town (1948) }\end{array}$ \\
\hline 田壮壮 & Tian Zhuangzhuang & $\begin{array}{l}\text { Director of Springtime in a Small Town } \\
(2002) \text { and The Blue Kite (1993) }\end{array}$ \\
\hline 周玉紋 & Zhou Yuwen & $\begin{array}{l}\text { Main female protagonist in Spring in a } \\
\text { Small Town }\end{array}$ \\
\hline 戴禮言 & Dai Liyan & $\begin{array}{l}\text { Main male protagonist and husband of } \\
\text { Yuwen in Spring in a Small Town }\end{array}$ \\
\hline 戴秀 & Dai Xiu & Dai Liyan's younger sister \\
\hline 章志忱 & Zhang Zhichen & $\begin{array}{l}\text { Main male protagonist; former lover } \\
\text { of Yuwen and school friend of Liyan in } \\
\text { Spring in a Small Town }\end{array}$ \\
\hline 老黃 & Lao Huang & The Dai housekeeper \\
\hline 陈凯歌 & Chen Kaige & A Chinese Director \\
\hline 红高粱 & Hong Gaoliang & Red Sorghum (1987) \\
\hline 三峡好人 & Sanxia hao ren & $\begin{array}{l}\text { Still Life released in } 2006 \text { by director Jia } \\
\text { Zhangke }\end{array}$ \\
\hline 贾樟柯 & Jia Zhangke & A Chinese director \\
\hline 霸王别姬 & Bawang Bie Ji & Farewell My Concubine, by Jia Zhangke \\
\hline 秋菊打官司 & Qiu Ju da guansi & The Story of Qiu Ju (1992) \\
\hline 蓝风筝 & Lan fengzheng & The Blue Kite (1993) \\
\hline 铁头 & Tietou & $\begin{array}{l}\text { One of the main male protagonists in } \\
\text { The Blue Kite }\end{array}$ \\
\hline 陈树娟 & Chen Shujuan & Main female protagonist in The Blue Kite \\
\hline 林少龙 & Lin Shaolong & Main male protagonist in The Blue Kite \\
\hline 李国栋 & Li Guodong & Main male protagonist in The Blue Kite \\
\hline 吴需生 & Wu Laisheng & Main male protagonist in The Blue Kite \\
\hline 陈树岩 & Chen Shuyan & Younger brother of Chen Shujuan \\
\hline
\end{tabular}




\section{References}

Abrams, J. J. (2007). Space, time and subjectivity in neo-noir cinema. In M. T. Conard (Ed.), The philosophy of neo-noir (pp. 7-20). Lexington: The University Press of Kentucky.

Alarming elderly suicides in rural China. (2014). New Tang Dynasty Television.

Retrieved from http://www.ntd.tv/en/programs/news-politics/china-forbiddennews/20141007/230577-alarming-elderly-suicides-in-rural-china-.html.

Alford, W. \& Shen, Y. (2004). Have you eaten? Have you divorced? Debating the meaning of freedom of marriage in China. In W. Kirby (Ed.), Realms of Freedom in Modern China, (pp. 234-263). Stanford: Stanford University Press.

All Upcoming Movie Remakes/ Reboots (2017-2022). IMDb. Retrieved 5 September 2017.

Aufderheide, P. (1998). Made in Hong Kong: translation and transmutation. In A. Horton \& S. Y. McDougal (Eds.), Play it again, Sam: retakes on remakes (pp. 191200). Berkeley: University of California Press.

Barton Palmer, R. (2004). Contemporary film directors:Joel and Ethan Coen. Champaign: University of Illinois Press.

Berry, C. (1994). A nation t(w/o)o: Chinese cinema(s) and nationhood(s). In W. Dissanayake (Ed.), Colonialism and nationalism in Asian cinema (pp. 42-64). Indianapolis: Indiana University Press.

Berry, C. (2009). Jia Zhangke and the temporality of postsocialist Chinese cinema: In the now (and then). In O. Khoos, Metzger, S (Ed.), Futures of Chinese Cinema (pp. 111-128). Bristol and Chicago: Intellect.

Berry, C., \& Farquhar, M. A. (2006). China on screen: Cinema and nation. New York: Columbia University Press.

Bird, K. (2003). In Kathryn Bird's words. In C. Stewart \& P. Hawker (Eds.), Leslie Cheung (pp. 24-25). Victoria: Australian Centre for the Moving Image.

Boggs, C., \& Pollard, T. (2003). Postmodern cinema and the demise of the family. The Journal of American Culture, 26(4), 445-463.

Bonds, A. B. (2008). Beijing Opera costumes: The visual communication of character and culture. Honolulu: University of Hawai'i Press.

Bordwell, D. (2000). Planet Hong Kong: popular cinema and the art of entertainment. Cambridge, MA: Harvard University Press.

Boretz, A. (2011). Gods, ghosts and gangsters: Ritual violence, martial arts and masculinity on the margins of Chinese society. Honolulu: University of Hawai'i Press.

Bould, M. (2013). Genre, Hybridity, Heterogeneity. In A. Spicer, \& Hanson, H. (Ed.), A Companion to Film Noir (pp. 33-49). West Sussex: Blackwell Publishing Ltd.

Bradshaw, P. (2003, 13 June). Springtime in a small town. The Guardian. 
Butler, J. (1993). Bodies that matter. London: Routledge.

Butler, J. (1999a). Gender trouble. New York: Routledge.

Butler, J. (1999b). Subjects of sex/gender/desire. In S. During (Ed.), The Cultural Studies Reader (2nd ed., pp. 340-353). Londonand New York: Routledge.

Butler, J. (2004). Undoing gender. New York: Routledge.

Chan, A. (1982). The glory and fall of the Ming dynasty. Norman: University of Oklahoma Press.

Chan, E. (2000). Postmodernism and Hong Kong cinema. In A. Dirlik, X. Zhang, W. Ning, A. D. King, A. Kusno, \& P.-H. Liao (Eds.), Postmodernism and China (pp. 294-322). Durham: Duke University Press.

Chan, F., \& Karpovich, A. (2011). Introduction. In F. Chan \& A. Karpovich (Eds.), Genre in Asian film and television (pp. 1-7). London and New York: Palgrave MacMillan.

Chan, K. (2009). Remade in Hollywood: the global Chinese presence in transnational cinemas. Hong Kong and London: Hong Kong University Press.

Chan, N. (2010). Queering body and sexuality: Leslie Cheung's gender representation in Hong Kong popular culture. In C. Yau (Ed.), As normal as possible: negotiating sexuality and gender in mainland China and Hong Kong (pp. 133-150). Hong Kong: Hong Kong University Press.

Chang, P. C. (2009). Globalized Chinese cinema and localized Western theory. China Media Research, 5(1), 10-20.

Chen, Y. (2011). Warriors as the feminised other: the study of male heroes in Chinese action cinema from 2000 to 2009. Doctoral dissertation, University of Canterbury.

Chi, R. (2012). Hong Kong cinema before the 1980s. In Y. Zhang (Ed.), A companion to Chinese cinema (pp. 75-94). Malden: Wiley-Blackwell.

Chi, W. (1986). Ideological conflicts in modern China : democracy and authoritarianism. New Brunswick: Transaction Books.

China: Parents can sue children for neglect. (2012, 28 December). The Independent. Retrieved from http://www.independent.co.uk/news/world/asia/china-parents-cansue-children-for-neglect-8432781.html.

Chow, R. (1991). Woman and Chinese modernity: The politics of reading between West and East. Minneapolis and Oxford: University of Minnesota Press.

Chu, Y.-W. (2004). Introduction: globalization and the Hong Kong film industry. In E. M. K. Cheung \& Y. Zhu (Eds.), Between Home and World: A reader in Hong Kong cinema. Oxford: Oxford University Press.

Clem, W. (2011, 3 March). The flowering of an unconventional revolution. South China Morning Post. Retrieved from http://www.scmp.com/article/739685/floweringunconventional-revolution.

Clover, C. J. (1987). Her body, himself: Gender in the slasher film. Representations, 20 (Special Issue: Misogyny, Misandry and Misanthropy), 187-228. Retrieved from http://www.jstor.org/stable/2928507. 
Clover, C. J. (1992). Men, women and chainsaws: Gender in the modern horror film. Princeton: Princeton University Press.

Collett, N. (2014). Firelight of a different colour: The life and times of Leslie Cheung KwokWing. Hong Kong: Signal 8 Press.

Conard, M. T. (2006). The philosophy of film noir. Lexington: University Press of Kentucky.

Conard, M. T. (2009). Introduction. In M. T. Conard (Ed.), The philosophy of the Coen brothers (pp. 1-6). Lexington: University Press of Kentucky.

Creed, B. (1993). The monstrous-feminine: Film, feminism, pyschoanalysis. London and New York: Routledge.

Creed, B. (2002). Horror and the monstroud-feminine: An imaginary abjection. In M. Jancovich (Ed.), Horror: The film reader. New York: Routledge.

Cui, S. (2003). Women through the lens: Gender and nation in a century of Chinese cinema. Honolulu: University of Hawai'i Press.

Dai, J. (2002). Cinema and desire: Feminist Marxism and cultural politics in the work of Dai Jinhua. London and New York: Verso.

Daruvala, S. (2007). The aesthetics and moral politics of Fei Mu's Spring in a Small Town. Journal of Chinese Cinemas, 1(3), 171-187.

De Lauretis, T. (1984). Alice Doesn't: Feminism, Semiotics, Cinema. Bloomington: Indiana University Press.

De Lauretis, T. (2008). Freud's Drive: Psychoanalysis, Literature and Film. New York: Palgrave Macmillan.

Doom, R. P. (2009). The brothers Coen: Unique characters of violence. Santa Barbara: Praeger.

Druxman, M. (1975). Make it again, Sam: A survey of movie remakes. Cranbury: A.S. Barnes.

Durham, C. A. (1998). Double takes: Culture and gender in French films and their American remakes. Hanover University Press of New England.

Durham, C. A. (2002). Three takes on motherhood, masculinity and marriage: Serreau's Trois hommes et un coffin, Nimoy's remake, and Ardolino's sequel. In J. A. Forrest \& L. R. Koos (Eds.), Dead ringers: The remake in theory and practice (pp. 243-272). Albany: The University of New York Press.

Eberwein, R. T. (1998). Remakes and cultural studies. In A. Horton \& S. Y. McDougal (Eds.), Play it again, Sam: Retakes on remakes (pp. 15-33). Berkeley: University of California Press.

Edgar, A., \& Sedgwick, P. R. (1999). Key concepts in cultural theory. London: Routledge. Edwards, L. (2010). Twenty-first century women warriors: Variations on a traditional theme. In G. D. Rawnsley \& M.-Y. T. Rawnsley (Eds.), Global Chinese Cinema: The culture and politics of Hero (pp. 65-77). New York: Routledge. 
Farquhar, M. (1993). Oedipality in Red Sorghum and Judou. Cinemas: Journal of Film Studies., $3(2-3), 60-86$.

Farquhar, M. (2002). Zhang Yimou. Senses of Cinema., 20(20). Retrieved from http:// sensesofcinema.com/2002/great-directors/zhang/.

FitzGerald, C. (2013). Fragmenting modernisms: Chinese wartime literature, art and film-1937-49. Leiden: Brill.

Flitterman-Lewis, S. (1990). To desire differently: Feminism and the French cinema. Urbana: University of Illinois Press.

Fluck, W. (2003). Film and memory. In U. J. Hebel (Ed.), Sites of memory in American literatures and cultures. Heidelberg: Universitätsverlag C. Winter.

Forrest, J., \& Koos, L. R. (2002). Reviewing remakes: An introduction. In J. A. Forrest \& L. R. Koos (Eds.), Dead ringers: the remake in theory and practice. Albany: State University of New York Press.

Frank, N. (1995). A new type of detective story. In W. Luhr (Ed.), The Maltese Falcon: John Houston, Director (pp. 132-135). New Brunswick: Rutgers University Press.

Fulfilling promises. (2012, 11 August). The Economist. Retrieved from http://www.econo mist.com/node/21560274.

Gilmore, R. (2009). Raising Arizona as an American comedy. In M. T. Conard (Ed.), The philosophy of the Coen brothers (pp. 7-26). Lexington: The University of Kentucky Press.

Goldstein, J. (2007). Drama kings: Players and publics in the re-creation of Peking Opera, 1870-1937. Berkeley: University of California Press.

Harrison, C. (2010). American culture in the 1990s. Edinburgh: Edinburgh University Press.

Hibbs, T. S. (2009). The human comedy perpetuates itself: Nihilism and comedy in Coen neo-noir. In M. T. Conard (Ed.), The philosophy of the Coen brothers (pp. 27-40). Lexington: University Press of Kentucky.

Hille, K. (2011, 23 February). 'Jasmine revolutionaries' call for weekly China protests. The Financial Times. Retrieved from https://www.ft.com/content/3ac349do-3efeneo-834e-00144feabdco.

Holden, S. (2002, 5 October). FILM FESTIVAL REVIEWS; A 'Picnic'- style hero in China. The New York Times. Retrieved from http://www.nytimes.com/2002/10/05/ movies/film-festival-reviews-a-picnic-style-hero-without-the-torn-t-shirt.html.

Hollinger, K. (1998). Theorizing mainstream female spectatorship: The case of the popular lesbian film. Cinema Journal, 37(2), 3-17. Retrieved from http://www.jstor.org/ stable/1225639.

Horton, A., \& McDougal, S. (1998). Introduction. In A. Horton \& S. Y. McDougal (Eds.), Play it again, Sam: retakes on remakes (pp. 1-13). Berkeley: University of California Press. 
Hsu, J.-H. (2012). Queering Chineseness: The Queer sphere of feelings in Farewell My Concubine and Green Snake. Asian Studies Review, 36(1), 1-17. doi: 10.1080/ 10357823.2011.651199.

Hudson, D. (200o). Modernity as crisis: Goeng si and vampires in Hong Kong cinema. In J. E. Browning \& C. J. Picart (Eds.), Draculas, vampires and other undead forms. Lanham, MD.: Scarecrow Press.

Jess-Cooke, C., \& Verevis, C. (2010). Second takes: Critical approaches to the film sequel. Albany: State University of New York Press.

Johns, E. K. (2009). A flip of the coin: Female resistance in the Coen brothers' No Country for Old Men. In L. C. King, R. Wallach, \& J. Velsh (Eds.), No Country for Old Men: From Novel to Film (pp. 139-154). Lanham; Toronto and Plymouth, U K: The Scarecrow Press Ltd.

Kahla, R. S. (2014). China 2013: One year rule of President Xi Jinping: An assessment. Strategic Analysis, 38(3), 265-269.

Klimke, M., Pekelder, J., \& Scharloth, J. (2011). Introduction. In M. Klimke, J. Pekelder, \& J. Scharloth (Eds.), Between Prague Spring and French May: Opposition and revolt in Europe, 1960-198o (pp. 1-14). New York: Berghahn Books.

Kline, P. (2014). Fact and fantasy in Freudian theory. London and New York: Routledge Press.

Kristeva, J. (1982). The powers of horror: An essay on abjection (R. L. S., Trans.). New York: Columbia University Press.

Kte'pi, B. (2012). Arab Spring: 1920 to present: Middle East. In A. Stanton, E. Ramsamy, P. Seybolt, \& C. Elliot (Eds.), Cultural sociology of the Middle East, Asia and Africa: An encyclopedia (pp. 1241-1246). Thousand Oaks: Sage Publications.

Kuipers, R. (2011, 3 February). Review: What Women Want. Variety. Retrieved from http://variety.com/2011/film/reviews/what-women-want-1117944491/.

Larson, W. (2011). The Fifth Generation: A reassessment. In S. H. Lim \& J. Ward (Eds.), The Chinese Cinema Book (pp. 113-121). New York and London: Palgrave Macmillan. Lee, C. (2008). Introduction. In C. Lee (Ed.), Violating time: History, memory and nostalgia in cinema (pp. 1-11). New York: Continuum.

Leitch, T. (1998). Twice-told tales: disavowal and the rhetoric of the remake. In J. A. Forrest \& L. R. Koos (Eds.), Dead ringers: The remake in theory and practice (pp. 37-62). Albany: State University of New York Press.

Leung, H. H.-S. (2008). Undercurrents: Queer culture and postcolonial Hong Kong. Vancouver: UBC Press.

Li, H. (2015). Alternative locality: Geopolitics and cultural identity in Ann Hui's A Simple Life. Asian Cinema, 26(1), 23-41.

Li, J. (2011). Transnational remakes: Gender and politics in Chinese cinemas and Hollywood (1990-2009). Doctoral Dissertation, Purdue University, Indiana. 
Lim, B. C. (2009). Translating Time. Durham: Duke University Press.

Lim, S. H. (2007). Positioning auteur theory in Chinese cinemas studies: Intratextuality, intertextuality, and paratextuality in the films of Tsai Ming-liang. Journal of Chinese Cinemas, 1(3), 223-245. doi: http://dx.doi.org/10.1386/jcc.1.3.223_7.

Liu, T. (2002). Confronting modernity in the cinemas of Taiwan and mainland China. New York: Cambridge University Press.

Lo, K.-C. (2006). Knocking off nationalism in Hong Kong cinema: Woman and the Chinese "thing" in Tsui Hark's films. Camera Obscura., 21(3), 37-61. doi: 10.1215/ 02705346-2006-011.

Loock, K., \& Verevis, C. (Eds.). (2012). Film remakes, adaptations and fan productions remake/remodel. Basingstoke: Palgrave Macmillan.

Louie, K. (2002). Theorising Chinese masculinity: Society and gender in China. Cambridge, U K: Cambridge University Press.

Louie, K. (2014). Chinese Masculinities in a Globalizing World. London: Taylor and Francis.

Lu, S. (1997). Transnational Chinese cinemas: Identity, nationhood, gender. Honolulu: University of Hawaii Press.

Luhr, W. (2012). Film Noir. Cambridge, u K: Cambridge University Press.

Lunbeck, E. (2012). Heinz Kohut's Americanisation of Freud. In J. Burnham (Ed.), After Freud left: A century of Psychoanalysis in America (pp. 209-232). Chicago and London: The University of Chicago Press.

Ma, S.-M. (2010). Diaspora literature and visual culture: Asia in flight. New York: Routledge.

Makinen, J. (2011, 20 March). 'What Women Want' translates easily now. Review. Los Angeles Times. Retrieved from http://articles.latimes.com/2011/mar/2o/ entertainment/la-ca-china-lion-sidebar-20110320.

Marchetti, G. (2000). Tian Zhuangzhuang. In S. Pendergast \& T. Pendergast (Eds.), International Dictionary of Films and Filmmakers (4th ed., Vol. 2, pp. 993-994). Detroit: St. James Press.

Mazdon, L. (2000). Encore Hollywood: Remaking French cinema. London: British Film Institute.

McFarland, D. (2009). Philosophies of comedy in O Brother, Where Art Thou? In M. T. Conard (Ed.), The philosophy of the Coen brothers (pp. 41-54). Lexington: The University Press of Kentucky.

McMahon, K. (1995). Misers, shrews, and polygamists: sexuality and male-female relations in eighteenth-century Chinese fiction. Durham: Duke University Press.

Meyers, N. (Writer). (2000). What Women Want. [Motion Picture] UsA: Paramount Pictures, New Films International.

Mitter, R. (2008). Modern China: A Very Short Introduction. Oxford and New York: Oxford University Press. 
Modleski, T. (1999). Old wives' tales: Feminist re-visions of film and other fictions. London: I.B. Tauris.

Mulvey, L. (1975). Visual pleasure and narrative cinema. Screen, 16(3), 6-16.

Neale, S., \& Krutnik, F. (1990). Popular film and television comedy. London and New York: Routledge.

Neilsen, H. B. (1999). The three father figures in Tian Zhuangzhuang's film The Blue Kite: The emasculation of males by the Communist Party. China Information, 13(4), 83-96.

Newman, M. Z. (2011). Indie: An American film culture. New York: Columbia University Press.

Ni, Z. (2002). Memoirs from the Beijing Film Academy: The genesis of China's fifth generation (C. Berry, Trans.). Durham and London: Duke University Press.

Nichols, B. (1994). Discovering form, inferring meaning: New cinemas and the film festival circuit. Film Quarterly, 47(3), 16-30. Retrieved from http://www.jstor.org/ stable/1212956.

Olimat, M. (2013). China and the Middle East from Silk Road to Arab Spring. New York: Routledge.

Olsen, M. (2011, 3 February 2011). Movie review: Chinese remake of What Women Want. Review. Los Angeles Times. Retrieved from http://articles.latimes.com/2011/feb/o3/ entertainment/la-et-what-women-want-20110203.

Palmer, R. B. (2004). Joel and Ethan Coen. Urbana and Chicago: University of Illinois Press.

Pickowicz, P. G. (2000). Victory as defeat: Postwar Visualizations of China's War of Resistance. In W.-h. Yeh (Ed.), Becoming Chinese: Passages to modernity and beyond (pp. 365-398). Berkeley: University of California Press.

Pye, L. (1999). An overview of 50 years of the People's Republic of China: Some progress, but big problems remain. The China Quarterly, 159, 569-579.

Qiang, X. (2011). The battle for the Chinese internet.Journal of Democracy, 22(2), 47-61. Qin, A. (2016, 21 October). Making online literature pay big in China. The New York Times. Retrieved from https://www.nytimes.com/2016/11/o1/world/asia/china-onlineliterature-zhang-wei.html.

Qin, L. (2010). Transmedia strategies of appropriation and visualisation: The case of Zhang Yimou's adaptation of novels of his early films. In Y. Zhu \& S. Rosen (Eds.), Art, politics, and commerce in Chinese cinema (pp. 163-174). Hong Kong and London: Hong Kong University Press.

Ramzy, A. (2011, 21 February). China cracks down after 'Jasmine Revolution' protest call. Time.

Rawnsley, G., \& Rawnsley, M.-Y. (2010). Introduction. In G. Rawnsley \& M.-Y. Rawnsley (Eds.), Global Chinese cinema: The culture and politics of Hero (pp. 1-10). New York: Routledge. 
Redmon, A. (2015). Constructing the Coens: From blood simple to inside Llewyn Davis. Blue Ridge Summit, PA: Rowman \& Littlefield Publishers.

Ross, D. (2012). Freud and the vicissitudes of modernism in the United States, 19401980. In J. Burnham (Ed.), After Freud left: a century of Psychoanalysis in America (pp. 163-188). Chicago and London: The University of Chicago Press.

Schlamm, L. (2010). Jung, Carl Justav and Eastern religious traditions. In D. A. Leeming, K. Madden, S. Marlan (Eds.), Encyclopedia of Psychology and Religion (pp. 483-486). New York: Springer Science+Business Media. DoI 10.1007/978-0-387-71802-6.

Schoppa, R. K. (2000). The Columbia guide to modern Chinese history. New York: Columbia University Press.

Scott, I. R. (2016). The creation of Modern China, 1894-2008: The rise of a world power. London: Anthem Press.

Sharrett, C. (2012). Death of the strong, silent type: The achievement of Brokeback Mountain. In T. Shary (Ed.), Millennial masculinity: Men in contemporary American cinema (pp. 165-180). Detroit: Wayne State University Press.

Sheridan, J. E. (1975). China in disintegration: the Republican era in Chinese history, 19121949. New York: Free Press.

Skues, R. (2012). Clark revisited: Re-appraising Freud in America. In J. Burnham (Ed.), After Freud left: A century of Psychoanalysis in America (pp. 49-84). Chicago and London: The University of Chicago Press.

Soh, K., \& Yecies, B. (2017). Korean-Chinese film remakes in a New Age of cultural globalisation: Miss Granny (2014) and 20 Once Again (2015) along the Digital Road. Global Media and China. 2 (1), 74-89.

Song, G. (2004). Fragile scholar: Power and masculinity in Chinese Culture. Hong Kong: Hong Kong University Press.

Spence, J. (2013). The search for modern China (3rd ed.). New York: W.W. Norton \& Company.

Stratton, D. (2002, 8 September). Review: Springtime in a small town. Variety.

Studlar, G. (2013). The corpse on reprieve: Film noir's cautionary tales of "tough guy" masculinity. In A. Spicer, \& Hanson, H. (Ed.), A Companion to Film Noir. West Sussex: Blackwell Publishing Ltd.

$\mathrm{Su}, \mathrm{W}$. (2010). New strategies of China's film industry as soft power. Global Media and Communication, 6(3), 317-322.

Tam, K.-K., \& Dissanayake, W. (1998). New Chinese cinema. Hong Kong and New York: Oxford University Press.

Tasker, Y. (2013). Women in film noir. In A. Spicer, \& Hanson, H. (Ed.), A Companion to Film Noir (pp. 353-368) West Sussex: Blackwell Publishing Ltd.

Taylor, J. R. (2013). Let one hundred flowers bloom, let one hundred thoughts contend: political science with Chinese characteristics. In S. Guo (Ed.), Political science 
and Chinese political studies (pp. 263-274). Heidelberg, New York, Dordrecht and London: Springer.

Teo, S. (1997). Hong Kong cinema: The extra dimensions. London: British Film Institute. Teo, S. (2006). Chinese melodrama: the wenyi genre. In L. Bradley, J. Barton Palmer, \& S. J. Schneider (Eds.), Traditions in world cinema (pp. 203-213). Edinburgh: Edinburgh University Press.

Teo, S. (2009). Chinese martial arts cinema: The Wuxia tradition. Edinburgh: Edinburgh University Press.

Teo, S. (2012). Film genre and Chinese cinema: A discourse of film and nation. In Y. Zhang (Ed.), A companion to Chinese cinema (pp. 284-298). Malden: WileyBlackwell.

Tian, Z. (Writer). (2002). Springtime in a Small Town (小城之春) [Motion picture]: USA: Palm Pictures and U K: Artificial Eye.

Tian, Z. (2003). Tian Zhuangzhuang: Springtime in a small town (Interview). The Movie Show.. s Bs. Retrieved from https://www.sbs.com.au/ondemand/video/11678275969/ tian-zhuangzhuang-springtime-in-a-small-town.

Townson, D. (1999). Prague Spring 1968. In D. Townson (Ed.), A Dictionary of Contemporary History.-Blackwell Reference OnlineBlackwell.

Udden, J. N. (2012). In search of Chinese film style(s) and technique(s). In Y. Zhang (Ed.), A companion to chinese cinema (pp. 265-283). West Sussex: Wiley-Blackwell.

Valck, M. d. (2007). Film festivals: from European geopolitics to global cinephilia. Amsterdam: Amsterdam University Press.

Vanderstaay, L. (2010). A textual analysis of female consciousness in twenty-first century Chinese women directors' films. Doctoral dissertation, University of Queensland, Brisbane.

Verevis, C. (2006). Film remakes. Edinburgh: Edinburgh University Press.

Wang, B. (2010). Socialist Realism. In B. Wang (Ed.), Words and their stories: Essays on the language of the Chinese revolution (pp. 101-118). Leiden: Brill.

Wang, Y. (2007). A star is dead, a legend is born: Practicing Leslie Cheung's posthumous fandom. In S. Redmond \& S. Holmes (Eds.), Stardom and Celebrity: A Reader. London: SAGE Publications Ltd.

Wang, Y. (2008). Remembering a film and "ruining" a remake: on Tian Zhuangzhuang's failure to remake Spring in a Small Town. In C. Lee (Ed.), Violating time: history, memory and nostalgia in cinema (pp. 104-123). New York: Continuum.

Wang, Y. (2013). Remaking Chinese cinema through the prism of Shanghai, Hong Kong, and Hollywood. Hong Kong: University of Hawai'i Press.

Ward, W. H. (2006). Anima/animus: Depardieu and the projection of masculinities. Doctoral Dissertation, University of Queensland, St. Lucia, Qld. Retrieved from http://espace.library.uq.edu.au/view/UQ:158383. 
A woman, a gun and a noodle shop press kit. (n.d.). (pp. 18): Sony Pictures Classics.

Wong, A.-L. (1998). Fei Mu: Poet Director. Hong Kong: Xianggang dianying pinglun xuehui.

Wong, E. (2012, 6 January, 2012). A filmmaker walks a line between artistic acceptance and offical approval. The New York Times. Retrieved from http://www.nytimes .com/2012/01/07/world/asia/filmmaker-zhang-yimou-walks-a-fine-line-in-china .html?_r=0.

Xu, G. G. (2012). Chinese cinema and technology. In Y. Zhang (Ed.), A companion to Chinese cinema (pp. 449-466). Malden: Wiley-Blackwell.

$\mathrm{Xu}, \mathrm{C}$. (2012). Peking Opera. Cambridge, U K and New York: Cambridge University Press. Yang, C. K. (1959). Chinese Communist society: the family and the village: Containing the Chinese family in the Communist Revolution and a Chinese village in early Communist transition. Cambridge, MA: M.I.T. Press.

Yau, C. (2010). Dreaming of normal while sleeping with impossible: Introduction. In C. Yau (Ed.), As normal as possible: negotiating sexuality and gender in mainland China and Hong Kong (pp. 1-14). Hong Kong: Hong Kong University Press.

Yau, E. (2001). Introduction: Hong Kong cinema in a borderless world. In E. Yau (Ed.), At full speed: Hong Kong cinema in a borderless world (pp. 1-28). Minneapolis: University of Minnesota Press.

Yue, A. (2000). Preposterous Hong Kong horror: Rouge's (be)hindsight and A(sodomitical) Chinese Story. In K. Gelder (Ed.), The Horror Reader (pp. 364-374). New York and London: Routledge.

Yue, A. (2010). Ann Hui's Song of the Exile. Hong Kong: Hong Kong University Press.

Zanger, A. (2006). Film remakes as ritual and disguise from Carmen to Ripley. Amsterdam: Amsterdam University Press.

Zarrow, P. (2005). China in war and revolution, 1895-1949. London ; New York: Routledge.

Zhang, J. (2011). To become an auteur: the cinematic manoeverings of Xu Jinglei. In L. Wang (Ed.), Chinese women's cinema: transnational contexts. New York: Columbia University Press.

Zhang, R. (2008). The cinema of Feng Xiaogang: commercialisation and censorship in Chinese cinema after 1989. Hong Kong: Hong Kong University Press.

Zhang, X. (2003). National trauma, global allegory: reconstruction of collective memory in Tian Zhuangzhuang's The Blue Kite. Journal of Contemporary China, 12(37), 623-638. Dor: 10.1080/1067056032000117678.

Zhang, X. (2008). Postsocialism and cultural politics: China in the last decade of the twentieth century. Durham: Duke University Press.

Zhang, Y. (2010). Cinema, space, and polylocality in a globalizing China. Honolulu: University of Hawaii Press.

Zhang, Y. (Ed.) (2012). A companion to Chinese cinema. Malden: Wiley-Blackwell. 
Zhu, Y., \& Robinson, B. (2010). The cinematic transition of the fifth generation auteurs. In Y. Zhu \& S. Rosen (Eds.), Art, politics and commerce in Chinese cinema (pp. 145162). Hong Kong: Hong Kong University Press.

Zhu, Y. (2015). The Sino-Hollywood relationship: Then and now. Weber: The Contemporary West. Spring/Summer, $26-36$.

杨东虎 (Writer). (2011). 三岔口 [Motion picture]. https://www.youtube.com/ watch?v=NdqvzYySoAg CCTV 11.

费穆 (Writer). (1948). 小城之春 [Motion picture]: 中国: 文华影业公司. 


\section{Index}

\section{A Chinese Ghost Story \\ generic classification $\quad 20,80-81$ \\ synopsis 78 \\ Anti-Rightist Campaign $\quad 125$ \\ A Woman, A Gun and a Noodle Shop}

generic classification $\quad 20,47-48,59-60$

synopsis 59

auteur

reasons for remaking $\quad 5^{-6}$

Beijing/Peking Opera

generic conventions $\quad 64-66$

traditional gendered roles $\quad 64-66,69-70$

chou 65

huadan 65

jing $\quad 65,69-70$

sheng $65,69-70$

wenxiaosheng 71

history $\quad 64-65$

use of space 66

costumes $\quad 65^{-66,70}$

Blood Simple

synopsis 48

Cheung, Leslie

sexuality and Hong Kong cinema $\quad 84-86$

Chinese New Year films

consumerism $\quad 44-46$

Feng Xiaogang $\quad 44-45$

Chinese-language cinema

censorship $31,99,112,122-123,137$

colonialism 12, 80, 99-100, 133

global soft power $8,11,46,127-128$,

137-138

global reception $\quad 75-77,110-115,137-138$

high and low art $\quad 135$

Hong Kong, Taiwan, mainland China cinema dynamics 10

representing the Chinese nation $\quad 45^{-46}$, $67,81,89,131-133,138$

post-feminist film $\quad 11,16-17$

self-exoticisation/Orientalisation 10 ,

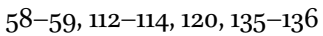

Sino-Hollywood relationship $\quad 10-12$, 16-18
Chinese stereotypes in Hollywood 16 sexualisation of Asian women in

Hollywood 16

transnational Chinese cinema $\quad 8-12,77$,

$135^{-136,138}$

Chinese literature

caizi $\quad 87-88$

miser 69

shrew 73

Chinese Communist Party

current cultural policy 111

Mao's cultural policy 104-106

cinematic "reality" 106-107, 122-123, 127

Coen brothers

American film noir $\quad 48-49,57$

American locations 48

failed masculinities, See genre: American film noir: failed masculinities

generic incongruity $49-52$

unconventional female characters $\quad 55^{-57}$

pastiche. See genre: pastiche

postmodern cinema, See genre:

postmodern cinema

comedy. See genre: comedy

consumerism

and gender $31-32,44-46,130-131$

and "Chinese characteristics" 45

Cultural Revolution $\quad$ 92-93, 109-110, 123

cultural authenticity $\quad 80,99-100,138$

family

$195^{\circ}$ Chinese Marriage Law

implications for family structures $\quad 38-39$

and war 109

as an economic unit $\quad 43-46,131$

Chinese Communist Party

caring for the elderly 43

historical influence on family structures $\quad 38-39$

father figure as representative of 'the

past' $\quad 40-42,130$

monogamy $\quad 87-88$

the family home as political

allegory 119-122, 134 
'the family' versus 'the couple' $37-38,131$ the ideal Chinese family model 38

Confucian family values

filial piety $43,46,130$

moral ethics 108

polygamy $\quad 86-87$

pre-modern Chinese notions of

sexuality 87

Fei Mu

as an auteur $\quad 104-107$

xuanxiang and kongqi 107, 127

silence 122

gender 107-109

political inclinations 104-106

femininity

appropriate forms of $\quad 29-30$

authentic female thoughts $27-28,30$, 130-131

class elitism $\quad 31-32$

femme fatale, see genre: American film noir: femme fatale

materialism and Chinese femininity $\quad 31^{-}$ $32,130-131$

motherhood $24-25,29-30,32-33,56,87$, 130

monstrous-feminine $\quad 90-92,96$

woman as survivor 56,75

woman warrior 68

women in the workplace 26

feminist film theory

female narration $17,108,123$

reading 'woman' $31-32,97$

Fifth Generation Directors

censorship $110,112,116-7,122-123$

defining themes 110

gender 113-114

influence on Chinese-language

cinema $\quad 58-60,110-112$

political controversies $\quad 58,110-111,115-116$

reception $\quad 58-60,67-68,75^{-77}, 110-117$, $127-128$

self-exoticisation/Orientalisation, see

Chinese-language cinema: self-

exoticisation/Orientalisation

social realism 110-111,

Film Festivals

international film festivals

censorship 109, 112, 116-117 film typologies $\quad 112$

significance for global cultural

production 111

Freud

American psyche, and the 34

critiques of theory 34

femininity and neuroticism $\quad 33-34,131$

femininity and sexual repression $\quad 33^{-34}$,

131

psychic trauma 101

role of the mother $\quad 3^{2-33}$

stages of development $\quad 3^{2-33}$

the libido 32

gender performativity $\quad 27-29,86,91$

gaze, the

definition 17,92

criticism of theory 92

disrupting the gaze $\quad 94-95$

interpretations in Chinese-language

cinema $17,92-93$

male as object of the gaze $\quad 89-90,95$

power and pleasure 93,95

woman as object of the gaze $\quad 92,96-97$ genre

American film noir

generic markers $\quad 48-49$

gender tropes $5^{0}$

failed masculinities, see masculinity: masculinity in crisis

the hero 53

the detective $\quad 54-55$

the jealous husband $\quad 53-54$

the femme fatale $\quad 55^{-57}$

Western noir $\quad 49-50,5^{2-53}$

American Western and masculinity $\quad 5^{2}$

Asian fantasy genre and views on history 100 modern China's disenchantment 100

Chinese post-war resistance films 105 , 109

comedy

Chinese sketch comedy $\quad$ 61-64

xiangsheng 61-63

Hollywood gangster films

Italian-American mafia stereotype 54 
melodrama/wenyi genre 108-109

pastiche $5^{0}-5^{1 n}$

post-modern cinema $\quad 5^{1-52}$

wuxia 68,81

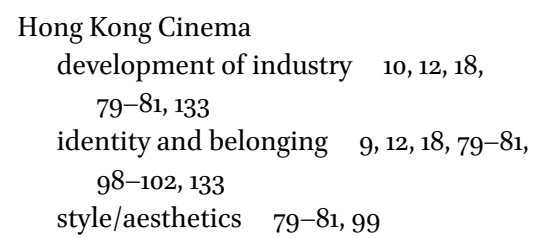

humour. See, genre: comedy

Jung

anima $29,35^{-3} 6$

animus 35

contra-sexuality 35

Eastern philosophy $\quad 35^{-36}$

gender fluidity $35^{-36}$

masculinity

a 'man's man' 24-25

America's glory days $\quad 25^{-26}$

Daoist masculinity $\quad 88-90,98$

feminised male warrior cinematic

trend 88-90, 95

homosocial/homosexual bonds $\quad 88-89$

in crisis $\quad 25^{-26}, 5^{0}, 5^{2-55}$

modern versus traditional modes of

Chinese masculinity $\quad 26-27,39-43$

wen and $w u \quad 27$

Ming Dynasty

rise and fall $\quad 120-121$

memory

amnesia

narrative function $\quad 97-98$

and trauma 97,101

symbolism 98-99, 101-102

methodologies

'fidelity' versus 'free' argument 14

comparative analysis $\quad 2,12,14,17-18$

intertextual analysis $\quad 5,14-15$

psychoanalytic analysis $\quad 32-35,79,130$

Nationalist Era 121, 122

Nationalist New Life Movement 104

One Hundred Flowers Movement 125 pastiche, see, genre: pastiche

political uprisings

Arab Spring $\quad 126$

Beijing Spring 126

Jasmine Revolution $\quad 126$

Prague Spring 125

post-modern cinema, see genre: post-modern cinema

post-socialism in China $12,16,45,106-107$, 115,120

remakes

and adaptation 3

as high and low art $7,100,135$

as a type of translation 22

audiences $1-3,5-8,12-13,45^{-47}, 64-65$, 75-76, 88-90-130-133, 135-136

Chinese/Korean collaborations $\quad$ 137-138

critical reviews $5,7,23-24$

cultural imperialism $\quad 7,11-12,14,99-102$, 129, 131-132

definition of $\quad 2-5,137$

extra-textual markers $\quad 4,36-37$

fan productions $\quad 137-8$

Franco-American remakes $\quad 6-7,13^{-15}$

Hollywood/Chinese remakes $\quad 8-13,15^{-19}$

Japanese/Hollywood remakes $\quad 7-8$

Japanese/Korean collaborations $\quad 7-8$

national identity $\quad 7-14,20,98-102$, 129-130, 133

originality $5^{-6}$

transnational cinema theory $\quad 135^{-136}$.

See Chinese-language cinema:

transnational cinema theory

taxonomies of $3^{-5}$

Spring in a Small Town (1948)

aesthetics $105^{-108}$

cinematic reality $\quad 106-107$. See also cinematic reality

conflict with social realist principles 104-106

Fei Mu (see Fei Mu)

synopsis 103

post-socialist era reception 106-107

Springtime in a Small Town (2002)

and censorship. See Fifth Generation

Directors: censorship 
critical reception $\quad 111$

nostalgia and the past 114-116

'Spring' and semiotics 124-127

the family/home as political allegory, See

family: the home as political allegory

social realism

definition and origin 104-106

influence on Fifth Generation films. See

Fifth Generation Directors: social realism

The Blue Kite (1993)

as national allegory $\quad 116-117$

synopsis $\quad 116$

Tian Zhuangzhuang

as an auteur $\quad 20,109-110,114-117,122-123$,

127-128, 134, 136

and socialist era class and gender

stereotypes 118-119

and post-socialist decadence 114-116

biography 109-110

critical reception $\quad 109-110$

Tsui Hark

political symbolism $\quad 80-81$ 'using the foreign to serve the

Chinese' $45^{-46}$

What Women Want (2000) and (2011) synopsis 23

yin and yang $\quad 35^{-36,86}$

\section{Zhang, Yimou}

and Beijing Opera $\quad 64-66,69-71,74,132$

and Chinese literary gender stereotypes $67,69,73$

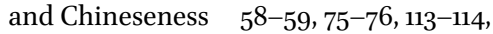
132,138

and political commentary $\quad 58,67,75$, 110-112

and representing women $\quad 68,72-75$,

113-114

and the patriarchy $67,70,75$

criticisms of $58-59,75,112-114$

domestic and international acclaim

$58-59,67-68,75^{-77}, 110-114,135^{-136}$ 